\title{
ipen
}

AUTARQUIA ASSOCIADA À UNIVERSIDADE DE SÃO PAULO

MOBILIDADE DE As, Cd, Mo, Pb e Zn EM COLUNAS DE LATOSSOLO ARGILOSO COM CINZA DE CARVÃO E CONTAMINAÇÃO DO SOLO

Juliana Cristina da Silva

Dissertação apresentada como parte dos requisitos para obtenção do Grau de Mestre em Ciências na Área de Tecnologia Nuclear - Materiais

Orientadora:

Profa. Dra. Iara Maria Carneiro de Camargo 


\title{
INSTITUTO DE PESQUISAS ENERGÉTICAS E NUCLEARES
}

Autarquia associada à Universidade de São Paulo

\section{MOBILIDADE DE As, Cd, Mo, Pb e Zn EM COLUNAS DE LATOSSOLO ARGILOSO COM CINZA DE CARVÃO E CONTAMINAÇÃO DO SOLO}

\author{
Juliana Cristina da Silva
}

\begin{abstract}
Dissertação apresentada como parte dos requisitos para obtenção do Grau de Mestre em Ciências na Área de Tecnologia Nuclear - Materiais

Orientadora:

Profa. Dra. lara Maria Carneiro de Camargo
\end{abstract}


À Deus, ao meu marido Douglas e minha mãe Ivete. 


\section{AGRADECIMENTOS}

À Deus por ter me dado esta oportunidade e por ter me ajudado em cada etapa que tive que passar.

Ao meu marido pelos conselhos, pelas conversas e muitas vezes por me ouvir.

À minha mãe Ivete pelo suporte que foi necessário em muitos momentos, pelos conselhos, orientações e por me fazer ir em frente.

Ao meu irmão Denis, Bill e Raquel por serem família e pelos conselhos dados.

À minha orientadora Dra. Iara Maria Carneiro de Camargo por sua orientação e paciência.

À FAPESP pelo auxílio financeiro do projeto.

À CAPES pela bolsa durante os anos de mestrado.

À minha mãe Ivete e meu avô José Pereira pelo auxílio financeiro no início do mestrado.

À Cibele, Douglas, Maynara e Juliana pela ajuda nas análises, pelas conversas e risadas.

À Carina, Juliana Izidoro, Juliana Ikebe, Paty e Renan pelas importantes orientações durante o mestrado, pelos ensinos, conselhos e pela alegria.

À Bruna e Gisela por serem amigas, em todos os momentos.

À Camila Lange por tudo que fez por mim.

Ao João Osso pela ajuda e amizade.

À Carol, Flávia e Luci pelas palavras, conversas e conselhos.

A todos do CQMA e que me ajudaram no trabalho com as análises e interpretações de dados: Luci, Gildo Pinheiro, Dra. Vera Lúcia, Cris, Dra. Elaine, Dra. Marycel, Douglas, Dr. Marcos Scapin, Laís, Dra. Elizabeth Dantas, Cleide, Elias, Martinha, Luciana Pavanelli, Carlinhos, Dra. Denise, Dra. Nilce, Neemias, Camila Lange e Dra. Iara Camargo.

Aos meus professores Dra. Maria Eugênia, Dra. Martha Vieira, Dra. Vera Lúcia, Dra. Wanda Araújo, Dr. Afonso Aquino, Dr. Marcos Scapin e Dr. Raphael Hypolito, que muito acrescentaram em conhecimento e no meu trabalho. 
Tudo tem o seu tempo determinado, e há tempo para todo o propósito debaixo do céu. Eclesiastes 3:1 


\title{
MOBILIDADE DE As, Cd, Mo, Pb e Zn EM COLUNAS DE LATOSSOLO ARGILOSO COM CINZA DE CARVÃO E CONTAMINAÇÃO DO SOLO
}

\author{
JULIANA CRISTINA DA SILVA
}

\begin{abstract}
RESUMO
A contaminação do solo tem sido motivo de preocupação ambiental e de saúde pública, uma vez que o homem depende do seu uso para sobreviver. O resíduo de cinza de carvão, gerado da queima de carvão em usina termoelétrica, é uma das fontes contaminadoras do solo quando disposto de forma inadequada. Os elementos tóxicos da cinza de carvão, quando depositada sobre o solo e exposta à chuva, podem ser lixiviados da cinza para o solo. No solo estes elementos podem ser sorvidos, transportados para a água subterrânea e superficial ou absorvido pelas plantas, o que pode contaminar estas matrizes ambientais. O objetivo do estudo foi avaliar a mobilidade de $\mathrm{As}, \mathrm{Cd}, \mathrm{Mo}, \mathrm{Pb}$ e $\mathrm{Zn}$ em colunas de Latossolo argiloso com cinza de carvão sobreposta ao solo e avaliar se a retenção destes elementos provoca a contaminação do solo. As colunas foram percoladas com uma solução ácida com pH 4,5 para simular água de chuva, por períodos de 168 e 336 dias. As amostras de cinza de carvão, solo e percolado das colunas foram analisadas quanto à concentração dos elementos e as características físicas, químicas e mineralógicas. $\mathrm{O}$ Pb não foi lixiviado da cinza de carvão, portanto, o solo e percolado do solo não foram contaminados por este elemento. Os elementos $\mathrm{As}, \mathrm{Cd}$, Mo e $\mathrm{Zn}$ foram lixiviados da cinza de carvão e não foram detectados no percolado das colunas, indicando que estes elementos ficaram retidos no solo. A concentração do Mo no solo não foi detectada acima do limite de quantificação do método. A concentração dos elementos foi comparada com os valores orientadores para solos estabelecidos pela CETESB. A maior parte do $\mathrm{Zn}$ detectado no solo foi proveniente do próprio solo utilizado no preparo da coluna e a concentração deste elemento no solo foi abaixo do valor de referência $\left(60 \mathrm{mg} \mathrm{kg}^{-1}\right)$. A concentração do $\mathrm{Cd}$ no solo foi acima do valor de referência $\left(<0,5 \mathrm{mg} \mathrm{kg}^{-1}\right)$ e abaixo do valor de intervenção $\left(3 \mathrm{mg} \mathrm{kg}^{-1}\right)$. A concentração do As no solo foi acima do valor de intervenção $\left(35 \mathrm{mg} \mathrm{kg}^{-1}\right)$, sendo o único elemento crítico do ponto de vista ambiental.
\end{abstract}




\title{
MOBILITY OF As, Cd, Mo, Pb AND Zn IN CLAYEY OXISOL COLUMNS WITH COAL FLY ASH AND SOIL CONTAMINATION
}

\author{
JULIANA CRISTINA DA SILVA
}

\begin{abstract}
Soil contamination has been an environmental and public health concern, once the man depends on its use to survive. Coal fly ash generated by coal burning in power plants is one source of soil contamination when it inadequately disposed. Toxic elements from coal fly ash, deposited on soil and exposed to rain, can be leached into the soil. In the soil these elements can be sorbed, transported to groundwater and surface water or even absorbed by plants, which can contaminate these environmental matrices. The aim of study was to evaluate the mobility of $\mathrm{As}, \mathrm{Cd}, \mathrm{Mo}, \mathrm{Pb}$ and $\mathrm{Zn}$ in clayey oxisol columns with coal fly ash on top soil, and also evaluate if these elements retention leads to soil contamination. The columns were percolated by acidic solution, $\mathrm{pH} 4.5$, to simulate rain water, in periods of 168 and 336 days. The elements concentration and physical, chemical and mineralogical characteristics were determined in coal fly ash, soil and column leachate samples. Lead was not leached from coal fly ash, therefore the soil and the column leachate were not contaminated by this element. The elements As, Cd, Mo and $\mathrm{Zn}$ were leached from coal fly ash and were not detected in leachate of soil, that means these elements were retained in soil. The Mo concentration was below the quantification limit of method. The As, $\mathrm{Cd}$ and Zn concentrations were compared with the CETESB guideline values established for soil. The majority of $\mathrm{Zn}$ detected in the soil came from the original soil used in the column preparation and this element concentration in soil was below the reference value $(60 \mathrm{mg}$ $\left.\mathrm{kg}^{-1}\right)$. Cadmium concentration in soil was above the reference value $\left(<0.5 \mathrm{mg} \mathrm{kg}^{-1}\right)$ and it was below the intervention value $\left(3 \mathrm{mg} \mathrm{kg}^{-1}\right)$. Arsenic in soil was above the intervention value $\left(35 \mathrm{mg} \mathrm{kg}^{-1}\right)$, so that was the most critical element by the environmental point of view.
\end{abstract}




\section{SUMÁRIO}

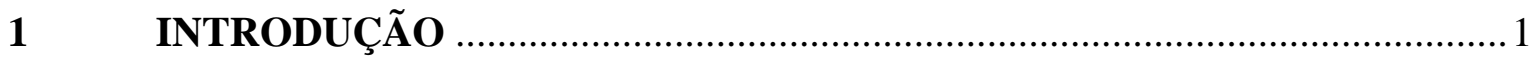

2 OBJETIVO

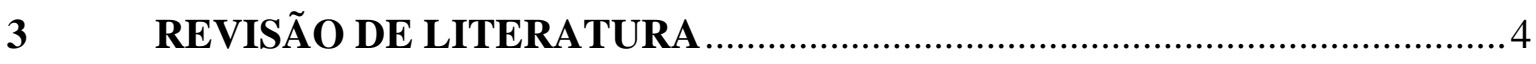

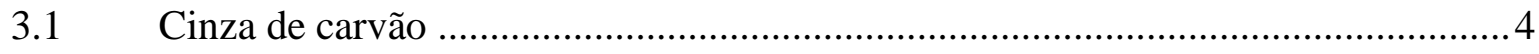

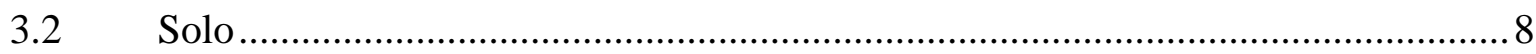

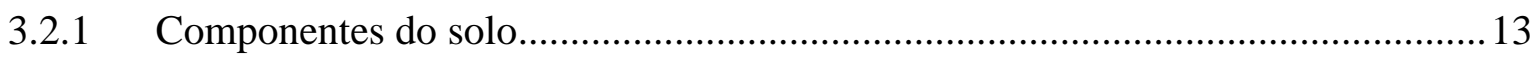

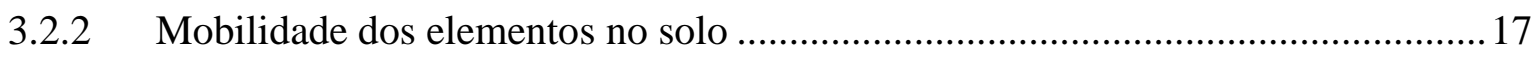

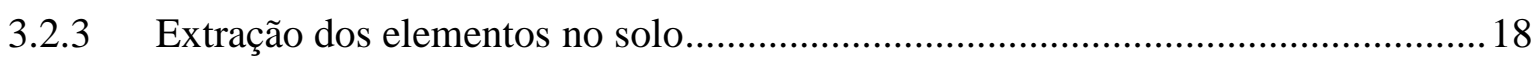

3.2.4 Comportamento químico de As, $\mathrm{Cd}, \mathrm{Mo}, \mathrm{Pb}$ e $\mathrm{Zn}$ no solo......................................2 20

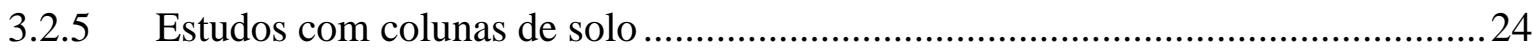

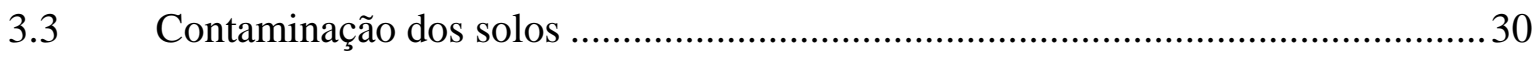

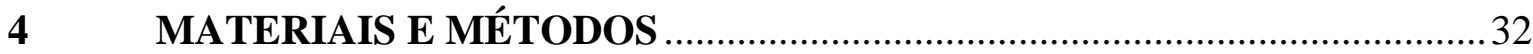

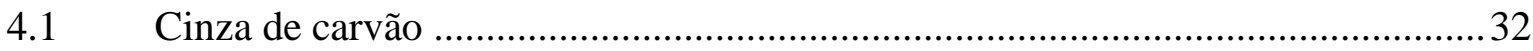

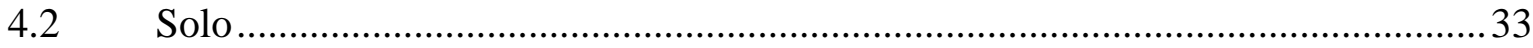

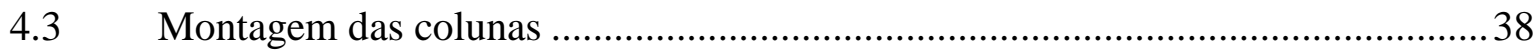

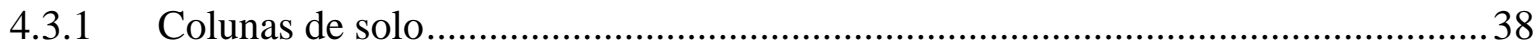

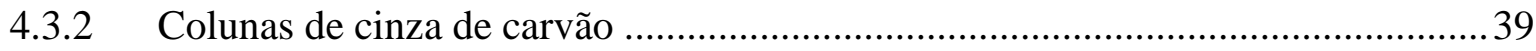

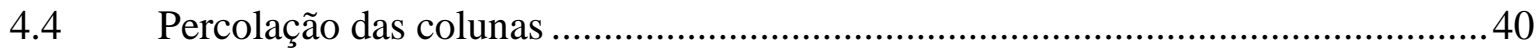

4.5 Determinação da vazão e do coeficiente de permeabilidade das colunas ..............42

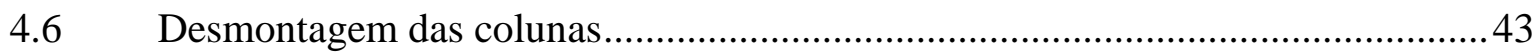

4.7 Caracterização física, química e mineralógica das amostras ................................ 44

4.7.1 Caracterização física do solo ...................................................................... 44

4.7.2 Caracterização química da cinza de carvão, solo e percolado das colunas ........... 45

4.7.3 Caracterização mineralógica de cinza de carvão e solo...................................... 46 
4.7.4 Determinação da concentração dos elementos majoritários e tóxicos 46

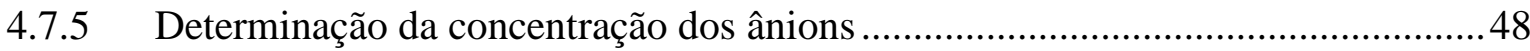

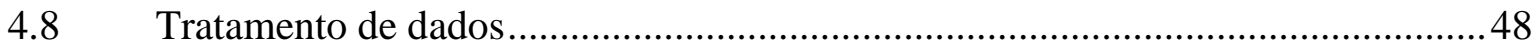

4.8.1 Cálculo da porcentagem de lixiviação dos elementos da cinza de carvão .............48

4.8.2 Cálculo da porcentagem de retenção dos elementos no solo.................................49

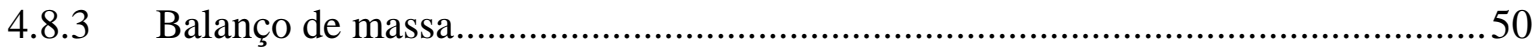

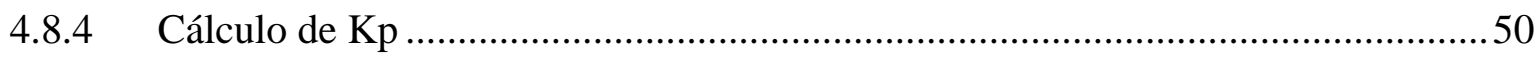

4.8.5 Cálculo da porcentagem de extração dos elementos no solo.................................51

$5 \quad$ RESULTADOS E DISCUSSÃO

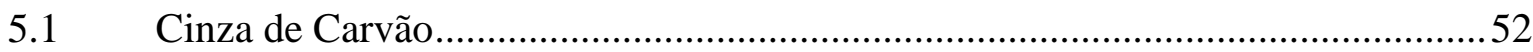

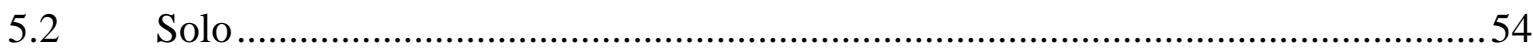

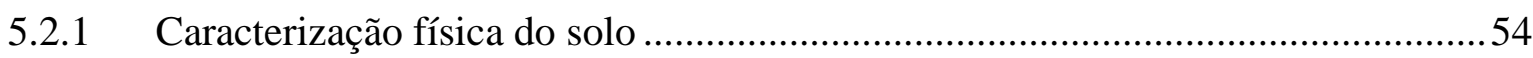

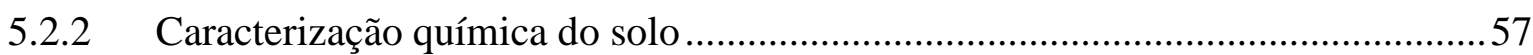

5.2.2.1 Caracterização química do solo após percolação................................................62

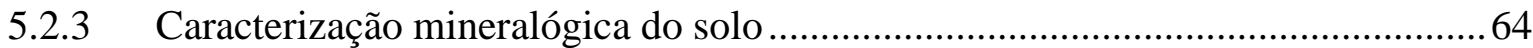

5.2.4 Concentração parcial dos elementos majoritários no extrato do solo obtido por

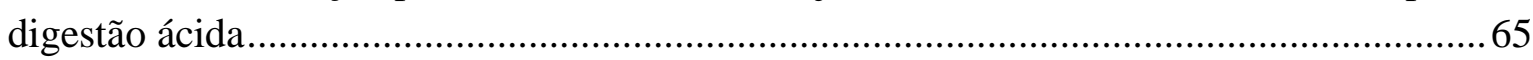

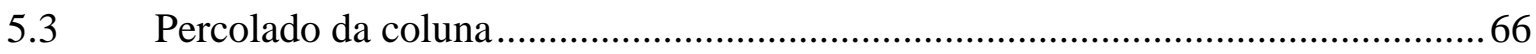

5.3.1 Características químicas do percolado da coluna .................................................67

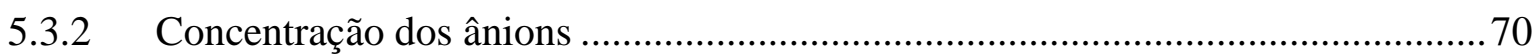

5.3.3 Vazão da coluna e coeficiente de permeabilidade .............................................. 70

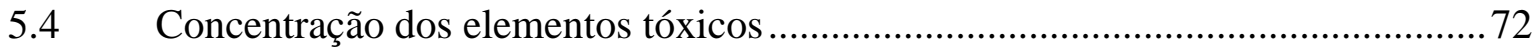

5.4.1 Concentração dos elementos tóxicos na cinza de carvão ...................................... 72

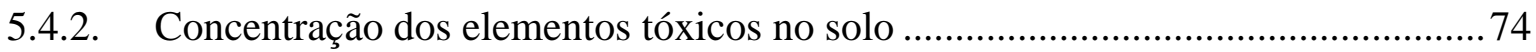

5.4.2.1 Concentração parcial dos elementos no extrato do solo obtido por digestão ácida. 
5.4.2.2 Comparação entre a concentração parcial dos elementos no solo ap e os valores de referência ambiental

5.4.2.3 Concentração biodisponível dos elementos no extrato do solo obtido por extração com EDTA

5.4.2.4 Concentração trocável dos elementos no extrato do solo obtido por extração com $\mathrm{Ca}\left(\mathrm{NO}_{3}\right)_{2}$ .81

5.4.3 Concentração dos elementos tóxicos no percolado das colunas............................. 83

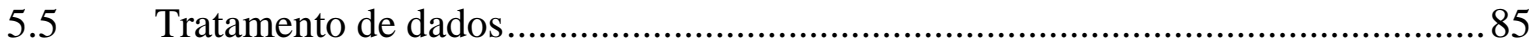

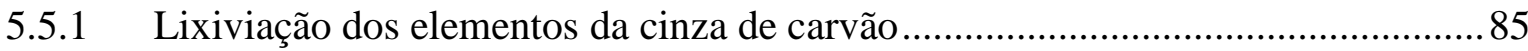

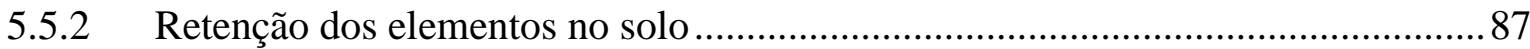

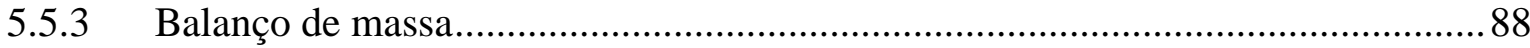

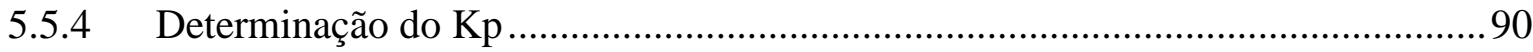

5.6 Comparação entre os dados dos solos argiloso e franco arenoso ...........................91

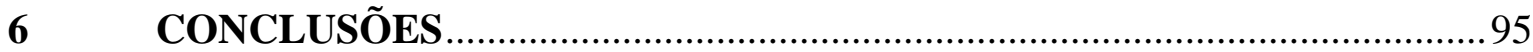

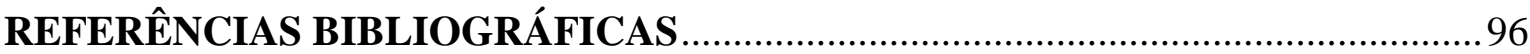




\section{LISTA DE TABELAS}

TABELA 1 - Usinas termoelétricas a carvão em operação no Brasil em setembro de 2003 4

TABELA 2 - Concentração dos elementos na cinza leve de usinas termoelétricas de municípios do sul do Brasil

TABELA 3 - Valores mundiais de elementos encontrados em solos............................................. 9

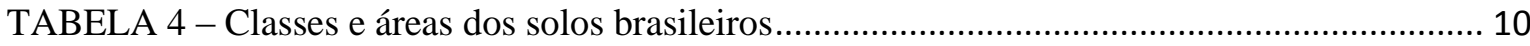

TABELA 5 - Soluções para extração dos elementos nas frações do solo ....................................... 19

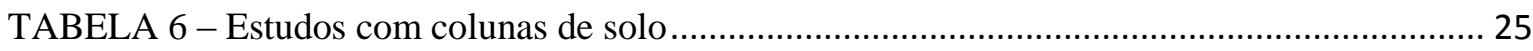

TABELA 7 - Toxicidade dos elementos em plantas e mamíferos ................................................. 31

TABELA 8 - Média pluviométrica mensal da cidade de São Paulo, 1933-2008 (IAG-USP), volume da solução simuladora de água de chuva adicionado em cada coluna e tempo de percolação acumulado

TABELA 9 - Características físicas do solo e métodos adotados pelos laboratórios de análise ..... 44

TABELA 10 - Características químicas do solo e métodos adotados pelos laboratórios de análise45

TABELA 11 - Composição química da cinza de carvão obtida por fluorescência de raios-X,

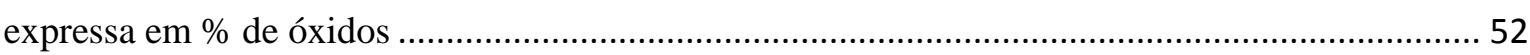

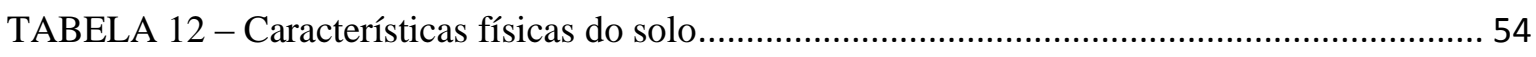

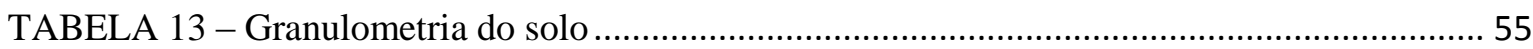

TABELA 14 - Composição química do solo obtida por fluorescência de raios-X, expressos em \%

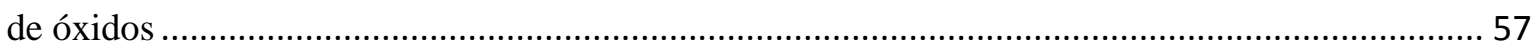

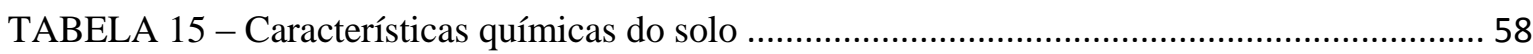

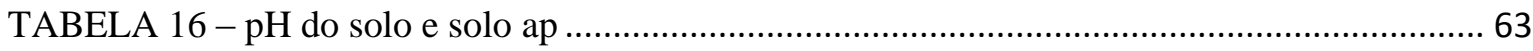

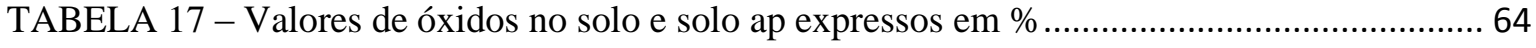

TABELA 18 - Concentração dos elementos majoritários no extrato do solo obtido por digestão

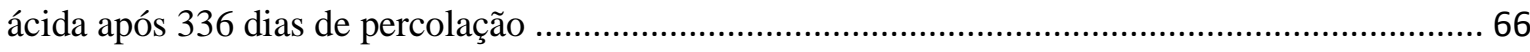

TABELA 19 - Concentração de carbono COD, CID e CT no percolado das colunas ao longo de 336 dias 68

TABELA 20 - Concentração dos elementos majoritários no percolado das colunas ........................ 69

TABELA 21 - Concentração de ânions no percolado das colunas.................................................. 70 
TABELA 22 - Concentração parcial dos elementos tóxicos no extrato da cinza de carvão obtido por digestão ácida.

TABELA 23 - Concentração parcial dos elementos nos extratos do solo e solo ap obtido por digestão ácida

TABELA 24- Concentração parcial dos elementos no extrato do solo ap obtido por digestão ácida e valores orientadores para solos estabelecidos pela CETESB (2005)

TABELA 25 - Concentração biodisponível do Zn no extrato do solo ap obtido por extração com EDTA

TABELA 26 - Porcentagem de extração do Zn no solo ap com EDTA em relação à digestão ácida

TABELA 27 - Concentração trocável do Zn no extrato do solo ap obtido por extração com $\mathrm{Ca}\left(\mathrm{NO}_{3}\right)_{2}$

TABELA 28 - Porcentagem de extração do $\mathrm{Zn}$ no solo (ap) com $\mathrm{Ca}\left(\mathrm{NO}_{3}\right)_{2}$ em relação à digestão ácida

TABELA 29 - Porcentagem de lixiviação dos elementos da cinza de carvão com base no método um . 86

TABELA 30 - Porcentagem de lixiviação dos elementos da cinza de carvão com base no método dois

TABELA 31 - Porcentagem de retenção dos elementos no solo 88

TABELA 32 - Balanço de massa dos elementos. 89

TABELA 33 - Valores calculados de Kp para Zn. 90

TABELA 34 - Características físicas e químicas dos solos argiloso e franco arenoso 92

TABELA 35 - Concentração dos elementos nos solos de argiloso e franco arenoso após o período de 336 dias de percolação das colunas

TABELA 36 - Retenção dos elementos no solo argiloso e franco arenoso 93 


\section{LISTA DE FIGURAS}

FIGURA 1 - Esquema de funcionamento de uma usina termoelétrica ............................................. 5

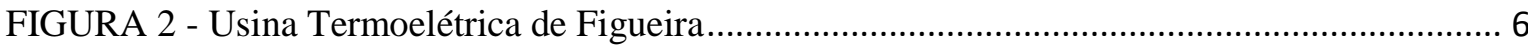

FIGURA 3 - Esquema da emissão e disposição inadequada das cinzas de carvão ............................. 6

FIGURA 4 - Disposição de cinzas de carvão geradas na Usina Termoelétrica de Figueira/PR ....... 7

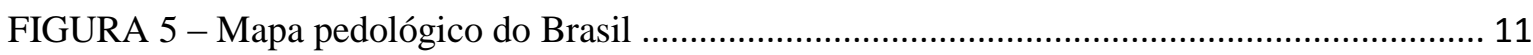

FIGURA 6 - Mapa pedológico do estado de São Paulo .............................................................. 12

FIGURA 7 - Adsorção de cátions em um cristal de argila com estrutura em lâminas ..................... 14

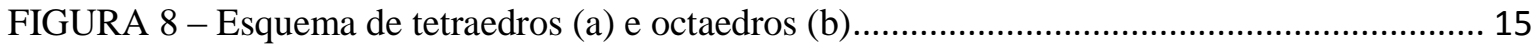

FIGURA 9 - Processos que controlam a solubilidade, disponibilidade e mobilidade dos elementos no solo.

FIGURA 10 - Fontes de poluição do solo e sua migração ................................................................. 30

FIGURA 11 - Imagem da localização do ponto da coleta do solo por meio do Google Earth: (a) localização entre os municípios de Piracicaba e Iracemápolis; (b) localização em relação à rodovia SP-127

FIGURA 12 - Identificação da rodovia Piracicaba-Rio Claro (SP - 127) e do município de Piracicaba por meio do mapa político do estado de São Paulo

FIGURA 13- Fotos do solo de Piracicaba: (a) e (b) área da coleta do solo; (c) coleta do solo com estrutura não deformada; (d) coleta do solo com estrutura deformada .......................................... 36

FIGURA 14 - Amostra do solo de Piracicaba com estrutura não deformada .................................. 37

FIGURA 15 - Amostra do solo de Piracicaba com estrutura deformada ........................................ 37

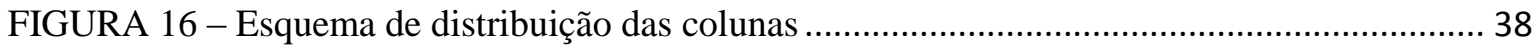

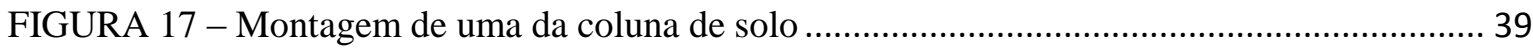

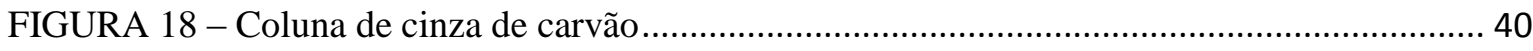

FIGURA 19 - Sistema de percolação das colunas de solo e as colunas no laboratório...................... 42

FIGURA 20 - Solo da coluna desmontada após separação da cinza de carvão ................................ 43

FIGURA 21 - Esquema do balanço de massa ………............................................................. 50

FIGURA 22 - Textura do solo de acordo com o diagrama adotado pela Sociedade Brasileira de

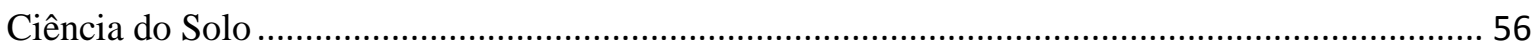


FIGURA 23 - (a) Cor do solo em estudo e a (b) classificação da matiz do Sistema de Munsell, linha vermelha

FIGURA 24 - (a) Mapa Pedológico do Estado de São Paulo; (b) Foto da área selecionada no Mapa Pedológico do Estado de São Paulo e localização do ponto de coleta do solo

FIGURA 25 - Percolados das colunas de solo ao longo de 168 dias de percolação 64

FIGURA 26 - Difratograma do solo obtido no laboratório LCT-POLI-USP. 65

FIGURA 27 - pH dos percolados das colunas ao longo de 336 dias de percolação 67

FIGURA 28 - Condutividade elétrica dos percolados das colunas ao longo de 336 dias de percolação 68

FIGURA 29 - Volume adicionado e percolado nas colunas. 71

FIGURA 30 - Vazão das colunas para 336 dias 71

FIGURA 31 - Coeficiente de permeabilidade das colunas para 336 dias 72

FIGURA 32 - Concentração dos elementos tóxicos $\left(\mathrm{mg} \mathrm{L}^{-1}\right)$ no percolado das colunas de cinza durante 336 dias de percolação 83

FIGURA 33 - Comportamento dos elementos nas amostras de cinza de carvão, solo e percolado da coluna no sistema de percolação das colunas 85

FIGURA 34 - Amostras dos solos com estrutura não deformada (a) Solo argiloso; (b) Solo franco arenoso 91 


\section{LISTA DE ABREVIATURAS E SIGLAS}

AAS - Espectrômetro de absorção atômica

ABNT - Associação Brasileira de Normas Técnicas

ANEEL - Agência Nacional de Energia Elétrica

AGEITEC - Agência Embrapa de Informação Tecnológica

CC - Coluna de cinza de carvão

CE - Condutividade elétrica

CETESB - Companhia Ambiental do Estado de São Paulo

CNEN - Comissão Nacional de Energia Nuclear

COD - Carbono Orgânico Dissolvido

CONAMA - Conselho Nacional do Meio Ambiente

CQMA - Centro de Química e Meio Ambiente

CS - Coluna de solo

CSC - Coluna de solo com cinza

CTC - Capacidade de Troca Catiônica

Dp - Densidade da partícula

Ds - Densidade do solo

EDTA - Ácido etilenodiamino tetra-acético

EMBRAPA - Empresa Brasileira de Pesquisa Agropecuária

EPA - Environmental Protection Agency

EPE - Empresa de Pesquisa Energética

ESALQ - Escola Superior de Agricultura "Luiz de Queiroz"

FAO -Food and Agriculture Organization of the United Nations

FAPESP - Fundação de Amparo à Pesquisa do Estado de São Paulo

IAG - USP - Instituto de Astronomia, Geofísica e Ciências Atmosféricas da Universidade de São Paulo

IBGE - Instituto Brasileiro de Geografia e Estatística

ICP/OES - Espectrometria de emissão óptica por plasma acoplado indutivamente

IPEN - Instituto de Pesquisas Energéticas e Nucleares

$\mathrm{Kp}$ - Coeficiente de partição 
LCT-POLI-USP - Laboratório de Caracterização Tecnológica da Escola Politécnica da Universidade de São Paulo

MO - Matéria Orgânica

NIST - National Institute of Standars and Technology

P - Porosidade

PDE - Plano Decenal de Expansão de Energia

POLI - Escola Politécnica da Universidade de São Paulo

SSSA - Soil Science Society of America

UF - Unidade Federal

USDA - United States Department of Agriculture

USP - Universidade de São Paulo

VMP - Valor máximo permitido para o consumo humano 


\section{INTRODUÇÃO}

Desde os primórdios o solo tem sido utilizado pelo homem especialmente como sustentação e meio de cultivo de alimentos, tendo-se considerado que solos favoráveis ao plantio foram responsáveis pelo desenvolvimento de alguns povos. Com o progresso da ciência o homem começou a estudar o solo, as características, a composição, a relação com as plantas, a influência do clima, entre outros (Lepsch, 2002). O solo tem sido cada vez mais utilizado como receptor de resíduos após a Revolução Industrial (CETESB, Companhia Ambiental do Estado de São Paulo, 2012). Isso tem gerado problemas de contaminação do próprio solo e dos mananciais aquáticos superficiais e subterrâneos (Chaves, 2008). A contaminação do solo tem sido motivo de preocupação ambiental e de saúde pública. Cada vez mais o solo é considerado um recurso limitado e fundamental no ecossistema mundial (CETESB, 2012).

A cinza de carvão é um resíduo gerado da queima do carvão em usinas termoelétricas. No Brasil 4.000.000 de toneladas de cinza são geradas por ano nas usinas termoelétricas brasileiras e outras unidades industriais, das quais somente em torno de 50\% são aproveitadas (Rohde et al., 2006). A composição da cinza depende do carvão do qual foi gerada e a concentração de elementos tóxicos como $\mathrm{As}, \mathrm{Cd}, \mathrm{Mo}, \mathrm{Pb}, \mathrm{Zn}$ e outros pode variar de uma cinza para outra.

No momento em que um elemento tóxico atinge a superfície do solo, este pode ser sorvido, arrastado pelo vento ou pelas águas do escoamento superficial, ou ainda lixiviado pelas águas de infiltração, passando para as camadas inferiores e atingindo as águas subterrâneas, sendo assim carregado para outras regiões, através do fluxo dessas águas. O solo frequentemente age como um filtro e imobiliza grande parte dos contaminantes ou poluentes nele depositados (CETESB, 2012).

O estudo da mobilidade de elementos tóxicos no solo é importante para a predição do comportamento destes e pode auxiliar no aperfeiçoamento da remediação de solos contaminados para evitar ou retardar uma possível contaminação da água subterrânea e outras matrizes ambientais. 
Este trabalho está inserido num projeto aprovado pela FAPESP - Fundação de Amparo à Pesquisa do Estado de São Paulo ( ${ }^{\circ}$ do processo: 08/06775-6) cujo título é "Mobilidade e transporte de As, Cd, Mo, Pb e Zn em colunas de solos tropicais contaminadas com cinza de carvão da usina termoelétrica de Figueira, Paraná". 


\section{OBJETIVO}

Avaliar a mobilidade de As, $\mathrm{Cd}, \mathrm{Mo}, \mathrm{Pb}$ e $\mathrm{Zn}$ em colunas de Latossolo argiloso com cinza de carvão sobreposta ao solo por meio da concentração destes elementos nas amostras de cinza, solo e percolado da coluna e das características físicas, químicas e mineralógicas do solo. Avaliar a contaminação do solo pelos elementos $\mathrm{As}, \mathrm{Cd}, \mathrm{Mo}, \mathrm{Pb}$ e Zn por meio da comparação da concentração destes elementos no solo com os valores orientadores para solos do estado de São Paulo. Avaliar a lixiviação dos elementos da cinza de carvão. Avaliar a retenção do elemento no solo. Avaliar o balanço de massa do sistema de percolação das colunas de solo com cinza de carvão. Comparar os resultados de mobilidade e retenção dos elementos no solo argiloso obtidos no presente trabalho com os de um solo franco arenoso. 


\section{REVISÃO DE LITERATURA}

\subsection{Cinza de carvão}

A cinza de carvão é o resíduo resultante da queima do carvão, realizada em usinas termoelétricas, para gerar energia elétrica (Rohde et al., 2006).

A energia obtida em usinas termoelétricas representa $42 \%$ da energia mundial, e existe uma previsão de que ocorra um aumento devido à alta produção mundial de carvão (World Coal, 2012). No Brasil, segundo o Plano Decenal de Expansão de Energia (PDE), é esperado um aumento na demanda de carvão mineral para os próximos anos, sendo a maior parte deste destinado à geração de energia elétrica em usinas termoelétricas (PDE, 2012). Com o crescimento da produção de energia elétrica por meio da queima do carvão, é subentendido também o aumento da geração de cinzas de carvão.

As usinas termoelétricas a carvão do Brasil estão localizadas nos estados da região sul, conforme descrito na TAB. 1.

TABELA 1 - Usinas termoelétricas a carvão em operação no Brasil em setembro de 2003

\begin{tabular}{cccc}
\hline Usina & Potência $(\mathbf{k W})$ & Proprietário & Município - UF \\
\hline Figueira & 20.000 & Copel Geração S/A & Figueira - PR \\
Jorge Lacerda I e II & 232.000 & Tractebel Energia S/A & Capivari de Baixo - SC \\
Jorge Lacerda III & 262.000 & Tractebel Energia S/A & Capivari de Baixo - SC \\
Jorge Lacerda IV & 363.000 & Tractebel Energia S/A & Capivari de Baixo - SC \\
Charqueadas & 72.000 & Tractebel Energia S/A & Charqueadas - RS \\
Presidente Médici A/B & 446.000 & Companhia de Geração Térmica de & Canergia Elétrica \\
& & Companhia de Geração Térmica de & RS \\
São Jerônimo & 20.000 & Energia Elétrica & São Jerônimo - RS
\end{tabular}

Fonte - Agência Nacional de Energia Elétrica - ANEEL, 2011.

Na FIG. 1 é apresentado um esquema de funcionamento de uma usina termoelétrica (Empresa de Pesquisa Energética, EPE, 2007). O carvão é levado pelas correias transportadoras até o silo de carvão, no qual é armazenado; depois o carvão é 
moído a pequenas partículas que são sopradas para os queimadores da caldeira, na qual o carvão é queimado gerando calor; esse calor aquece a água que corre por tubos no interior da caldeira e a transforma em vapor. $\mathrm{O}$ vapor faz com que as turbinas girem e movimentem os geradores de energia e estes produzem a eletricidade. As cinzas pesadas caem no fundo da caldeira e as cinzas leves são recolhidas no filtro ciclone e manga (Eletrosul, 2012).

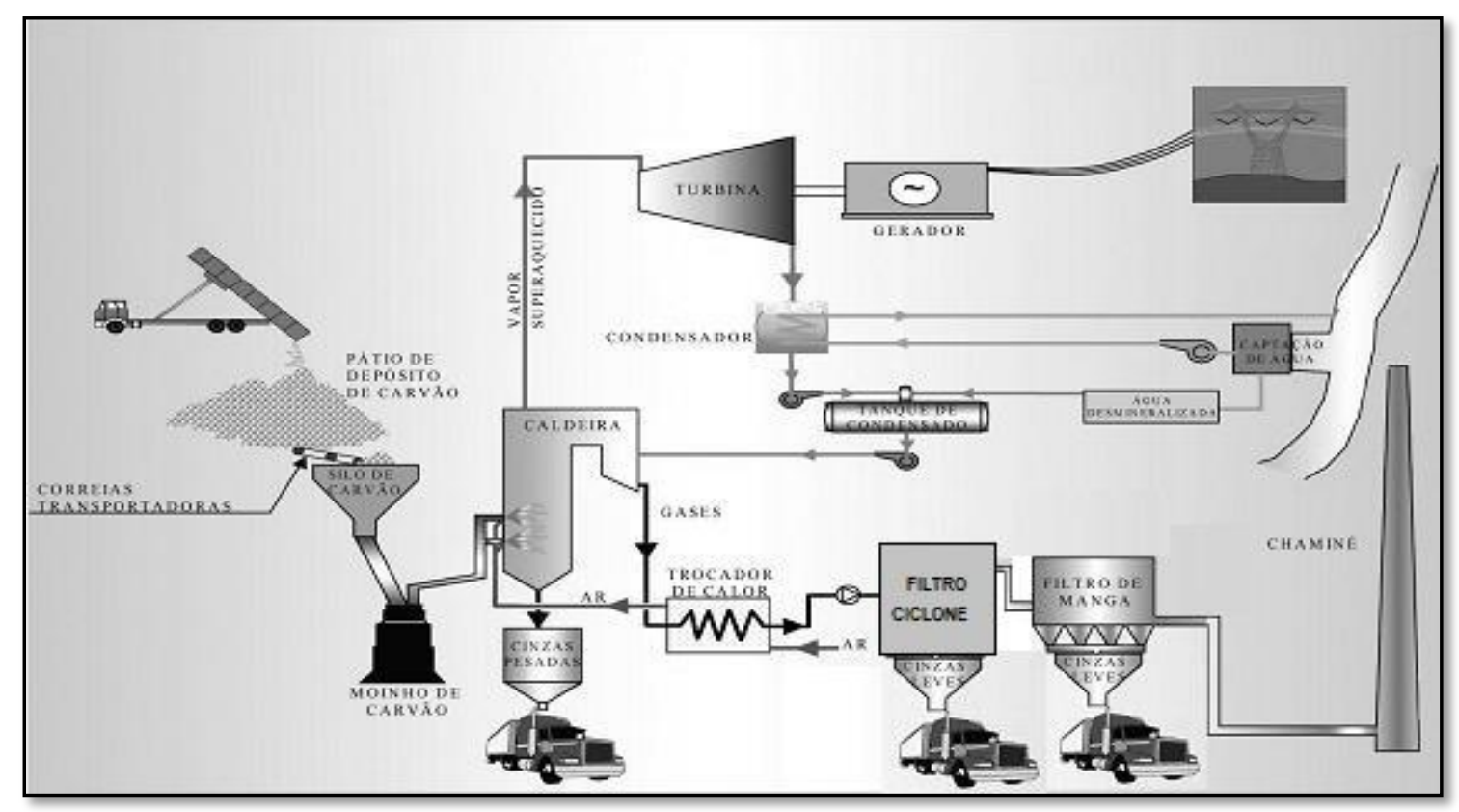

FIGURA 1 - Esquema de funcionamento de uma usina termoelétrica Fonte - Adaptado de EPE, 2007.

As cinzas de carvão são classificadas como escória, retirada pelo fundo da fornalha com granulometria grosseira e teores de 10 a $20 \%$ de carbono não queimado, cinza de fundo, cai para o fundo das fornalhas e gaseificadores, com granulometria grossa e teores de 5 a $10 \%$ de carbono não queimado, e cinza leve ou volante, retidas nos filtros ou precipitadores eletrostáticos e com granulometria fina, partículas menores que $0,15 \mathrm{~mm}$. Dos resíduos gerados nas usinas termoelétricas 70 a $80 \%$ são cinza leve (Rohde et al., 2006). A quantidade de cinza leve liberada para a atmosfera pode ser reduzida de $10 \%$ para $0,5 \%$ devido à presença de filtros e sistemas de retenção (Flues et al., 2008).

De acordo com Rohde et al. (2006), a capacidade máxima de geração de cinzas ao ano na Usina Termoelétrica de Figueira é de $50.000 \mathrm{t}$ de cinza volante e $5.000 \mathrm{t}$ de cinza pesada. 
A Usina Termoelétrica de Figueira (FIG.2) funciona desde 1963, com filtros ciclone e manga instalados em 1998 (Flues et al., 2008).

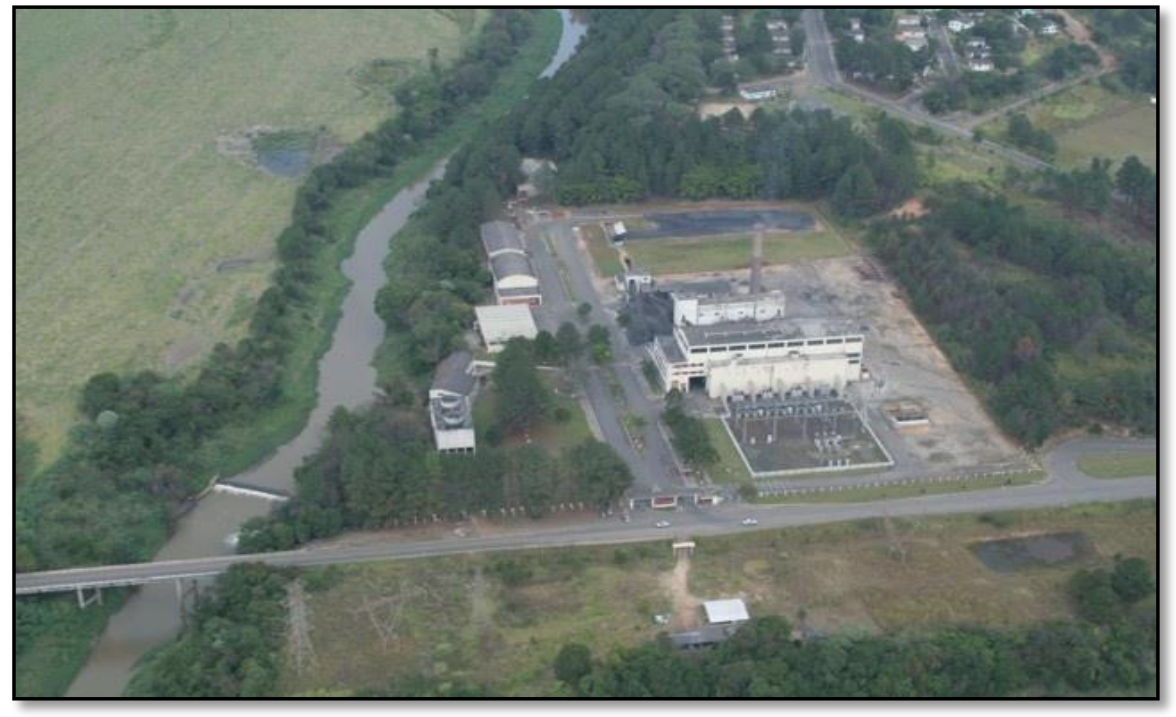

FIGURA 2 - Usina Termoelétrica de Figueira

Fonte - Carbonífera do Cambuí, 2011.

Além da emissão da cinza volante ou leve para a atmosfera (FIG.3), que pode favorecer a formação de chuvas ácidas devido aos óxidos de enxofre e nitrogênio em sua composição (Monteiro Coord., 2004), a destinação das cinzas retidas nos filtros e no fundo da caldeira é motivo de preocupação ambiental.

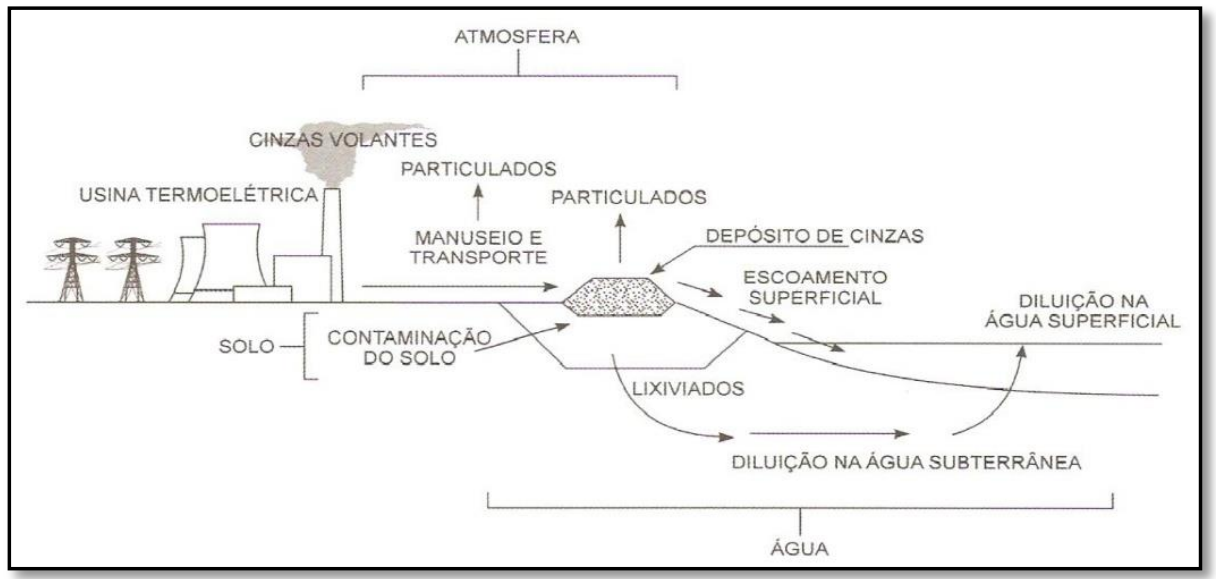

FIGURA 3 - Esquema da emissão e disposição inadequada das cinzas de carvão Fonte - Rohde et al., 2006. 
Parte da cinza leve retida nos filtros e sistemas de retenção, como o precipitador eletrostático, é disposta no solo de maneira inadequada (FIG.4), o que pode provocar danos à saúde humana e ao meio ambiente, devido à lixiviação de elementos tóxicos presentes na cinza (Izidoro, 2008). Essa lixiviação pode causar a contaminação do solo, da água subterrânea e superficial (FIG.3).

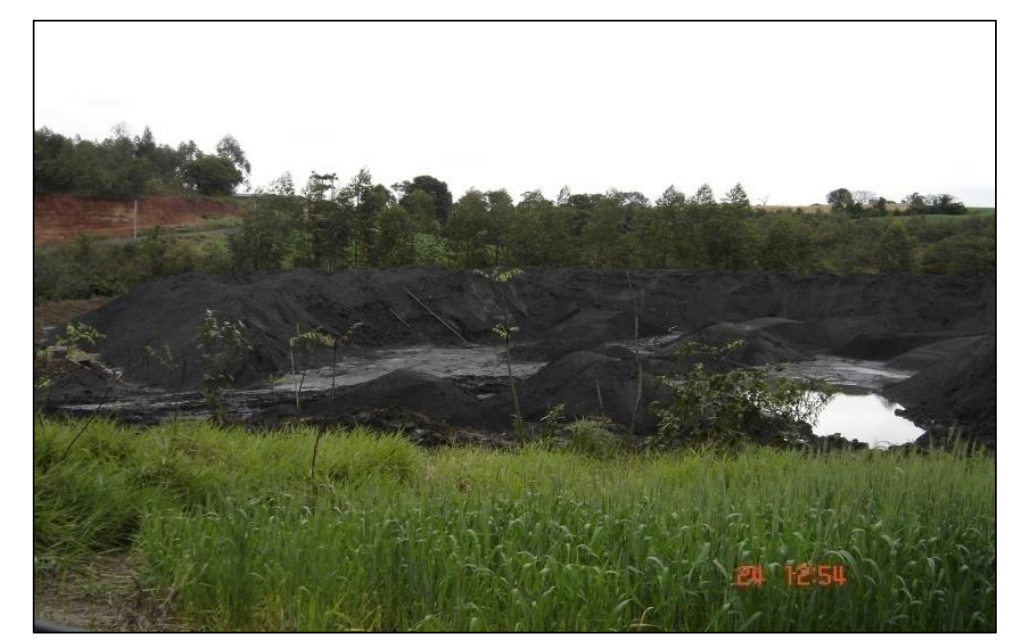

FIGURA 4 - Disposição de cinzas de carvão geradas na Usina Termoelétrica de Figueira/PR

Fonte - Ferreira, 2011.

A cinza leve retida no filtro manga (FIG.1) apresenta concentração de alguns elementos tóxicos maior do que a das outras cinzas geradas na mesma usina (Levandowski e Kalkreuth, 2009; Magdalena, 2010; Flues et al., 2013).

As características químicas da cinza dependem do carvão do qual provém (Rohde et al., 2006). As cinzas de carvão são predominantemente compostas de sílica $\left(\mathrm{SiO}_{2}\right)$, alumina $\left(\mathrm{Al}_{2} \mathrm{O}_{3}\right)$ e óxido de ferro $\left(\mathrm{Fe}_{2} \mathrm{O}_{3}\right)$, contribuindo com mais de $90 \%$ da sua composição química. Óxidos de cálcio, magnésio, sódio, potássio, titânio, e elementos, tais como, As, B, Cd, Cu, Cr, Hg, Mn, Mo, Ni, Pb, S, Se e Zn, podem estar presentes em porcentagens menores (Monteiro Coord., 2004; Rohde et al., 2006; Izidoro, 2008).

Depoi (2007) determinou a concentração dos elementos traço nas cinzas leves de quatro usinas termoelétricas localizadas no sul do Brasil (TAB.2). 
TABELA 2 - Concentração dos elementos na cinza leve de usinas termoelétricas de municípios do sul do Brasil

\begin{tabular}{ccccc} 
& \multicolumn{4}{c}{ Concentração em $\boldsymbol{\mu g ~ g ~}^{-1}$} \\
& Figueira & Charqueadas & Candiota & Capivari de Baixo \\
\hline $\mathrm{As}$ & $1263-2475$ & $19,6-75,3$ & $6,03-17,1$ & $9,34-135$ \\
$\mathrm{Ba}$ & $537-816$ & $113-513$ & $157-751$ & $68,8-762$ \\
$\mathrm{Cd}$ & $10,7-21,4$ & $0,51-1,00$ & $0,39-0,79$ & $0,32-3,14$ \\
$\mathrm{Cr}$ & $104-115$ & $66,5-96,5$ & $27,5-47,2$ & $30,8-182$ \\
$\mathrm{Cu}$ & $39,2-59,8$ & $18,0-37,4$ & $18,7-22,9$ & $9,65-61,6$ \\
$\mathrm{Mn}$ & $274-334$ & $46,6-109$ & $216-394$ & $73,5-275$ \\
$\mathrm{Mo}$ & $181-563$ & $3,56-7,38$ & $3,2-5,63$ & $1,68-14,9$ \\
$\mathrm{Ni}$ & $40,3-57,2$ & $21,1-52,9$ & $13,3-64,3$ & $8,43-59,8$ \\
$\mathrm{~Pb}$ & $2710-4086$ & $32,8-75,6$ & $17,1-37,3$ & $16,2-139$ \\
$\mathrm{U}$ & $393-916$ & $4,98-11,6$ & $3,52-7,21$ & $2,89-22,7$ \\
$\mathrm{Zn}$ & $1603-2841$ & $84,8-203$ & $44,7-109$ & $65,7-647$ \\
\hline
\end{tabular}

Fonte - Depoi, 2007.

Observando a TAB. 2, nota-se que a cinza leve de Figueira apresenta concentrações de $\mathrm{As}, \mathrm{Ba}, \mathrm{Cd}, \mathrm{Mo}, \mathrm{Pb}, \mathrm{U}$ e $\mathrm{Zn}$ maiores do que as concentrações destes elementos na cinza leve dos outros municípios.

\subsection{Solo}

Solos são materiais complexos resultantes do processo de intemperismo sobre a rocha matriz e dos resíduos orgânicos (Sposito, 1989; McBride, 1994).

De acordo com Brady (1989), o solo apresenta normalmente uma maior quantidade de matéria orgânica nas camadas superiores. Segundo Moniz et al. (1972), solos com matéria orgânica inferior a $20 \%$ podem ser classificados como solo mineral e com porcentagem superior a $20 \%$ como solo orgânico.

O solo é dividido em fases sólida, composta por minerais, matéria orgânica e pequenos fragmentos de rocha, e líquida e gasosa, compostas pela água e ar no espaço poroso do solo, respectivamente (Lepsch, 2002; Brady, 1989). Da parte sólida do solo, 
90\% são representados pelos componentes inorgânicos do solo, tais como, minerais primários e secundários (Sparks, 1995). Minerais primários são aqueles que não foram alterados quimicamente e ocorrem principalmente na fração areia e silte do solo; os exemplos mais comuns são o quartzo e o feldspato. Os minerais secundários são aqueles resultantes do intemperismo sobre os minerais primários; um dos mais comumente encontrados são os minerais aluminosilicatos e os óxidos (Sparks, 1995; Luchese et al., 2002).

Os elementos que podem ser encontrados nos solos mundiais foram descritos na TAB. 3 (Sparks, 1995).

TABELA 3 - Valores mundiais de elementos encontrados em solos

\begin{tabular}{cccccc}
\hline Elemento & Média & $\begin{array}{c}\text { Intervalo } \\
\mathbf{m g ~ k g}\end{array}$ & Elemento & Média & $\begin{array}{c}\text { Intervalo } \\
\mathbf{m g ~ k g}^{-1}\end{array}$ \\
\hline $\mathrm{Al}$ & 71.000 & $10.000-300.000$ & $\mathrm{Mn}$ & 1.000 & $20-10.000$ \\
$\mathrm{As}$ & 6 & $0,10-40$ & $\mathrm{Mo}$ & 1,2 & $0,1-40$ \\
$\mathrm{Ba}$ & 500 & $100-3.000$ & $\mathrm{~N}$ & 2.000 & $200-5.000$ \\
$\mathrm{C}$, total & 20.000 & $7.000-500.000$ & $\mathrm{Na}$ & 5.000 & $150-25.000$ \\
$\mathrm{Ca}$ & 15.000 & $700-500.000$ & $\mathrm{Ni}$ & 50 & $2-750$ \\
$\mathrm{Cd}$ & 0,35 & $0,01-2$ & $\mathrm{O}$ & 490.000 & - \\
$\mathrm{Cu}$ & 30 & $2-250$ & $\mathrm{~Pb}$ & 35 & $2-300$ \\
$\mathrm{Fe}$ & 40.000 & $2.000-550.000$ & $\mathrm{Si}$ & 330.000 & $250.000-410.000$ \\
$\mathrm{~K}$ & 14.000 & $80-37.000$ & $\mathrm{Ti}$ & 5.000 & $150-25.000$ \\
$\mathrm{Mg}$ & 5.000 & $400-9.000$ & $\mathrm{Zn}$ & 90 & $1-900$ \\
\hline
\end{tabular}

Os solos das diversas regiões do mundo possuem diferenças entre si que são controladas pelos seguintes fatores (Lepsch, 2002):

- Clima: dependendo do clima da região o material provindo da mesma rocha pode formar solos diferentes; a maioria dos solos das regiões úmidas são ácidos e em regiões áridas e semi-áridas o solo é neutro ou alcalino;

- Organismos: micro-organismos ajudam na formação do húmus, os vegetais aceleram o intemperismo; 
- Material de origem (rocha): influencia na granulometria e textura do solo;

- Relevo: influencia na cor do solo, e na infiltração da chuva que favorece o intemperismo;

- Tempo: influencia na espessura do solo (solos mais jovens são menos espessos) e no desenvolvimento do solo.

Os solos podem ser classificados quanto às características cor, textura e mineralogia do solo (Prado, 2003).

No Brasil, existem treze classes de solo com base no atual Sistema Brasileiro de Classificação de Solos (Embrapa - Empresa Brasileira de Pesquisa Agropecuária, 2006) que são Argissolos, Cambissolos, Chernossolos, Espodossolos, Gleissolos, Latossolos, Luvissolos, Neossolos, Nitossolos, Organossolos, Planossolos, Plintossolos e Vertissolos. As classes predominantes no Brasil são os Latossolos, Argissolos e Neossolos, que representam aproximadamente 70\% do território brasileiro (Ageitec - Agência Embrapa de Informação Tecnológica, 2012) (TAB.4).

TABELA 4 - Classes e áreas dos solos brasileiros

\begin{tabular}{ccc}
\hline Classes & Área absoluta $\left(\mathbf{k m}^{\mathbf{2}}\right)$ & Área relativa $\mathbf{( \% )}$ \\
\hline Latossolos & $2.681 .588,69$ & 31,49 \\
Argissolos & $2.285 .609,41$ & 26,84 \\
Neossolos & $1.122 .603,82$ & 13,18 \\
Plintossolos & $594.599,98$ & 6,98 \\
Cambissolos & $448.268,08$ & 5,26 \\
Gleissolos & $397.644,27$ & 4,67 \\
Luvissolos & $241.910,74$ & 2,84 \\
Planossolos & $226.561,75$ & 2,66 \\
Espodossolos & $160.892,69$ & 1,89 \\
Nitossolos & $96.533,02$ & 1,13 \\
Chernossolos & $37.206,29$ & 0,44 \\
Vertissolos & $17.630,98$ & 0,21 \\
Organossolos & $2.231,33$ & 0,03 \\
\hline
\end{tabular}

Fonte - Adaptado Ageitec, 2012. 
Na FIG. 5 as classes de solos estão representadas conforme a distribuição no mapa de solos do Brasil.

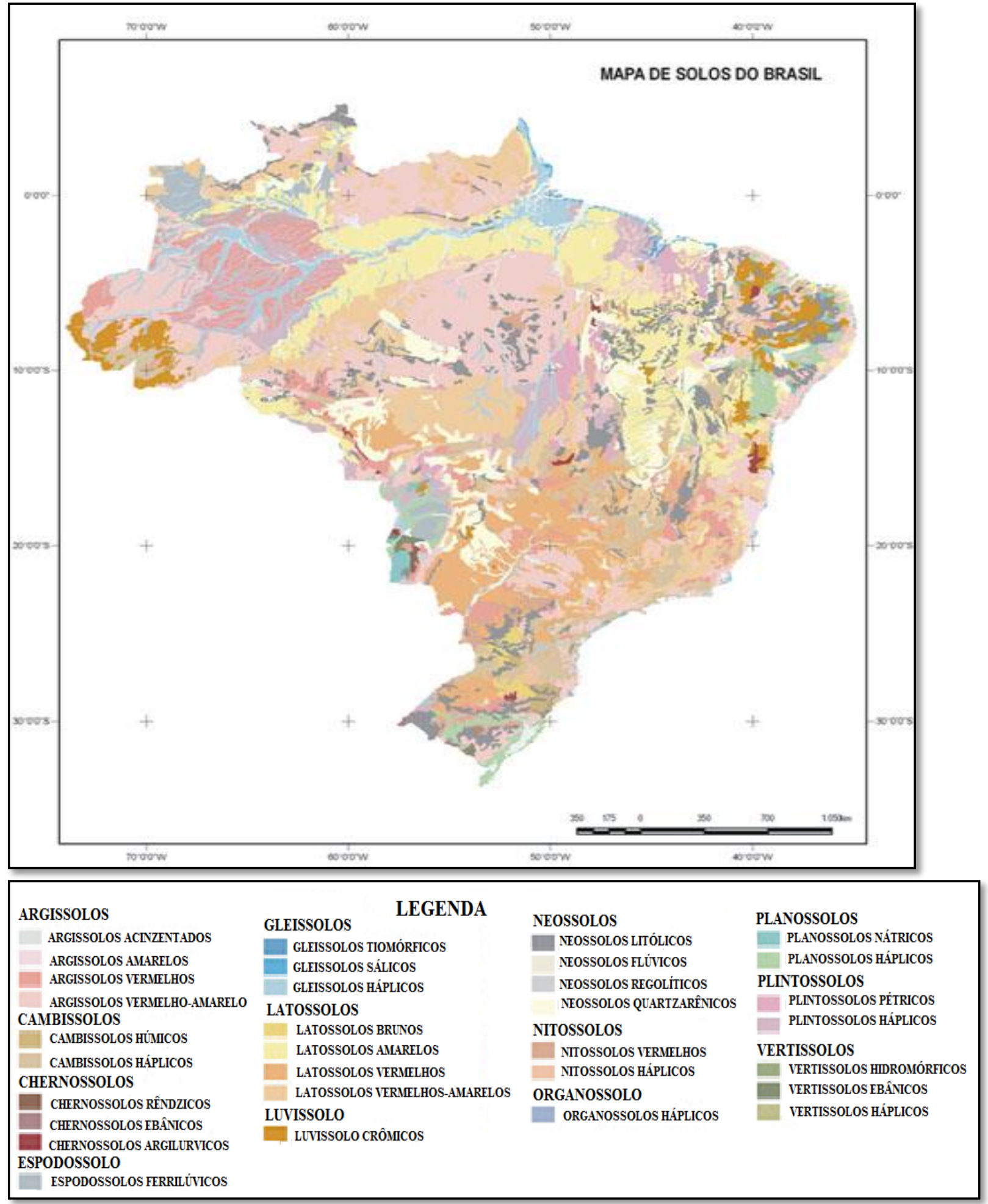

FIGURA 5 - Mapa pedológico do Brasil

Fonte - Ageitec, 2012. 
Na FIG. 6 foram listadas as classes de solo encontradas no estado de São Paulo. Os Latossolos e os Argissolos são classes predominantes em São Paulo, representam mais de 80\% dos solos do estado (Rossi e Oliveira, 2000; Soares, 2004).

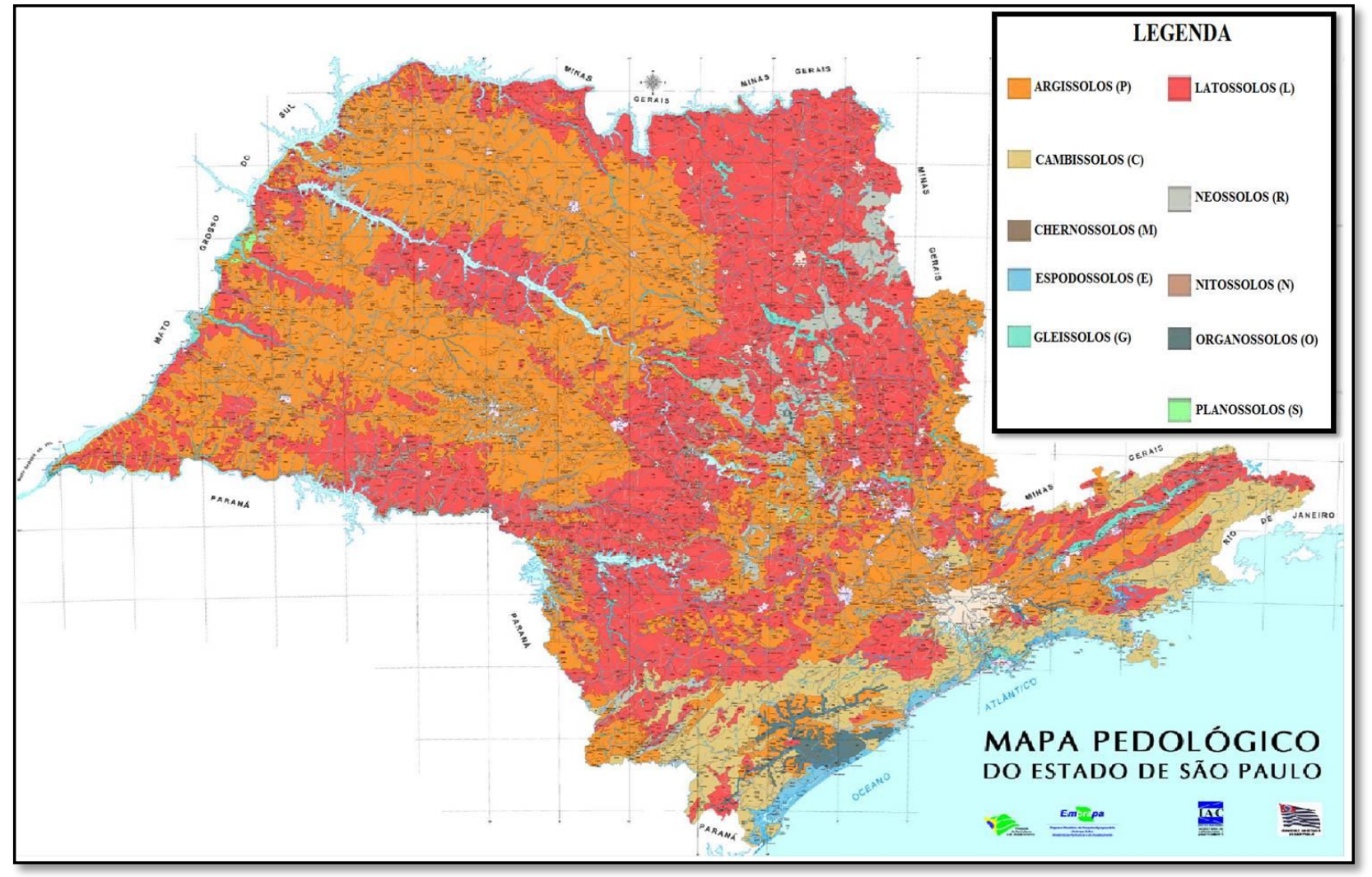

FIGURA 6 - Mapa pedológico do estado de São Paulo

Fonte - Adaptado Rossi e Oliveira, 2000.

O Latossolo é o solo mais representativo no Brasil, 31,49\% de área relativa (TAB. 4). É um solo intemperizado, pouco fértil e com predominância do argilomineral caulinita, que é responsável pela típica cor avermelhada devido ao revestimento por óxidos de ferro (Lepsch, 2002).

O Nitossolo é bem menos representativo no Brasil, $1,13 \%$ de área relativa (TAB. 4). É um solo intemperizado, porém menos do que o Latossolo. Os valores de Ki (coeficiente de intemperização) do Nitossolo são maiores do que os do Latossolo, e quanto maior o Ki menor o intemperismo (Ker, 1998; Dias et al, 2001; Lepsch, 2002). O Nitossolo é uma classe de solo qualificada por muitos como o melhor solo para a agricultura. Os argilominerais mais encontrados no Nitossolo são a caulinita e a haloisita e 
em menores quantidades a ilita (FAO, Food and Agriculture Organization of the United Nations, 2013).

\subsubsection{Componentes do solo}

O solo é composto por componentes que estão relacionadas com a mobilidade e retenção dos elementos no solo como a argila, óxidos e matéria orgânica.

A granulometria do solo é dividida em frações com grãos de diferentes diâmetros como o calhaus ou pedras (200 a $20 \mathrm{~mm}$ ), cascalho (de 20 a $2 \mathrm{~mm}$ ), areia (de 2 a 0,05 mm), silte $(0,05$ a 0,002 $\mathrm{mm}$ ) e argila (menor que 0,002 mm) (Lepsch, 2002). As argilas são divididas em argilas silicatadas, que ocorrem mais em regiões temperadas, e argilas óxido-hidratadas de ferro e de alumínio, presentes geralmente em solos tropicais e semitropicais (Brady, 1989).

Os argilominerais apresentam comportamento coloidal, mesmo as maiores partículas $(2 \mu \mathrm{m})$ que têm dimensões superiores a $1 \mu \mathrm{m}$ (Brady, 1989). Colóide é um estado da matéria que consiste em partículas muito finas (máximo $1 \mu \mathrm{m}$ ) (Tan, 1992) e apresenta cargas negativas e positivas que atraem íons de sinais opostos para sua superfície (Hypolito et al., 2011).

As partículas de argila silicatada geralmente possuem cargas negativas, essas cargas atraem cátions para sua superfície, formando uma camada denominada de dupla camada iônica. As partículas de argila constituem a camada iônica interior que possui uma forte carga negativa e a camada iônica exterior é formada pelos cátions atraídos, estes estão fracamente retidos na partícula de argila, sendo assim cada partícula de argila tem em sua superfície um grande número de cátions adsorvidos (Brady, 1989). Na FIG. 7 foi apresentada a adsorção de cátions em argila com estrutura em lâminas. 


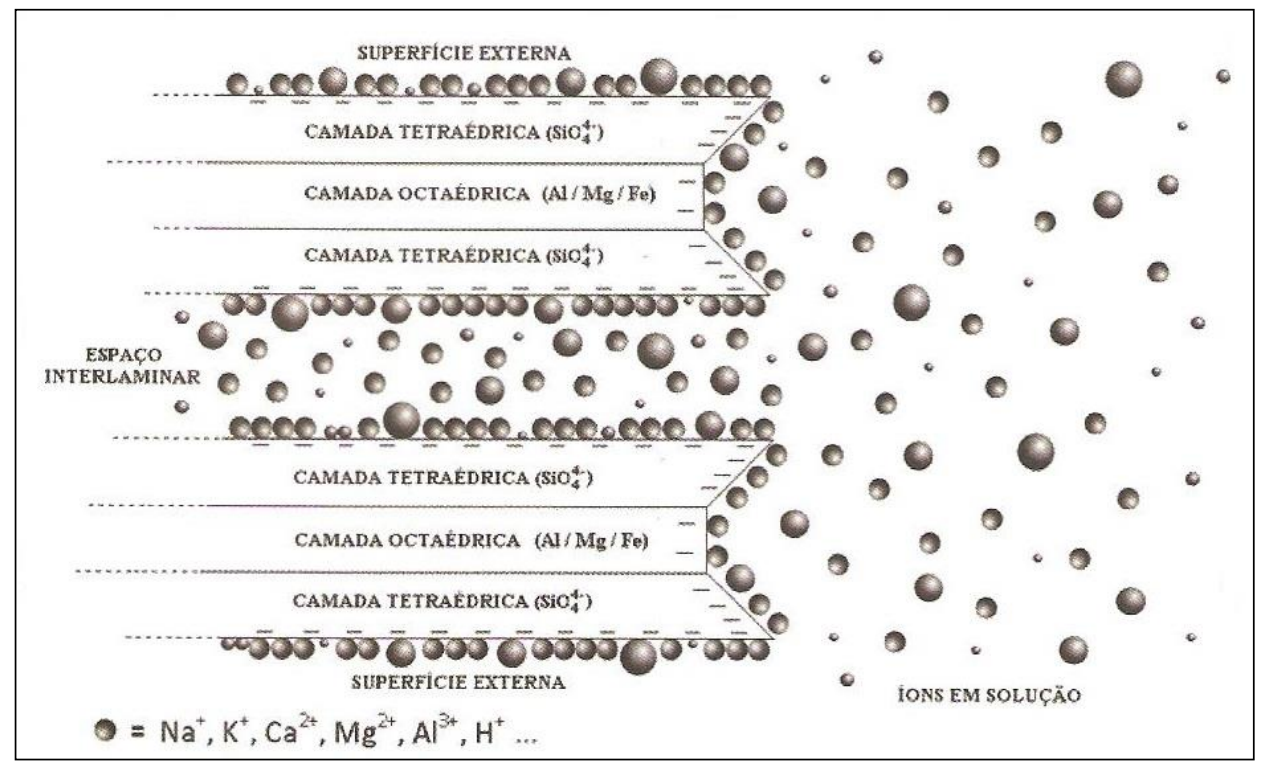

FIGURA 7 - Adsorção de cátions em um cristal de argila com estrutura em lâminas Fonte - Hypolito et al., 2011.

A maior parte dos argilominerais do solo apresenta estrutura cristalina, mas algumas como a sílica, a alumina entre outras, apresentam poucos cristais ou têm a estrutura desordenada (amorfa) (Tan, 1992). A estrutura amorfa de uma partícula com elevada superfície específica adsorve mais do que as partículas bem cristalizadas (Hypolito et al., 2011).

O quartzo é um dos minerais que têm estrutura cristalina, e é considerado um mineral com baixa capacidade de retenção de cátions e facilmente laváveis pela água de percolação no solo (Luchese et al., 2002).

As estruturas das camadas de argila são formadas por lâminas tetraédricas e octaédricas compostas de cátions circundados e ligados a ânions de oxigênio e hidroxila. Lâminas tetraédricas são formadas por uma série de tetraedros de silício ligados por ânions de oxigênio, e lâminas octaédricas são formadas por octaedros de alumínio ou magnésio ligados por oxigênio ou hidroxila (FIG.8) (Brady, 1989). 


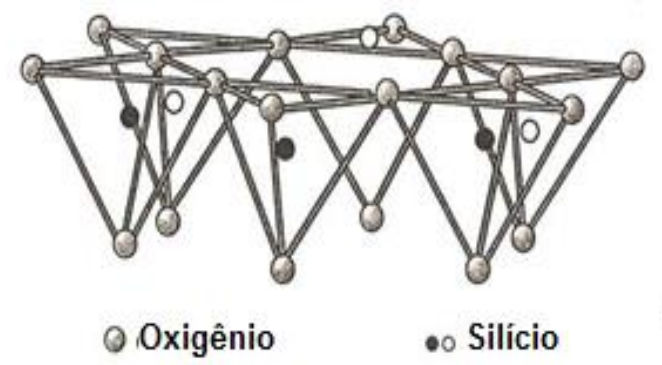

(a)

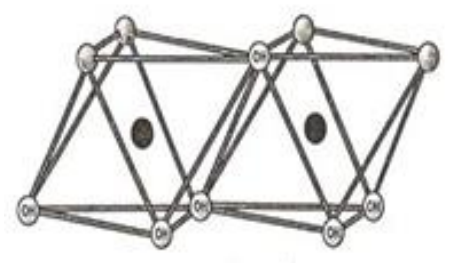

(b)
(3) Oxidrilos

O Oxigênio

Alumínio ou magnésio

FIGURA 8 - Esquema de tetraedros (a) e octaedros (b)

Fonte - Adaptado Luchese et al., 2002.

As camadas podem ser do tipo 1:1 que são formadas por uma lâmina tetraédrica e uma lâmina octaédrica ou do tipo 2:1 formadas por duas lâminas tetraédricas intercaladas por uma octaédrica (Brady, 1989).

A caulinita é um exemplo de mineral formado por camadas do tipo 1:1, que se unem com muita rigidez tornando a adsorção interna nula ou quase nula, sendo possível apenas a adsorção externa. A troca de cátions e a substituição isomórfica ocorrem pouco na caulinita. A caulinita é uma estrutura que tem menor quantidade de sítios para trocar cátions do que outros minerais, tais como, a montmorilonita. A carga da caulinita depende do $\mathrm{pH}$ do meio, em meio ácido tem carga positiva e adsorve ânions e em meio básico tem carga negativa e adsorve cátions (Luchese et al., 2002).

Alguns elementos componentes das lâminas tetraédricas $(\mathrm{Si})$ e octaédricas ( $\mathrm{Al}$ e $\mathrm{Mg}$ ) podem ser substituídos por outros íons de tamanho semelhante, determinado pelo raio iônico. Esta substituição é denominada substituição isomórfica (Brady, 1989).

Os minerais do tipo 2:1 têm a capacidade de se expandir, o que faz com que seja possível além da adsorção externa a adsorção interna entre as camadas. Um exemplo desse tipo de mineral é montmorilonita que possui atração menos intensa entre as camadas permitindo uma maior expansão (Luchese et al., 2002), sendo possível uma maior adsorção nas superfícies internas e externas. 
Os óxidos, hidróxidos e oxihidróxidos são derivados do intemperismo da rocha matriz, sendo o óxido de Fe o mais encontrado no solo. Os óxidos de ferro e alumínio são encontrados em regiões temperadas ou em solos tropicais e semitropicais com intenso intemperismo. Os óxidos mais comuns presentes nos solos são a gibbsita e goethita (Brady, 1989). Os óxidos de $\mathrm{Al}, \mathrm{Fe}$ e $\mathrm{Mn}$ têm baixa solubilidade no solo e são mais comuns do que os óxidos de Ti e Si (Yong e Mulligan, 2004). Nas superfícies de óxidos de Fe e Al não ocorre substituição isomórfica o que resulta em uma baixa CTC, mas pode ocorrer sorção de íons inorgânicos (McBride, 1994; Hypolito et al., 2011). A presença dos óxidos de carga variável devido ao $\mathrm{pH}$ pode alterar a mobilidade de alguns elementos aumentando a adsorção no solo (Yong e Mulligan, 2004).

O alofânio é uma combinação que pode ser definida como silicato de alumínio com fórmula semelhante a $\mathrm{Al}_{2} \mathrm{O}_{3} \cdot 2 \mathrm{SiO}_{2} \cdot \mathrm{H}_{2} \mathrm{O}$, e tem uma grande capacidade de adsorção de cátions e ânions (Brady, 1989).

Osei e Singh (2000) estudaram os efeitos da remoção da MO e de óxidos de Fe na área de superfície específica das argilas de 10 solos tropicais. Os resultados mostraram que a área aumentou com a remoção da MO e diminuiu com a remoção de óxidos de Fe; o aumento pode ter sido causado pelo bloqueio dos poros dos agregados da argila feito pela MO. A diminuição da área de superfície causada pela remoção dos óxidos de Fe mostra que estes são responsáveis por uma parte significativa da área superficial do solo. Essa informação mostra o quanto os óxidos podem interferir na retenção de elementos no solo devido à área superficial na qual eles podem ser adsorvidos.

A matéria orgânica encontra-se em estado coloidal e devido a isso tem alta capacidade de troca de cátions, superior ao do mineral caulinita (Moniz et al., 1972). A seletividade dos elementos pela MO depende do nível de adsorção entre eles, do pH e da força iônica da solução (McBride, 1994). A CTC da MO depende do pH, pois aumenta com o aumento do pH (Moniz et al., 1972).

A MO influencia nas propriedades químicas e físicas do solo, aumentando a porosidade, a retenção de água e retendo nutrientes por troca catiônica, entre outros (McBride, 1994). A matéria orgânica é uma fração importante do solo para fins agrícolas. 
A CTC representa a capacidade do solo para trocar os cátions ligados em sua superfície por outros da solução do solo. O valor da CTC do solo está relacionado com outras características do solo como granulometria, argilominerais e MO (Brady, 1989).

Biasioli et al. (2012) avaliaram 140 amostras de solo contaminado com compostos orgânicos e inorgânicos em um distrito inteiro do norte da Itália, e observaram que o solo de uso urbano apresentou baixa CTC e provavelmente está relacionado a baixa MO desse solo.

\subsubsection{Mobilidade dos elementos no solo}

A solubilidade e a mobilidade dos elementos no solo dependem de sua forma iônica, dos complexos que eles formam no solo e do $\mathrm{pH}$ do solo. De um modo geral, os elementos que formam cátions apresentam como tendência uma maior mobilidade em solo ácido e isso reduz com o aumento de pH. Entretanto, para ânions o comportamento é inverso, a mobilidade diminui em solo ácido e aumenta em solo neutro ou básico (Alloway, 1990; McBride, 1994).

Na FIG. 9 foram apresentados os processos que controlam a solubilidade, disponibilidade e mobilidade dos elementos no solo.

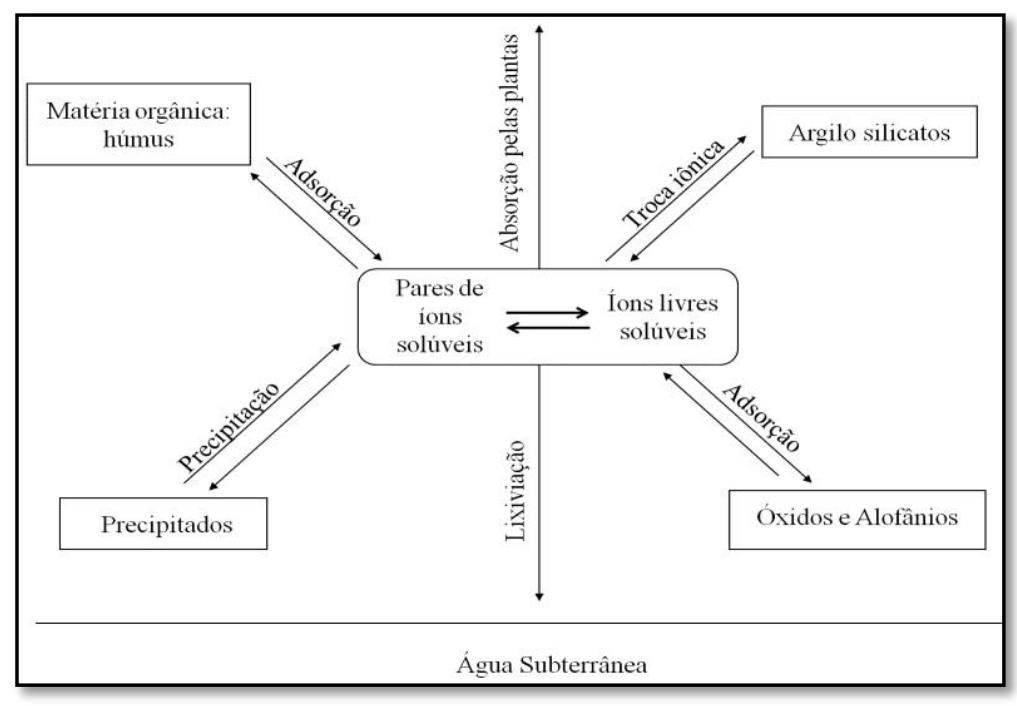

FIGURA 9 - Processos que controlam a solubilidade, disponibilidade e mobilidade dos elementos no solo Fonte - Adaptado de McBride, 1994. 
Adsorção é o processo que mais afeta o comportamento dos elementos no solo, controla a concentração dos elementos na solução do solo e exerce influência na absorção pela raiz das plantas. Os elementos também podem ser adsorvidos nos ácidos húmicos, parte orgânica do solo, formar complexos orgânicos e precipitar com óxidos (Alloway, 1990, McBride, 1994).

$\mathrm{O}$ pH é um dos parâmetros mais importantes que estão relacionados com a mobilidade e retenção de elementos no solo, pois controla as reações de troca iônica, dissolução, precipitação, redução, oxidação, adsorção e complexação (Alloway, 1990; McBride, 1994).

A troca iônica se trata da troca entre os contra íons, íons de sinais opostos, que estão na superfície do colóide, com os íons na solução do solo (Alloway, 1990; Hypolito et al., 2011).

A precipitação, formação de um corpo insolúvel em um líquido, juntamente com a adsorção são processos que retardam a migração de íons no solo (Hypolito et al., 2011).

\subsubsection{Extração dos elementos no solo}

Os elementos no solo estão presentes nas frações solúvel, trocável, orgânica, óxidos e residual do solo.

$\mathrm{Na}$ fração solúvel, os elementos estão na solução do solo, na trocável os elementos estão fracamente ligados ao solo de maneira que podem ser trocados por outros elementos (Camargo, 2005). Na fração orgânica os elementos estão sorvidos e ligados à parte orgânica do solo. $\mathrm{Na}$ fração óxidos, os elementos estão ligados e fixados aos óxidos e aos argilominerais. E na fração residual os elementos estão na estrutura do mineral primário (Alloway, 1990). Os elementos que estão na fração trocável do solo são mais fáceis de serem extraídos do solo do que os elementos da fração residual, na qual é necessário o uso de ácidos mais fortes concentrados para que ocorra a extração. 
Na TAB. 5 foram apresentados alguns exemplos de soluções de extração dos elementos nas frações do solo.

TABELA 5 - Soluções para extração dos elementos nas frações do solo

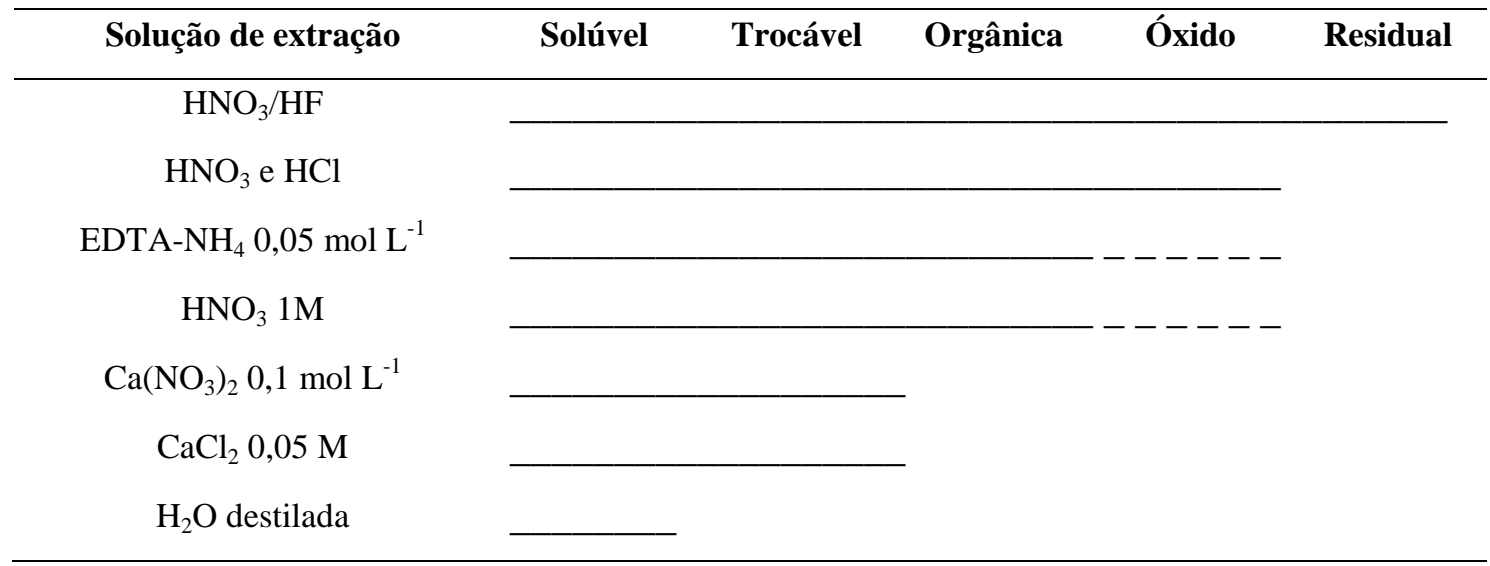

Linha sólida indica extração; linha pontilhada indica extração parcial.

Fonte - Adaptado de Alloway, 1990.

Os ácidos concentrados nítrico e clorídrico extraem os elementos do solo ligados nas frações solúvel, trocável, orgânica e óxidos; a solução de EDTA extrai elementos das frações solúvel, trocável, orgânica e parcialmente dos óxidos, esta extração não extrai todos os elementos ligados aos óxidos como na digestão ácida; a solução de $\mathrm{Ca}\left(\mathrm{NO}_{3}\right)_{2}$ extrai elementos das frações solúvel e trocável, essa extração não extrai os elementos ligados na parte orgânica do solo como a extração com EDTA.

Os elementos extraídos do solo pelas soluções de extração (TAB.5) podem representar os elementos presentes na fase sólida ou líquida do solo. O coeficiente de partição, Kp, é a razão entre a concentração do elemento na fase sólida do solo e a concentração do elemento na fase líquida do solo, ou seja, na solução do solo.

$\mathrm{Kp}=\frac{\text { Concentração do elemento na fase sólida do solo }}{\text { Concentração do elemento na fase líquida do solo }}$

$\mathrm{O}$ valor de Kp de um elemento é um valor relativo, quando o valor é baixo representa que o elemento se encontra mais na solução do solo do que na fase sólida do solo quando comparado com um valor de $\mathrm{Kp}$ mais alto. $\mathrm{O}$ valor de $\mathrm{Kp}$ mais baixo favorece 
o transporte do elemento para a água subterrânea ou para ser absorvido pelas plantas (Camargo et al., 2007).

\subsubsection{Comportamento químico de As, Cd, Mo, Pb e Zn no solo}

O arsênio pode ser encontrado nos solos em condição anaeróbica como arsenito (+3) nas formas $\mathrm{As}(\mathrm{OH})_{3}, \mathrm{As}(\mathrm{OH})_{4}^{-}, \mathrm{AsO}_{2}(\mathrm{OH})^{2-}$ e $\mathrm{AsO}_{3}{ }^{3-}$, e nos solos em condição aeróbica como arsenato (+5) na forma $\mathrm{AsO}_{4}{ }^{3-}$ (McBride, 1994). O arsênio pode ser adsorvido em óxidos e hidróxidos de $\mathrm{Fe}, \mathrm{Al}$ e $\mathrm{Mn}$, argilominerais e substâncias húmicas. O arsenato é fortemente adsorvido por oxihidróxidos férricos (Brady, 1989; Perk, 2006). O As na forma aniônica apresenta tendência de menor mobilidade em solos ácidos e maior em solos neutros ou básicos (Alloway, 1990; McBride, 1994).

Goldberg e Glaubig (1988) estudaram a sorção de arsênio num solo calcário com montimorrilonita em função do $\mathrm{pH}$ entre 2 e 11 e foi observado que a sorção do arsenato aumentou com o aumento do $\mathrm{pH}$ com sorção máxima próxima do $\mathrm{pH}$ 10,5.

Ladeira et al. (2002) analisaram três amostras de solo para avaliar a retenção do As e observaram que o solo que apresentou maior concentração de As, ou seja, que apresentou mais As adsorvido, foi o que apresentou maior quantidade de óxidos de $\mathrm{Al}$ e Fe, maior área superficial específica e menor granulometria.

Campos et al. (2007) estudaram a adsorção de arsênio em 17 amostras de Latossolos brasileiros e observaram que o teor de argila e os óxidos de $\mathrm{Fe}$ e $\mathrm{Al}$ apresentaram influência positiva na adsorção de As no solo.

Assis (2010) estudou a adsorção de As em cinco solos das classes de Latossolos, Argissolos e Cambissolo com textura variando de argilosa a muito argilosa. O As apresentou correlação positiva com a argila e os óxidos e hidróxidos de Fe livres cristalinos e mal cristalizados e uma tendência de adsorção nos minerais na seguinte ordem gibbsita>hematita>goethita. 
Aredes et al. (2012) estudaram a remoção de As da água com solo laterítico rico em Fe por meio de diferentes tempos de agitação e foi observado que quanto maior o tempo de contato com o solo a concentração de As na água diminuía e portanto, o As apresentou afinidade com o Fe.

$\mathrm{O} \mathrm{Cd}^{2+}$ tem alta mobilidade no solo em $\mathrm{pH}$ menor que 6 , adsorve fracamente na MO, argilosilicatos e óxidos, e é a forma do cádmio mais adsorvida na superfície do solo (Alloway, 1990; McBride, 1994). O cádmio tende a ser mais móvel nos solos do que outros metais e em altas concentrações pode precipitar com fosfatos e carbonatos (Alloway, 1990).

Cavallaro e McBride (1978) estudaram a adsorção de Cd em dois solos, um ácido e outro neutro, e os resultados mostraram que o solo ácido tem menor capacidade de retenção do que o solo neutro.

Gabas (2005) estudou a adsorção de $\mathrm{Cd}$ e $\mathrm{Pb}$ em solo laterítico em três valores de $\mathrm{pH}$ 3,0, 5,5 e 8,0 por meio de ensaios de extração sequencial realizados em amostras de solo contaminadas em ensaios de difusão. Foi observado que o $\mathrm{Cd}$ mostrou maior afinidade pela fração trocável associada aos argilominerais e o $\mathrm{Pb}$ foi ligado fortemente aos óxidos de Fe e Al.

Pierangeli et al. (2005) estudaram o efeito do pH na adsorção de $\mathrm{Cd}$ em 17 amostras de latossolos com variações de $\mathrm{pH}, 4,5,5,5$ e 6,5. Os resultados obtidos mostraram um aumento na adsorção de $\mathrm{Cd}$ com o aumento do $\mathrm{pH}$, a adsorção do $\mathrm{Cd}$ foi de $27 \%$ em pH 4,5 e $55 \%$ em pH 6,5.

Serrano et al. (2005) estudaram a sorção do $\mathrm{Cd}$ e $\mathrm{Pb}$ em quatro amostras de solos ácidos e observaram que os solos com maior valor de $\mathrm{pH}$ e argila apresentaram a maior capacidade de sorção e todos os solos apresentaram melhor capacidade de sorção para o $\mathrm{Pb}$ do que para $\mathrm{Cd}$. 
Adhikari e Singh (2008) estudaram a sorção do Cd em três classes de solos diferentes de pH entre 6,30 e 7,69 e observaram um aumento na sorção deste elemento com o aumento de MO do solo, o que indica uma possível afinidade do Cd com a MO.

Oliveira et al. (2010) estudaram a adsorção do íon $\mathrm{Cd}$ em solos de diferentes classes e observaram que os solos que apresentaram maior retenção de $\mathrm{Cd}$ foram os que tinham maiores valores de CTC, argila, e argilominerais, como a caulinita.

Braz (2011) determinou coeficiente de distribuição $(\mathrm{Kd})$ de metais pesados em solos paraenses, dentre eles o $\mathrm{Kd}$ do $\mathrm{Cd}$. Foi observado que o $\mathrm{Kd}$ do $\mathrm{Cd}$ apresentou correlação positiva com o pH e os óxidos de Mn e Fe.

Cerqueira et al. (2011) estudaram a sorção do $\mathrm{Cd}$ em quatro solos de classes diferentes Luvissolo, Umbrissolo e Cambissolos e os resultados indicaram que a sorção do $\mathrm{Cd}$ foi mais influenciada pelo $\mathrm{pH}$, óxidos de $\mathrm{Mn}$ e argila.

O molibdênio é encontrado no solo na forma de molibdato, $\mathrm{MoO}_{4}{ }^{2-}$, que pode ser sorvido por óxidos, aluminosilicatos, e em menor quantidade por argilosilicatos. A mobilidade do molibdênio é alta em solos neutros e alcalinos, e média em solos ácidos. A solubilidade é menor em solos ácidos, sobretudo na presença de óxido de Fe, com o qual pode ser sorvido ou precipitado (McBride, 1994; Siegel, 2002).

O chumbo pode ser encontrado naturalmente no solo, no estado de oxidação mais comum, $\mathrm{Pb}^{2+}$. $\mathrm{O}$ aumento do $\mathrm{pH}$ torna o $\mathrm{Pb}$ menos solúvel no solo, favorecendo a complexação deste elemento com a MO, a sorção com óxidos e a precipitação com carbonato, hidróxido ou fosfato. Este elemento tem alta afinidade com óxidos de Mn no solo. (McBride, 1994; Siegel, 2002; Yong e Mulligan, 2004).

Linhares et al. (2009) estudaram quatro Latossolos e um Argissolo, que apresentaram valores de $\mathrm{pH}_{\mathrm{KCl}}$ entre 4,61-5,81, com diferentes texturas e teor de óxidos de Fe e $\mathrm{Al}$ a fim de se calcular correlação com a adsorção de $\mathrm{Pb}$ e $\mathrm{Cd}$ no solo, e observaram a correlação positiva da adsorção de $\mathrm{Pb}$ com o pH, óxidos de $\mathrm{Fe}$ e $\mathrm{Al}$, e de $\mathrm{Cd}$ com o pH e a CTC. 
$\mathrm{O}$ zinco é um cátion que pode ser encontrado no solo, na forma $\mathrm{Zn}^{2+}$. Em solos ácidos a mobilidade do Zn é média, e acima de $\mathrm{pH}$ 7,5 não é muito móvel (McBride, 1994; Yong e Mulligan, 2004). Zinco tem alta mobilidade quando o $\mathrm{pH}$ é menor que 5, conforme foi observado por Scokart et al. (1983). No solo o zinco pode ser sorvido ou precipitado com os óxidos de Fe e Mn (Siegel, 2002).

Segundo McBride (1994), o $\mathrm{Cd}, \mathrm{Pb}, \mathrm{Zn}$ e Mo podem formar complexos com a matéria orgânica em solos pouco drenados e dependendo do $\mathrm{pH}$ do solo. Em pH baixo a MO é geralmente insolúvel e em $\mathrm{pH}$ alto pode ocorrer a dissolução da MO (Chirenje et al., 2002).

Martínez e Motto (2000) estudaram sete solos de diferentes cidades e observaram que a solubilidade do $\mathrm{Pb}$ e do $\mathrm{Zn}$ diminuiu com o aumento do $\mathrm{pH}$. Os resultados sugeriram que a solubilidade dos metais pode ser controlada por características como $\mathrm{pH}, \mathrm{MO}$ e a mineralogia do solo.

No trabalho de Hellweg et al. (2005) foi descrito o fator de retenção do $\mathrm{Cd}^{2+}$,

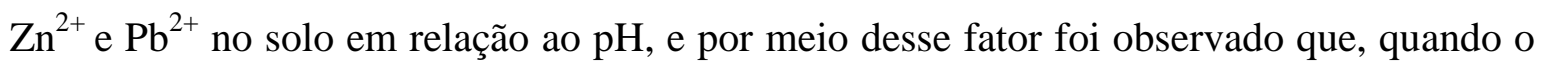
valor de $\mathrm{pH}$ aumentou, de 3,5 a 7,5, o fator de retenção também aumentou. O fator de retenção de $\mathrm{Pb}$ foi maior que o do $\mathrm{Cd}^{2+}$ e $\mathrm{Zn}^{2+}$, mostrando que o $\mathrm{Pb}$ foi o elemento menos móvel ou mais retido no solo.

Chaturvedi et al. (2007) estudaram lixiviação e sorção de $\mathrm{Pb}$ e $\mathrm{Zn}$ em solo coletado numa área de rejeito de mina de $\mathrm{Zn}$. Os dados mostraram que a lixiviação de $\mathrm{Pb}$ e $\mathrm{Zn}$ diminuiu muito quando o solo foi tratado com MO e argila em todos os $\mathrm{pH}$ testados, 3 , 5, 7 e 9 e que o $\mathrm{Pb}$ tem maior afinidade com $\mathrm{MO}$ e argila que o $\mathrm{Zn}$.

Beesley et al. (2010) analisaram o As, Cd e Zn em solo contaminado por meio da extração sequencial. Os autores observaram que a maior parte do As estava ligado nas frações residual e óxidos de $\mathrm{Fe}$ e $\mathrm{Al}$ e a menor parte na fração solúvel e a maior parte do $\mathrm{Cd}$ e $\mathrm{Zn}$ provavelmente estava associado com a $\mathrm{MO}$, pois foram extraídos com $\mathrm{HCl}$. 


\subsubsection{Estudos com colunas de solo}

Vários autores têm estudado a mobilidade de elementos (As, $\mathrm{Cd}, \mathrm{Cu}, \mathrm{Cr}, \mathrm{Ni}, \mathrm{Pb}$ e Zn) em colunas de solo em função do acúmulo destes elementos no solo, pH, óxido de ferro, matéria orgânica (Camobreco et al., 1996; Sun et al., 2001; Antoniadis e Alloway, 2002; Chirenje et al., 2002; Navarro-Pedreño et al., 2003; Ashworth e Alloway, 2004; Hartley et al., 2004; Ma e Dong, 2004; Norrström, 2005; Zhang et al., 2006; Chotpantarat et al., 2011). Estes autores utilizaram colunas de diversos tamanhos, com diâmetro variando entre 1,5 e $20 \mathrm{~cm}$ e comprimento entre 5 e $60 \mathrm{~cm}$. A mobilidade dos elementos tem sido estudada em solos contaminados ou solos limpos pós-contaminados por solução dos elementos, lodo de esgoto, cinza.

Na TAB. 6 foram descritos alguns trabalhos com colunas de solo. 
TABELA 6 - Estudos com colunas de solo

\begin{tabular}{|c|c|c|c|c|c|c|c|}
\hline Característica do solo & Fonte contaminadora & $\begin{array}{l}\text { Solução de } \\
\text { percolação }\end{array}$ & $\begin{array}{l}\text { Elementos } \\
\text { analisados }\end{array}$ & $\begin{array}{l}\text { Período de } \\
\text { percolação }\end{array}$ & Coluna & $\begin{array}{l}\text { Dimensões da } \\
\text { coluna }\end{array}$ & Referência \\
\hline $\begin{array}{l}\text { Solo franco siltoso, } \mathrm{pH}_{\mathrm{H} 2 \mathrm{O}} \\
\qquad 7,3-6,8\end{array}$ & $\begin{array}{c}\text { Solução com } \mathrm{Cd}, \mathrm{Cu}, \mathrm{Pb} \\
\text { e } \mathrm{Zn}\end{array}$ & $\begin{array}{l}\text { Solução com sais } \\
\text { de } \mathrm{Cu}, \mathrm{Cd}, \mathrm{Pb}, \mathrm{e} \\
\mathrm{Zn} .\end{array}$ & $\mathrm{Cd}, \mathrm{Cu}, \mathrm{Pb}$ e $\mathrm{Zn}$ & 31,5 dias & $\begin{array}{l}\text { Solo com estrutura } \\
\text { não deformada e } \\
\text { deformada; não } \\
\text { saturada }\end{array}$ & $\begin{array}{c}\mathrm{h}=35 \mathrm{~cm} \mathrm{e} \varnothing=20 \\
\mathrm{~cm}\end{array}$ & $\begin{array}{c}\text { Camobreco et al., } \\
1996\end{array}$ \\
\hline $\begin{array}{l}\text { Solo franco arenoso, } \mathrm{pH} \\
\text { н20 } 7,21, \mathrm{pH}_{\mathrm{CaCl} 2} 6,68\end{array}$ & Lodo de esgoto & Água deionizada & Cd, Ni e Zn & 3 meses & $\begin{array}{c}36 \text { colunas; } \\
\text { solo com estrutura } \\
\text { deformada }\end{array}$ & $\begin{array}{l}\mathrm{h}=450 \mathrm{~mm} \mathrm{e} \\
\emptyset=150 \mathrm{~mm}\end{array}$ & $\begin{array}{c}\text { Antoniadis e } \\
\text { Alloway, } 2002\end{array}$ \\
\hline $\begin{array}{c}\text { Solo calcário, } 26 \% \text { areia, } \\
34 \% \text { silte, } 40 \% \text { argila, } \mathrm{pH} \\
8,66\end{array}$ & Lodo de esgoto & Água & $\mathrm{Cd}, \mathrm{Cr}$ e Ni & 7 dias & $\begin{array}{c}48 \text { colunas; } \\
\text { solo com estrutura } \\
\text { deformada }\end{array}$ & $\begin{array}{c}\mathrm{h}=60 \mathrm{~cm} \mathrm{e} \emptyset=10,5 \\
\mathrm{~cm}\end{array}$ & $\begin{array}{l}\text { Navarro-Pedreño et } \\
\text { al., } 2003\end{array}$ \\
\hline $\begin{array}{l}\text { Solo franco arenoso, } \\
\qquad \mathrm{pH}_{\mathrm{H} 2 \mathrm{O}} 6,7\end{array}$ & Lodo de esgoto & Água deionizada & $\mathrm{Cu}, \mathrm{Ni}$ e $\mathrm{Zn}$ & 40 horas & $\begin{array}{c}6 \text { colunas saturadas; } \\
\text { solo com estrutura } \\
\text { deformada }\end{array}$ & $\begin{array}{c}\mathrm{h}=10 \mathrm{~cm} \text { e } \emptyset=2,5 \\
\mathrm{~cm}\end{array}$ & $\begin{array}{l}\text { Ashworth e Alloway, } \\
2004\end{array}$ \\
\hline $\begin{array}{l}\text { Solos com pH 6,47-8,19, } \\
\text { tratados com goetita, grãos } \\
\text { de Fe, sulfato de Fe (II) e } \\
\text { (III) + cal e cal. }\end{array}$ & $\begin{array}{c}\text { Solos contaminados com } \\
\text { As }\end{array}$ & $\begin{array}{l}\text { Água deionizada } \\
\text { acidificada (pH 4) }\end{array}$ & $\begin{array}{c}\text { As, } \mathrm{Cd}, \mathrm{Cu}, \mathrm{Pb} \text { e } \\
\mathrm{Zn}\end{array}$ & 3 semanas & $\begin{array}{l}\text { Solo com estrutura } \\
\text { deformada; não } \\
\text { saturada. }\end{array}$ & $\mathrm{h}=20 \mathrm{~cm} \mathrm{e} \emptyset=5 \mathrm{~cm}$ & Hartley et al., 2004 \\
\hline $\begin{array}{c}\text { Solo laterítico, } \mathrm{pH}_{\mathrm{H} 2 \mathrm{O}} 5,3, \\
21,8 \% \text { areia, } 24,4 \% \text { silte, } \\
53,8 \% \text { argila. }\end{array}$ & $\begin{array}{c}\text { Solução com Pb, Zn, Ni } \\
\text { e Mn }\end{array}$ & $\begin{array}{c}\text { Solução com Pb, } \\
\text { Zn, Ni e Mn }\end{array}$ & $\mathrm{Pb}, \mathrm{Mn}, \mathrm{Ni}$ e $\mathrm{Zn}$ & 3 semanas & $\begin{array}{l}\text { Solo com estrutura } \\
\text { deformada; saturada }\end{array}$ & $\begin{array}{c}\mathrm{h}=10 \mathrm{~cm} \text { e } \emptyset=2,5 \\
\mathrm{~cm}\end{array}$ & $\begin{array}{l}\text { Chotpantarat et al., } \\
2011\end{array}$ \\
\hline
\end{tabular}


Camobreco et al. (1996) avaliaram a mobilidade dos metais pesados em colunas de solo com estrutura deformada e não deformada (TAB.6). Estes autores observaram que os metais foram retidos completamente nas colunas de solo com estrutura deformada, ao passo que, no lixiviado das colunas com estrutura não deformada os elementos $\mathrm{Cd}, \mathrm{Zn}, \mathrm{Cu}$ e $\mathrm{Pb}$, foram detectados. Os autores explicaram a diferença de mobilidade dos metais no solo para os dois tipos de colunas com base no maior contato da solução com o solo nas colunas de solo com estrutura deformada, favorecendo a retenção dos metais no solo e na coluna com estrutura não deformada o fluxo preferencial da solução favorece a percolação dos metais. Os autores também descreveram a ordem de mobilidade dos elementos nas colunas com estrutura não deformada: $\mathrm{Cd}>\mathrm{Zn}>>\mathrm{Cu}>\mathrm{Pb}$.

Antoniadis e Alloway (2002) estudaram a lixiviação dos metais, $\mathrm{Cd}$, Ni e $\mathrm{Zn}$, provindos do lodo de esgoto em colunas de solo franco arenoso em dois regimes de percolação. Neste trabalho foram montadas 36 colunas de solo com estrutura deformada com diferentes quantidades de lodo e volumes de percolação (450 e 900 mm/ano). A mobilidade dos elementos no perfil do solo foi mais significante na condição de maior quantidade de lodo e volume de percolação, e isso foi observado por meio da quantidade dos elementos no lixiviado. Outro resultado observado foi o aumento de carbono orgânico dissolvido (COD) no lixiviado da mesma forma que ocorreu para os metais. Os autores descreveram que os metais formaram complexos com o COD, que são dissolvidos em uma determinada variação de $\mathrm{pH}$. Na dissolução do carbono orgânico, os elementos com estes complexados também foram lixiviados.

No estudo de Navarro-Pedreño et al. (2003) foram montadas colunas de solo calcário contaminado com lodo de esgoto, com a finalidade de observar a mobilidade de $\mathrm{Cd}, \mathrm{Cr}$ e $\mathrm{Ni}$ presentes no lodo. O lodo foi misturado com o solo nos primeiros $15 \mathrm{~cm}$ da coluna. Não foi observada mobilidade significante para nenhum dos elementos, pois no lixiviado não foram detectadas quantidades significantes dos elementos.

Ashworth e Alloway (2004) estudaram a mobilidade de $\mathrm{Cu}$, $\mathrm{Ni}$ e $\mathrm{Zn}$ provindos de lodo de esgoto em seis colunas de solo franco arenoso com estrutura deformada e avaliaram a influência da matéria orgânica na mobilidade desses 
elementos. O lodo foi disposto no topo da coluna em cima de um papel de filtro. A concentração de $\mathrm{Cu}$ e $\mathrm{Ni}$ no lixiviado apresentou o mesmo comportamento do COD. O Zn ficou retido no solo, resultado descrito pelos autores como inesperado, visto que o Zn é considerado um elemento relativamente móvel.

Hartley et al. (2004) realizaram um estudo de percolação de colunas com três tipos de solos contaminados por As, a fim de investigar a imobilização do As no solo. No estudo o solo foi tratado com goetita, grãos de ferro, sulfato de Fe (II) e (III) com cal e cal. O lixiviado das colunas de solos tratados quando comparados com a coluna de solo não tratada apresentou uma redução na concentração de As principalmente com as colunas de solo tratadas com sulfato de Fe (II) e (III) com cal. Os resultados mostraram que o As pode ter afinidade com o Fe.

Os solos analisados nos estudos apresentados na TAB. 6 são de origem estrangeira. A mobilidade de metais em colunas de solo brasileiro também tem sido estudada e alguns estudos relacionados a isso foram descritos a seguir.

Amaral Sobrinho et al. (1998) avaliaram a mobilidade de metais em dez colunas de solo argiloso, $\mathrm{pH}_{\text {н2о }} 4,6$, tipicamente utilizado em aterro de resíduos industriais sobrepostas de resíduo siderúrgico em uma proporção 4:1 (solo:resíduo). As colunas foram lixiviadas com 50 volumes de poros (correspondente a quatro anos de chuva) de água deionizada com $\mathrm{pH}$ 4,5 a fim de simular chuva ácida. Estes autores observaram que as maiores concentrações de $\mathrm{Cu}, \mathrm{Cr}$ e $\mathrm{Pb}$ foram determinadas nos primeiros $5 \mathrm{~cm}$ da coluna de solo, ao passo que, para os metais $\mathrm{Cd}$, $\mathrm{Ni}$ e $\mathrm{Zn}$ foram determinadas nas frações mais inferiores da coluna.

Cornu et al. (2001) avaliaram o impacto de $\mathrm{Cu}, \mathrm{Fe}, \mathrm{Ni}$ e $\mathrm{Pb}$ de lodo de esgoto em colunas de solo $\left(\mathrm{pH}_{\text {н2о }} 4\right.$ - 4,5; de 0,3 a 3\% de carbono orgânico; com predominância de caulinita, quartzo, goetita, muscovita e gibbsita) quanto à qualidade da água e do solo. Foram montadas sete colunas de solo com estrutura indeformada provindo de Suzano, Brasil. O lodo de esgoto foi adicionado no topo da coluna e esta foi percolada com água duplamente deionizada durante dois meses, simulando um ano de chuva em estações de cheia $(16 \mathrm{~mm} /$ dia $)$ e de seca $(5 \mathrm{~mm} /$ dia $)$. Estes autores 
observaram que houve um aumento na concentração dos metais no lixiviado das colunas. Níquel foi o elemento mais móvel e $\mathrm{Pb}$ o menos móvel.

Matos et al. (2001) estudaram a mobilidade de $\mathrm{Cd}, \mathrm{Cu}, \mathrm{Pb}$ e $\mathrm{Zn}$ em três solos de duas classes, Latossolos e Argissolos, que foram lixiviados com solução contendo os metais citados, e observaram que a mobilidade de todos os metais diminui com o aumento do $\mathrm{pH}$, de 4,61 a 8,70 .

Stuermer (2005) avaliou a adsorção de $\mathrm{Cd}$ e $\mathrm{Pb}$ em solo saprolítico, de textura siltosa e pH 5,5 aproximadamente, em coluna de solo preparada em laboratório. As colunas foram percoladas individualmente com solução de $\mathrm{Cd}$ e solução de $\mathrm{Pb}$ em $\mathrm{pH}$ 1, 3, e 5,5. Os resultados mostraram que o $\mathrm{Pb}$ foi mais adsorvido do que o $\mathrm{Cd}$ e que a adsorção para ambos aumenta com o pH. O Cd apresentou baixa adsorção em $\mathrm{pH} 1 \mathrm{e}$ foi significantemente adsorvido em $\mathrm{pH} 3$ e 5,5 e o $\mathrm{Pb}$ foi retido no solo nos três valores de $\mathrm{pH}$.

Gazano (2006) avaliou a contaminação do solo causada pelo descarte de pilhas por meio de colunas de solo de estrutura não deformada de textura média com $39 \%$ de argila, $12 \%$ de silte e $49 \%$ de areia e $\mathrm{pH}_{\mathrm{KCl}} 4,01$. As colunas foram percoladas com uma solução simuladora de água de chuva composta de $\mathrm{HNO}_{3}$ e $\mathrm{H}_{2} \mathrm{SO}_{4}$, de pH aproximadamente igual a 4. Foram preparadas quatro colunas, duas de solo e duas de solo com pilhas sobrepostas ao solo, sendo uma de cada coluna lixiviada nos períodos de 6 meses e um ano. Os elementos analisados foram $\mathrm{Cd}, \mathrm{Cu}, \mathrm{Cr}, \mathrm{Mn}, \mathrm{Ni}, \mathrm{Pb}$ e $\mathrm{Zn}$. $\mathrm{Os}$ resultados indicaram que a lixiviação de pilhas pode causar uma contaminação no solo para $\mathrm{Cd}, \mathrm{Pb}, \mathrm{Mn}$ e $\mathrm{Zn}$.

Agourakis et al. (2006) estudaram o comportamento de Mn e $\mathrm{Zn}$ em duas colunas de solo com estrutura não deformada caracterizado como franco arenoso com $\mathrm{pH}_{\mathrm{KCl}} 4,1$ e $\mathrm{MO}$ 1,4\%, das quais uma delas foram adicionadas pilhas alcalinas no topo do solo. As colunas foram percoladas com solução simuladora de chuva ácida de $\mathrm{pH}$ aproximadamente igual a 4, por um ano. Após a percolação, o solo foi analisado quanto às concentrações de $\mathrm{Mn}$ e $\mathrm{Zn}$. O Mn apresentou maior mobilidade do que o $\mathrm{Zn}$ no solo e o descarte de pilhas aumentou a concentração de $\mathrm{Mn}$ e $\mathrm{Zn}$ no solo. Os resultados 
indicaram que o pH do solo foi uma característica importante na retenção dos elementos na camada superficial do solo. Os estudos de Gazano (2006), descrito anteriormente, e de Agourakis et al. (2006) fazem parte dos trabalhos desenvolvidos pelo mesmo grupo do presente trabalho.

Messias et al. (2007) estudaram a mobilidade de $\mathrm{Fe}, \mathrm{Cu}, \mathrm{Zn}$ e $\mathrm{Cd}$ em solo de textura média com $\mathrm{pH}_{\mathrm{H} 2 \mathrm{O}} 6,3$, tratado com lodo de esgoto. O estudo foi desenvolvido com 12 colunas de solo com estrutura deformada $20 \mathrm{~cm}$ de altura e o lodo foi misturado nos primeiros $5 \mathrm{~cm}$ da coluna. O período de lixiviação foi de 60 dias, sendo aplicados $40 \mathrm{~mL}$ de água deionizada por dia. Os elementos ficaram retidos nas primeiras camadas de solo e os resultados mostraram que quanto menor o $\mathrm{pH}$ maior a disponibilidade dos elementos.

Garcés et al. (2008) estudaram a relação entre o COD e metais no lixiviado de colunas de solo com estrutura não deformada tratadas com estrume de porco sobreposto à superfície das colunas. Os elementos $\mathrm{Cd}, \mathrm{Cu}$ e $\mathrm{Zn}$ apresentaram correlação positiva com o COD. Para o $\mathrm{Pb}$ a correlação foi significativamente negativa, ou seja, quanto maior o COD, menor a concentração deste elemento no lixiviado. Os resultados indicaram que a complexação dos metais com a MO tem um papel importante na mobilidade dos metais.

Almeida (2009) avaliou o comportamento e atenuação de metais em colunas deformadas de solo arenoso $\left(\mathrm{pH}_{\mathrm{CaCl} 2} 4,3\right)$ lixiviadas com o chorume proveniente de aterro sanitário. O solo e o lixiviado foram coletados no mesmo aterro, a lixiviação das colunas ocorreu em fluxo ascendente de $200 \mathrm{~mL}$ por dia. Foi observado que a preferência em ordem decrescente de sorção dos elementos no solo foi de: $\mathrm{Cu}>\mathrm{Cd}>\mathrm{Zn}>\mathrm{Ni}$.

Nos estudos de mobilidade dos elementos em solos estrangeiros e brasileiros foi observado que a maior parte dos trabalhos utiliza colunas de solo com estrutura deformada. A coluna com estrutura deformada tem como principal vantagem a reprodutibilidade dos ensaios (Lewis e Sjöstrom, 2010). Nas colunas de solo com estrutura não deformada, as amostras são preservadas na coleta quanto à estrutura, umidade, compacidade e consistência (Hypolito et al, 2011). 


\subsection{Contaminação dos solos}

A contaminação do solo causada por compostos inorgânicos tem sido motivo de preocupação devido à toxicidade a seres humanos, animais e plantas (Brady, 1989).

Os elementos tóxicos no solo são comumente associados à disposição de resíduos e efluentes, utilização de fertilizantes e agrotóxicos, deposição atmosférica e depósito de resíduos (Alloway, 1990; Yong e Mulligan, 2004; CETESB, 2012). Essa contaminação do solo causada pelos elementos tóxicos pode atingir a água subterrânea e ser transportada para outras regiões pelo fluxo da água (FIG.10) (CETESB, 2012).

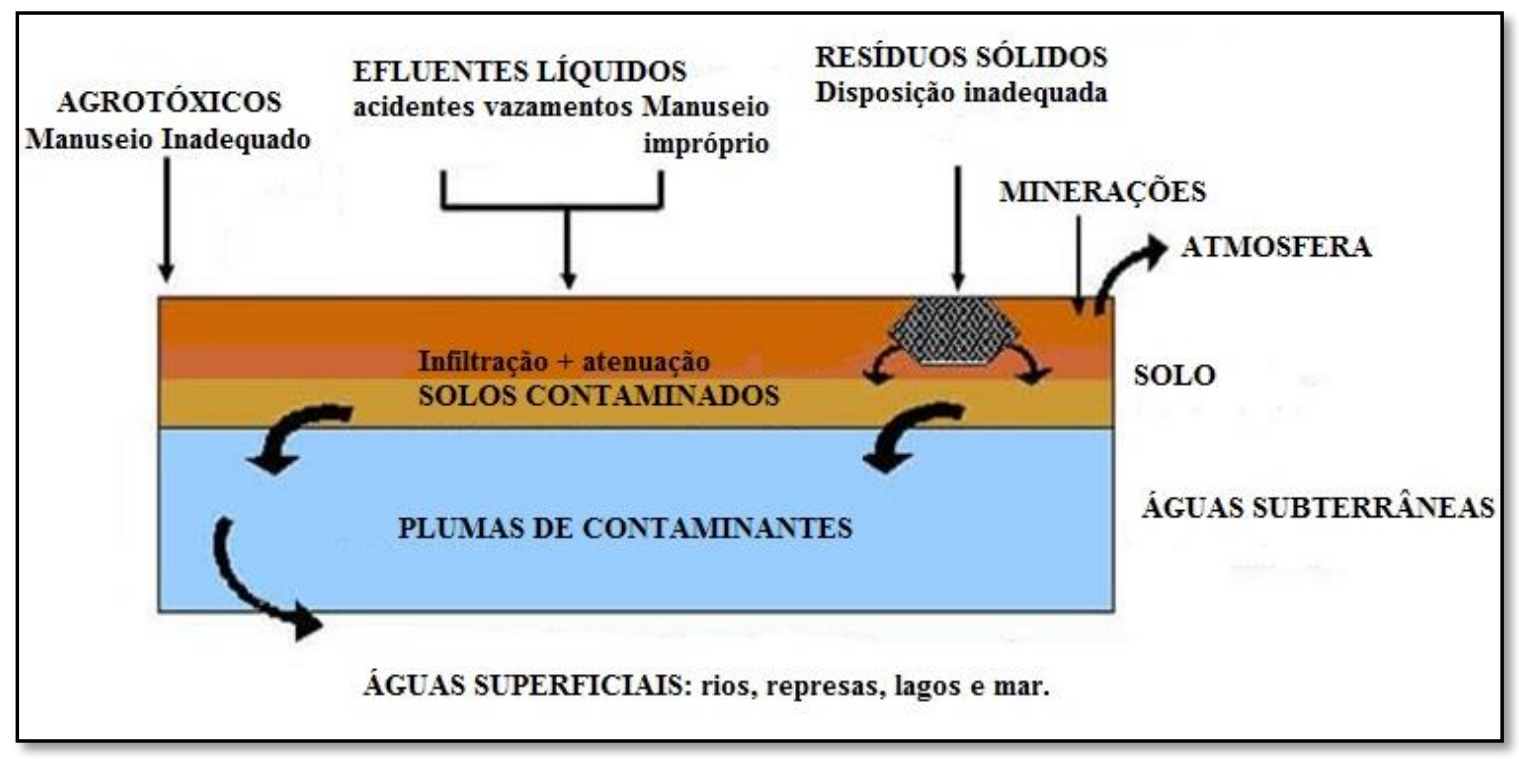

FIGURA 10 - Fontes de poluição do solo e sua migração

Fonte - Adaptado de CETESB, 2012

Na TAB. 7 foi apresentada a toxicidade de alguns elementos em plantas e mamíferos. 
TABELA 7 - Toxicidade dos elementos em plantas e mamíferos

\begin{tabular}{ccc}
\hline Elemento & Fitotoxicidade & $\begin{array}{c}\text { Toxicidade em } \\
\text { mamíferos }\end{array}$ \\
\hline Arsênio & Média - Alta & Alta \\
Cádmio & Média - Alta & Alta \\
Molibdênio & Média & Média \\
Chumbo & Média & Alta \\
Zinco & Baixa - Média & Baixa - Média \\
\hline
\end{tabular}

Fonte - McBride, 1994.

De acordo com McBride o As e Cd são mais tóxicos para plantas e o As, Cd e Pb para mamíferos (TAB.7).

As fontes de arsênio são tintas, herbicidas, produtos farmacêuticos, produção de cimento entre outras (Yong e Mulligan, 2004).

O cádmio se tornou motivo de preocupação recentemente (20 anos ou mais) devido à utilização desse elemento como material de revestimento, na indústria plástica, em chapas de aço, em estabilização de pigmentos, em pilhas níquel-cádmio, fungicidas, óleo de motor, lodo de esgoto e fertilizantes (Yong e Mulligan, 2004).

O molibdênio é encontrado na fabricação do aço e ligas metálicas, em fertilizantes, lodo de esgoto, na queima de combustíveis fosseis, cinza de carvão entre outros (Alloway, 1990).

O chumbo pode ser encontrado em baterias, na fumaça do escapamento do carro, em áreas de fundição e mineração, no carvão, plásticos, em pneus desgastados, inseticidas, lodo de esgoto entre outros (Alloway, 1990).

O zinco pode ser encontrado em produtos galvanizados, cosméticos, tintas, vidros, televisão, baterias, revestimentos de metais entre outros (Yong e Mulligan, 2004). 


\section{MATERIAIS E MÉTODOS}

O presente trabalho faz parte de um projeto financiado pela FAPESP, conforme descrito na introdução, item 1. Neste projeto foram utilizados dois tipos de solo, um coletado entre os municípios de Araras e Conchal (Lange, 2012) e o outro no município de Piracicaba (presente estudo) para avaliar a mobilidade dos elementos tóxicos nos solos.

Para atingir o objetivo deste trabalho foi necessário: coletar um solo com pouca perturbação antropogênica; preparar colunas de solo, de cinza de carvão e de solo coberto com cinza de carvão; percolar as colunas com uma solução ácida; determinar a concentração dos elementos presentes na cinza, solo e percolado das colunas; determinar a concentração dos ânions e do carbono no percolado das colunas; determinar características físicas, químicas e mineralógicas das amostras.

Essas atividades experimentais foram realizadas no Centro de Química e Meio Ambientes (CQMA) do Instituto de Pesquisas Energéticas e Nucleares, IPEN/CNEN-SP, exceto a coleta do solo, a montagem das colunas e algumas características das amostras de cinza de carvão e de solo que serão descritas posteriormente.

\subsection{Cinza de carvão}

A cinza de carvão foi coletada no filtro manga da usina termoelétrica localizada no município de Figueira, no estado do Paraná.

Foram coletados seis lotes de cinza de carvão, de dois em dois meses entre os anos de 2001 - 2002. Os três últimos lotes coletados foram misturados homogeneamente e essa mistura composta da cinza foi utilizada para a montagem das colunas (Lange, 2012). 


\subsection{Solo}

O Latossolo foi selecionado para o estudo pela sua representatividade dos solos brasileiros e do estado de São Paulo, e a textura argilosa foi selecionada pela característica de retenção dos elementos tóxicos no solo, conforme descrito na revisão da literatura no item 3.2. A área de coleta do Latossolo argiloso foi selecionada com base nos dados dos Latossolos do estado de São Paulo caracterizados por Soares (2004).

O solo foi coletado no estado de São Paulo em 28 de maio de 2009 no ponto de coordenada geográfica $22^{\circ} 37^{\prime} 2.73^{\prime}$ S e 47³6'6.74” O. Inserindo esta coordenada geográfica no Google Earth (2012) foi observado que o ponto de coleta está entre os municípios de Piracicaba e Iracemápolis (FIG.11a) e à esquerda da rodovia PiracicabaRio Claro, SP-127 (FIG.11b). 


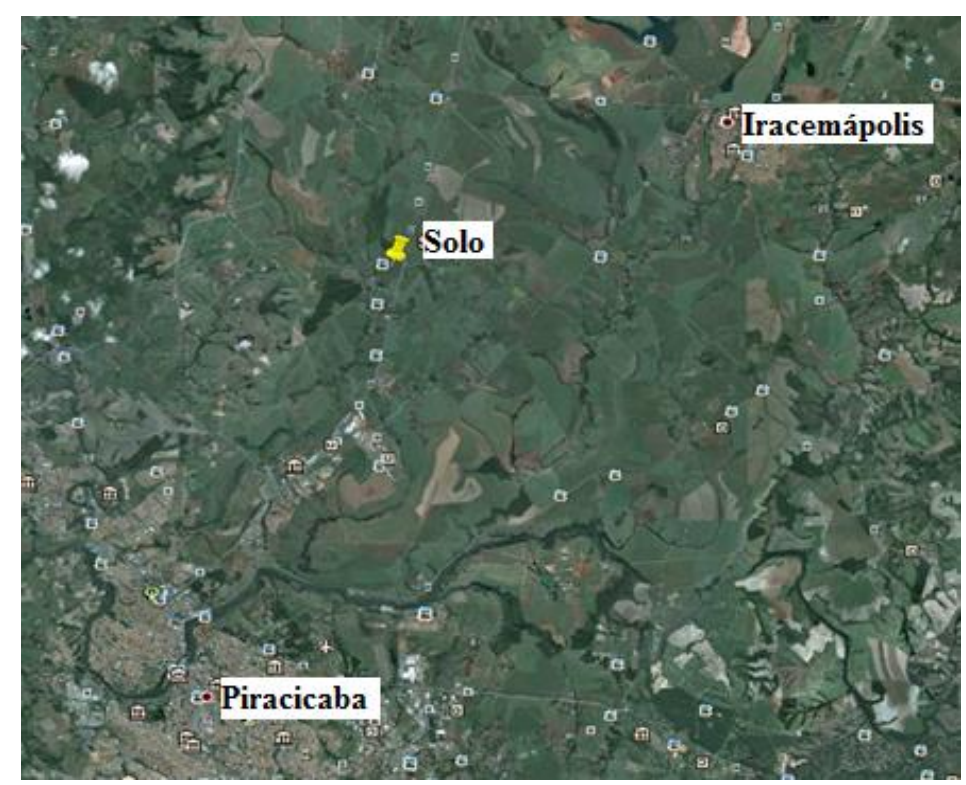

(a)

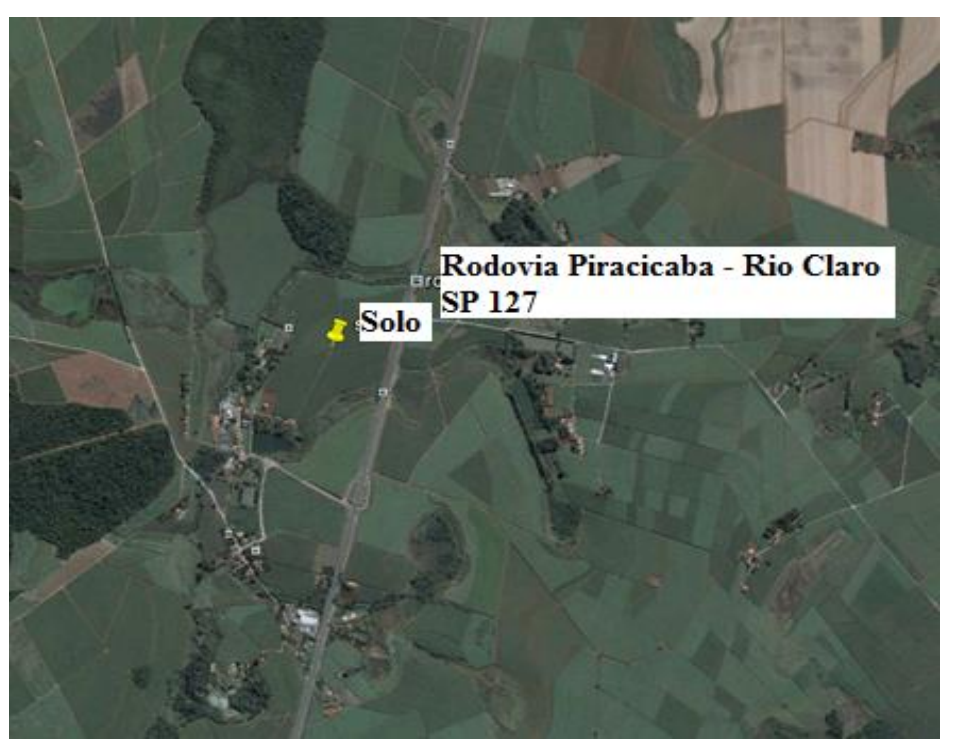

(b)

FIGURA 11 - Imagem da localização do ponto da coleta do solo por meio do Google Earth: (a) localização entre os municípios de Piracicaba e Iracemápolis; (b) localização em relação à rodovia $\mathrm{SP}-127$

Considerando a rodovia Piracicaba-Rio Claro (SP-127) e o mapa político do estado de São Paulo (FIG.12) o ponto de coleta do solo foi identificado no município de Piracicaba. 


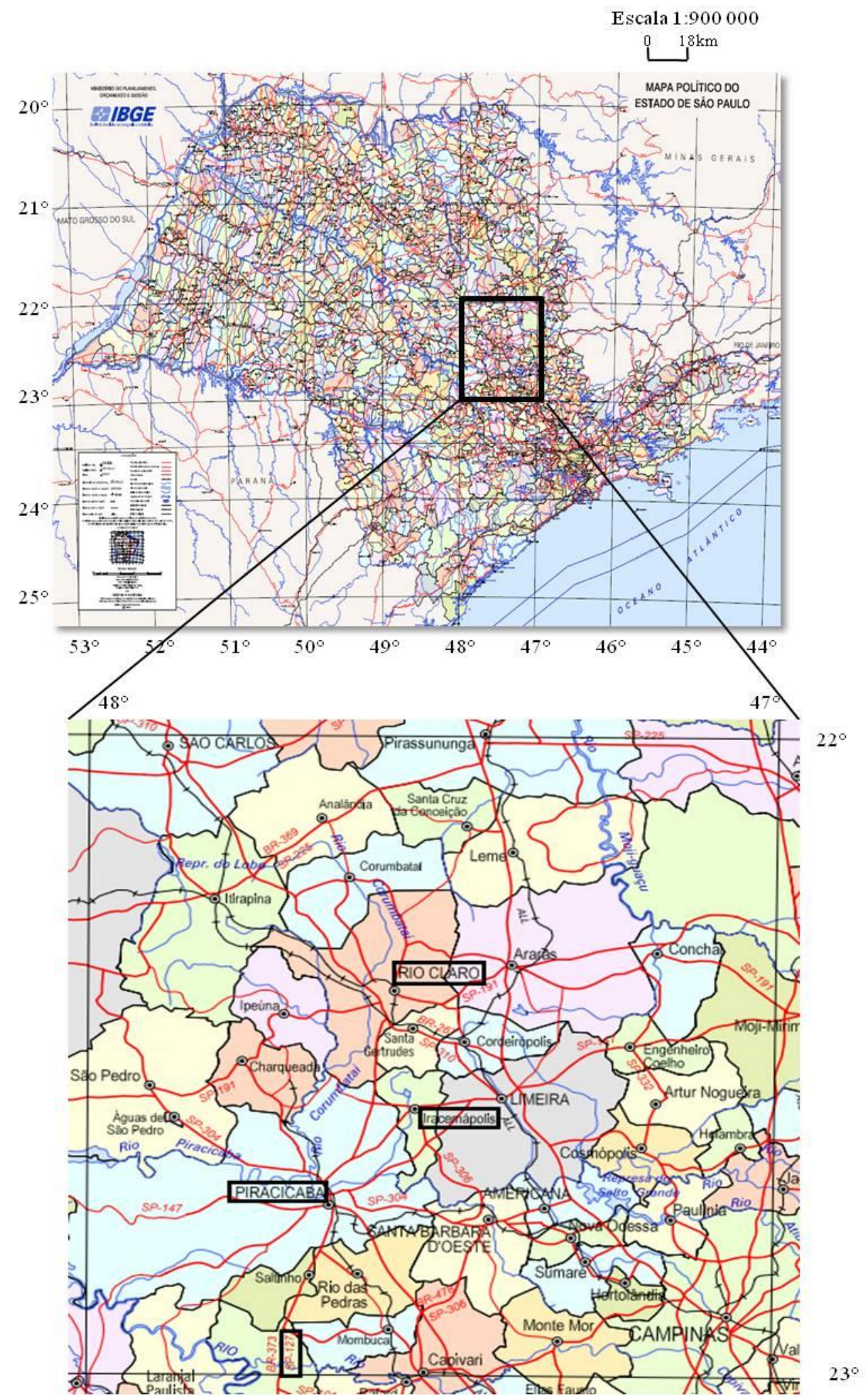

FIGURA 12 - Identificação da rodovia Piracicaba-Rio Claro (SP - 127) e do município de Piracicaba por meio do mapa político do estado de São Paulo

Fonte - Instituto Brasileiro de Geografia e Estatística - IBGE, 2012. 
O solo foi coletado em área de mata nativa ou de reflorestamento antigo, ou seja, com pouca perturbação antropogênica. Após a remoção da vegetação rasteira, o solo foi coletado em profundidade de $20 \mathrm{~cm}$ aproximadamente. Na FIG. 13 foram apresentadas fotos da coleta do solo de Piracicaba.

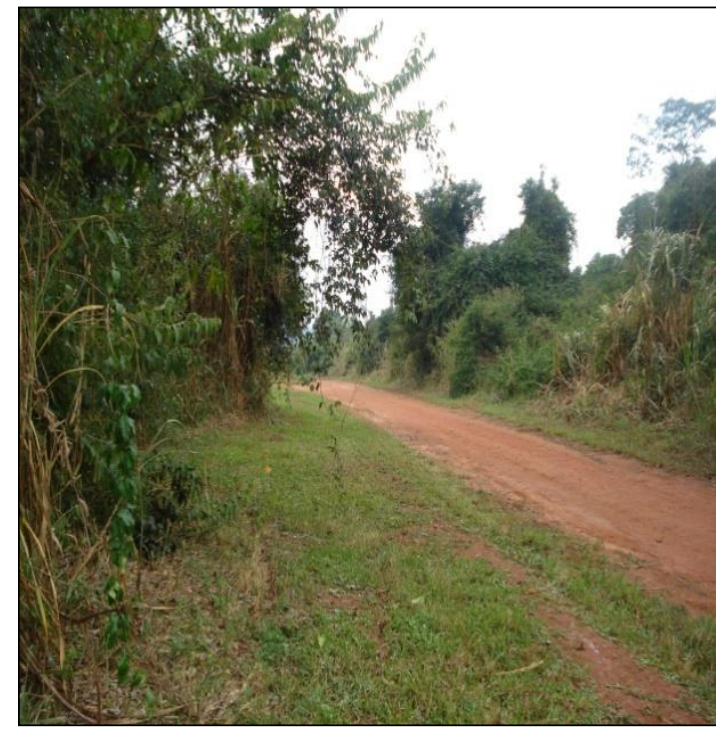

(a)

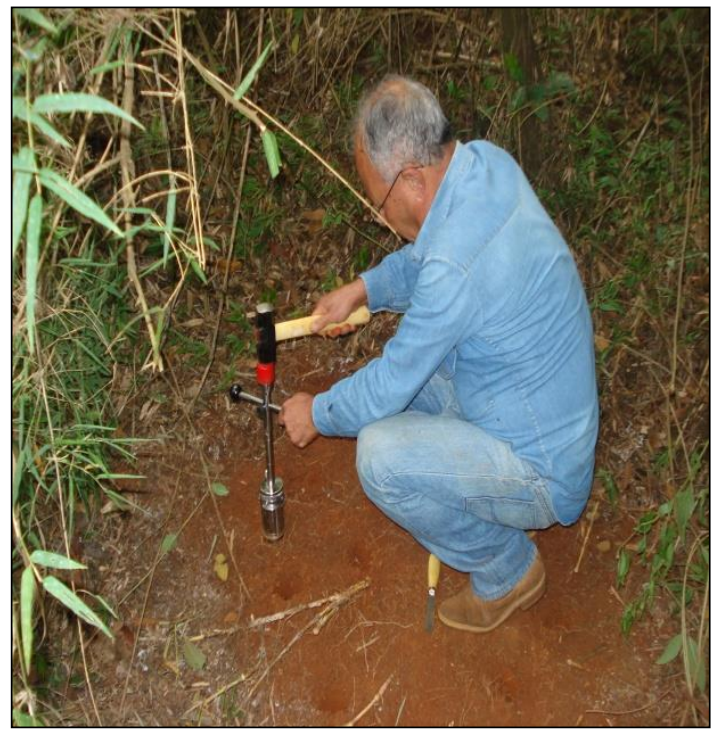

(c)

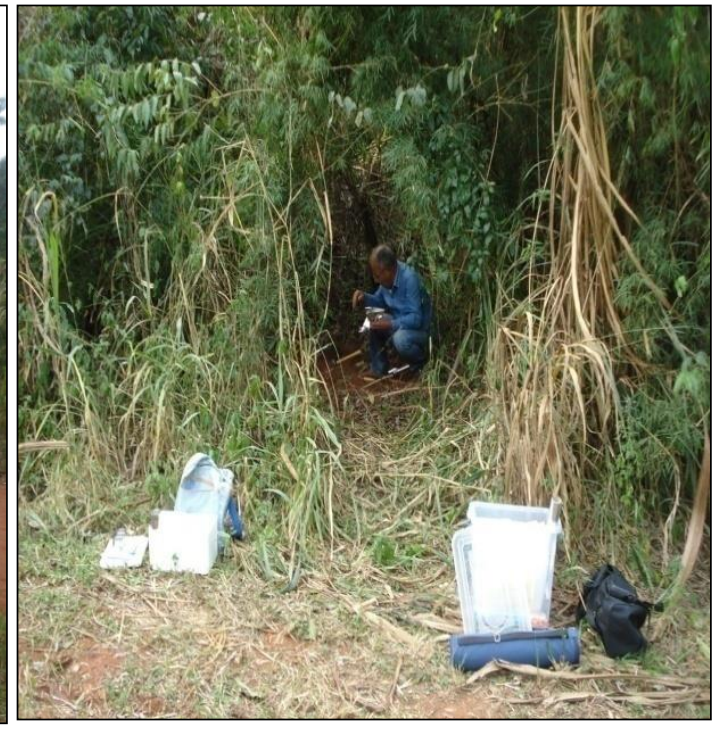

(b)

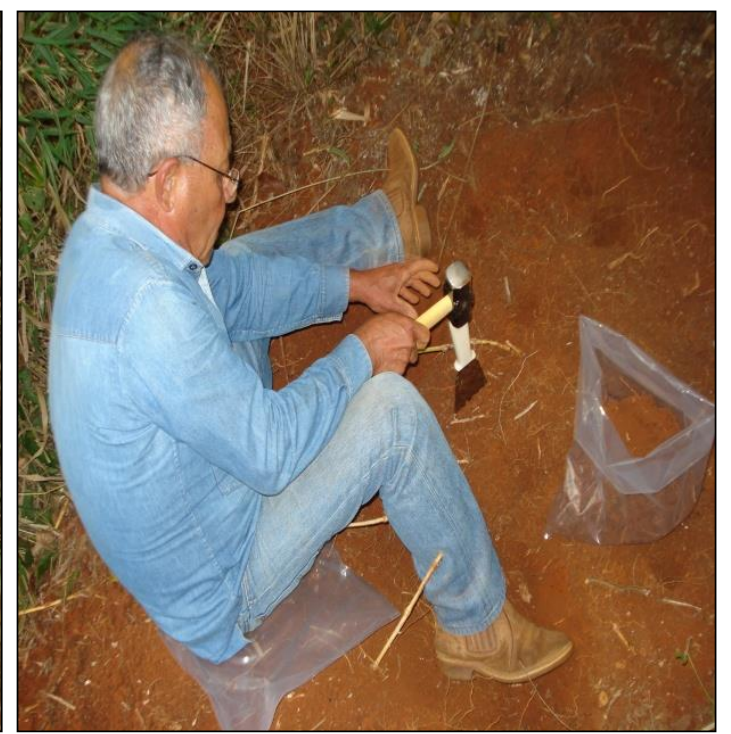

(d)

FIGURA 13- Fotos do solo de Piracicaba: (a) e (b) área da coleta do solo; (c) coleta do solo com estrutura não deformada; (d) coleta do solo com estrutura deformada

As amostras de solo foram coletadas em duas porções: amostras com estrutura não deformada, coletadas com trado de amostra não deformada de aço 
inoxidável em 12 anéis volumétricos de $100 \mathrm{~cm}^{3}$ cada (FIG.13c), e $20 \mathrm{~kg}$ de amostra de solo com estrutura deformada, coletada com pá de aço inoxidável e armazenada em sacos plásticos (FIG.13d). As amostras de solo com estrutura não deformada (FIG.14) foram utilizadas para se determinar a densidade e umidade do solo coletadas em campo.

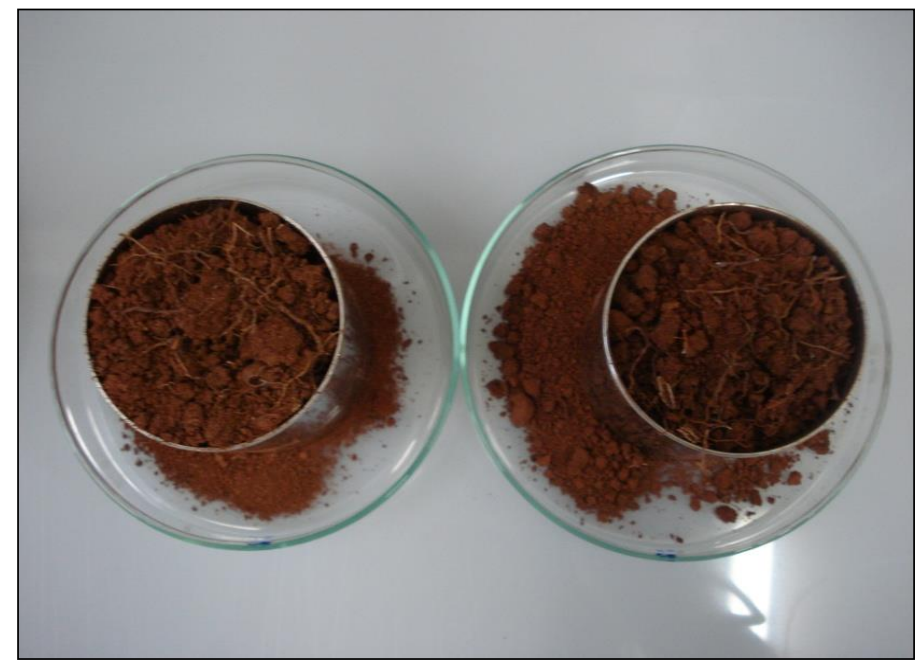

FIGURA 14 - Amostra do solo de Piracicaba com estrutura não deformada

A amostra de solo com estrutura deformada foi disposta em bandejas de polietileno para secagem a temperatura ambiente por alguns dias (FIG.15). Posteriormente à secagem os grãos maiores foram desagregados, peneirados a $2 \mathrm{~mm}$, homogeneizados, quarteados e armazenados em frascos de plástico para montagem das colunas de solo e determinação das características físicas, químicas e mineralógicas do solo.

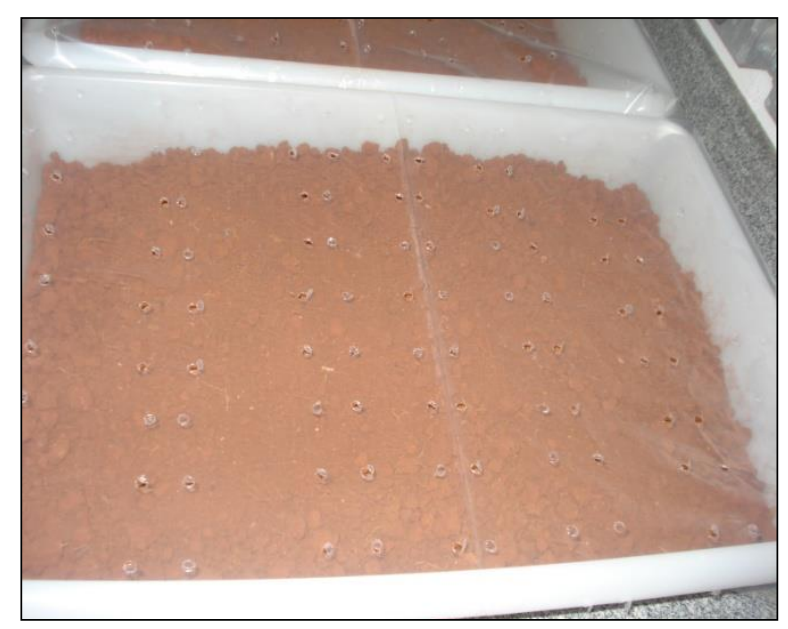

FIGURA 15 - Amostra do solo de Piracicaba com estrutura deformada 


\subsection{Montagem das colunas}

Foram preparadas 10 colunas, sendo 4 colunas de solo, 4 colunas de solo coberto com cinza de carvão e 2 colunas de cinza de carvão sobreposta numa coluna de areia inerte (FIG.16).

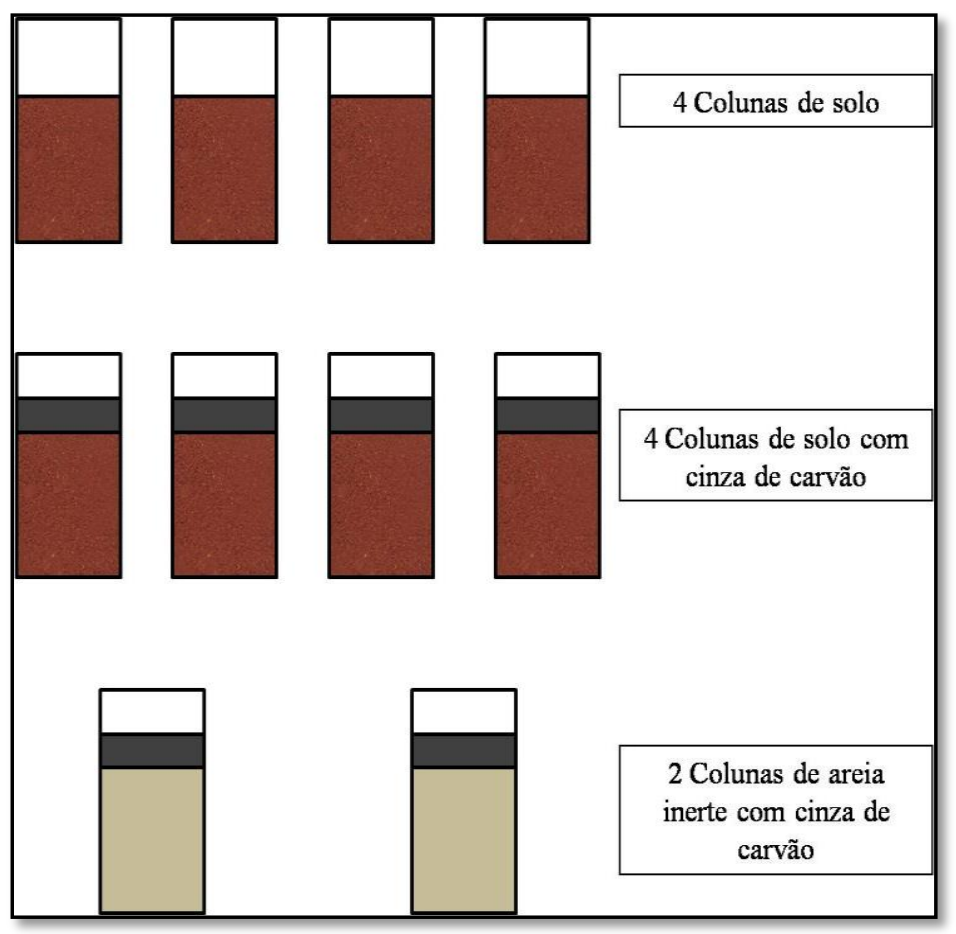

FIGURA 16 - Esquema de distribuição das colunas

\subsubsection{Colunas de solo}

Após o pré-tratamento do solo descrito no item 4.2, este foi umedecido para simular a umidade e a densidade do solo coletado em campo conforme descrito por Lange (2012). Posteriormente uma massa de $279 \mathrm{~g}$ do solo umedecido foi pesada para a montagem de cada coluna de solo. Essa massa foi dividida em cinco partes iguais de 55,8 g e cada parte do solo foi compactada em camadas em coluna de acrílico (diâmetro $9 \mathrm{~cm}$ e altura $13 \mathrm{~cm}$ ), utilizando uma prensa manual CBR segundo procedimento adotado pelo Laboratório de Solos da Engenharia Civil da Universidade de São Paulo (FIG.17), conforme descrito por Lange (2012). A massa total do solo foi compactada numa altura de $5 \mathrm{~cm}$ e $8 \mathrm{~cm}$ de diâmetro. 

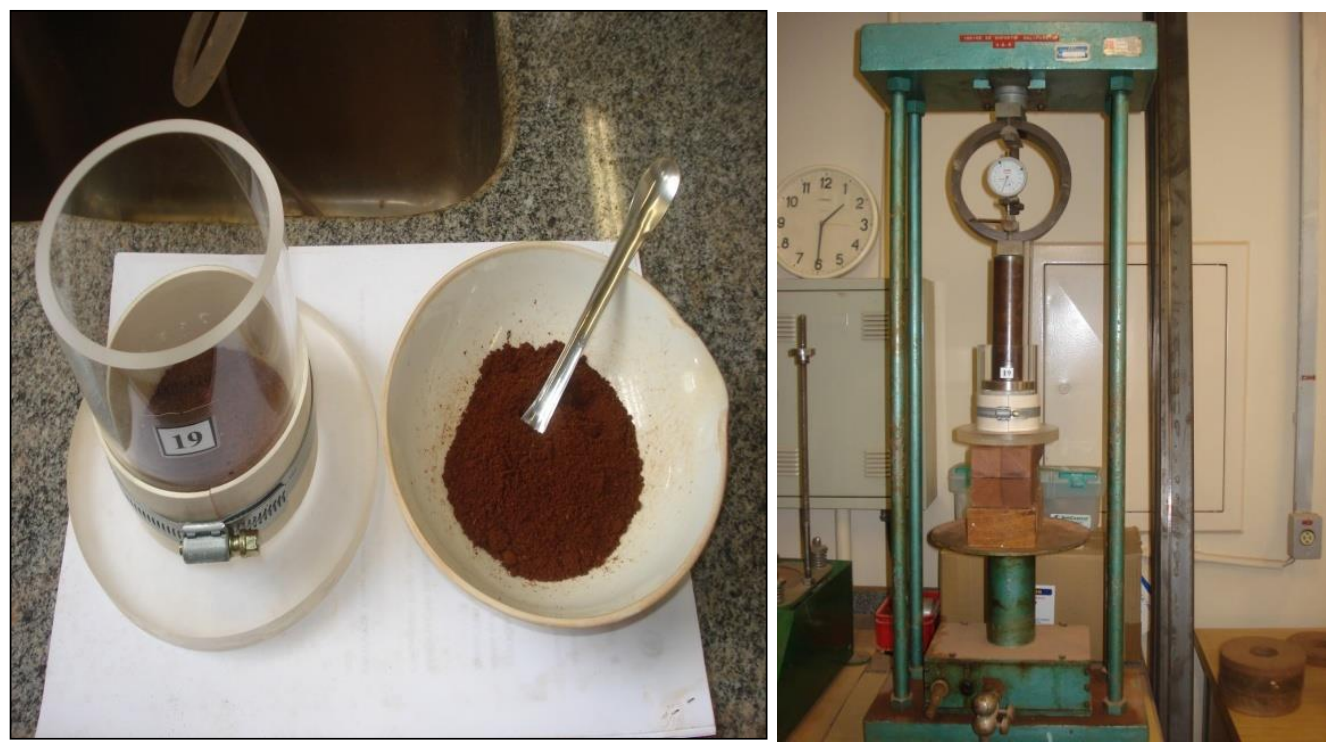

FIGURA 17 - Montagem de uma da coluna de solo

Fonte - Lange, 2012.

A quantidade de colunas de solo foi oito, distribuídas em 4 colunas de solo (CS) e 4 colunas de solo com $50 \mathrm{~g}$ de cinza de carvão (CSC) adicionada no topo das colunas. Entre o solo e a cinza de carvão foi adicionado um papel de filtro qualitativo dobrado no formato de um copo.

\subsubsection{Colunas de cinza de carvão}

Foram montadas 2 colunas de cinza (CC) em colunas de acrílico de mesmas dimensões que as do solo (FIG.18). Foi adicionada areia inerte até uma altura de $5 \mathrm{~cm}$ e sobre o topo desta foi adicionado um papel de filtro qualitativo dobrado no formato de um copo no qual foram adicionados $50 \mathrm{~g}$ de cinza de carvão, conforme descrito por Lange (2012). 


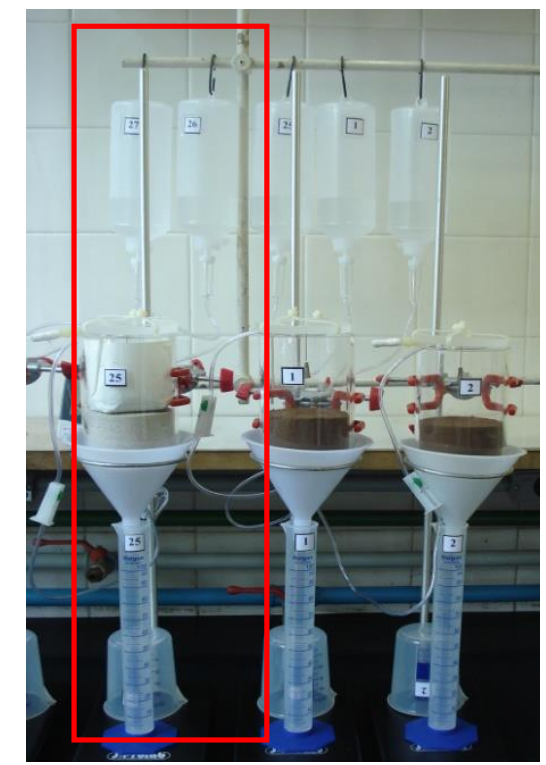

FIGURA 18 - Coluna de cinza de carvão

No topo das colunas de acrílico foi adicionada uma tampa de acrílico com uma mangueira de equipo de $2 \mathrm{~mm}$ de diâmetro atravessada pela tampa. Na extremidade superior da mangueira foi acoplado um frasco para nutrição enteral de $500 \mathrm{~mL}$.

$\mathrm{Na}$ extremidade inferior das colunas de cinza de carvão e de solo foram adicionados dois papéis de filtro qualitativo sobre uma placa de polietileno com vários furos pequenos e um funil, conforme descrito por Lange (2012). Na extremidade inferior do funil das colunas foi introduzida uma proveta de $100 \mathrm{~mL}$. A coluna de acrílico e o funil foram fixados num suporte universal.

\subsection{Percolação das colunas}

As colunas foram percoladas com uma solução simuladora de água de chuva com pH em torno de 4,5, composta por $\mathrm{HNO}_{3} 10^{-5}$ mol L $\mathrm{L}^{-1} \mathrm{H}_{2} \mathrm{SO}_{4} 10^{-5}$ mol L ${ }^{-1}$ misturados numa proporção 1:1 com base nos estudos de Rocha et al. (2003) e Flues et al. (2002), conforme descrito por Lange (2012). O volume da solução adicionado nas colunas foi calculado com base na média dos índices pluviométricos mensais (TAB.8) registrados nos últimos anos da cidade de São Paulo pelo Instituto de Astronomia, Geofísica e Ciências Atmosféricas da Universidade de São Paulo (IAG-USP) conforme descrito por Lange (2012). A vazão de entrada da solução foi controlada por meio da mangueira de equipo para aproximadamente 10 gotas por minuto. 
O volume mensal da solução adicionado em cada coluna (TAB.8), calculado pela multiplicação entre a área da secção transversal da coluna de solo $(50,3$ $\mathrm{cm}^{2}$ ) e a média pluviométrica mensal, foi dividido em quatro partes iguais e cada parte foi adicionada semanalmente nas colunas, numa vazão de 10 gotas por minutos aproximadamente. Sendo assim, cada coluna foi percolada a cada 28 dias com um volume mensal da solução de outubro a setembro apresentado na TAB. 8, por um período de 168 dias e 336 dias, conforme descrito por Lange (2012). A percolação das colunas foi iniciada com o volume mensal da solução referente ao mês de outubro, início do período mais chuvoso do ano. Foram percoladas cinco colunas no período de 168 dias: duas de solo, duas de solo com cinza e uma de cinza. A mesma quantidade e distribuição de colunas foram percoladas por um período de 336 dias.

TABELA 8 - Média pluviométrica mensal da cidade de São Paulo, 1933-2008 (IAGUSP), volume da solução simuladora de água de chuva adicionado em cada coluna e tempo de percolação acumulado

\begin{tabular}{ccccc}
\hline Mês & $\begin{array}{c}\text { Média } \\
\text { pluviométrica } \\
\text { mensal (mm) }\end{array}$ & Molume adicionado na coluna (mL) & $\begin{array}{c}\text { Tempo de } \\
\text { percolação } \\
\text { acumulado } \\
\text { (dias) }\end{array}$ \\
\cline { 2 - 3 } Outubro & 125 & 629 & Semanal & \\
Novembro & 125 & 628 & 157 & 28 \\
Dezembro & 182 & 916 & 157 & 56 \\
Janeiro & 221 & 1112 & 229 & 84 \\
Fevereiro & 207 & 1039 & 278 & 112 \\
Março & 165 & 827 & 260 & 168 \\
Abril & 81 & 405 & 207 & 196 \\
Maio & 64 & 323 & 101 & 224 \\
Junho & 50 & 252 & 81 & 252 \\
Julho & 41 & 206 & 63 & 280 \\
Agosto & 38 & 193 & 52 & 308 \\
Setembro & 76 & 384 & 48 & 336 \\
\hline
\end{tabular}

Fonte - Adaptado de Lange, 2012. 
O percolado gerado das colunas foi coletado mensalmente, armazenado em frasco plástico e refrigerado a $5^{\circ} \mathrm{C}$ para posterior caracterização química e determinação da concentração dos elementos, ânions e carbono dissolvido.

Na FIG. 19 foi apresentado um exemplo do sistema de percolação das colunas.
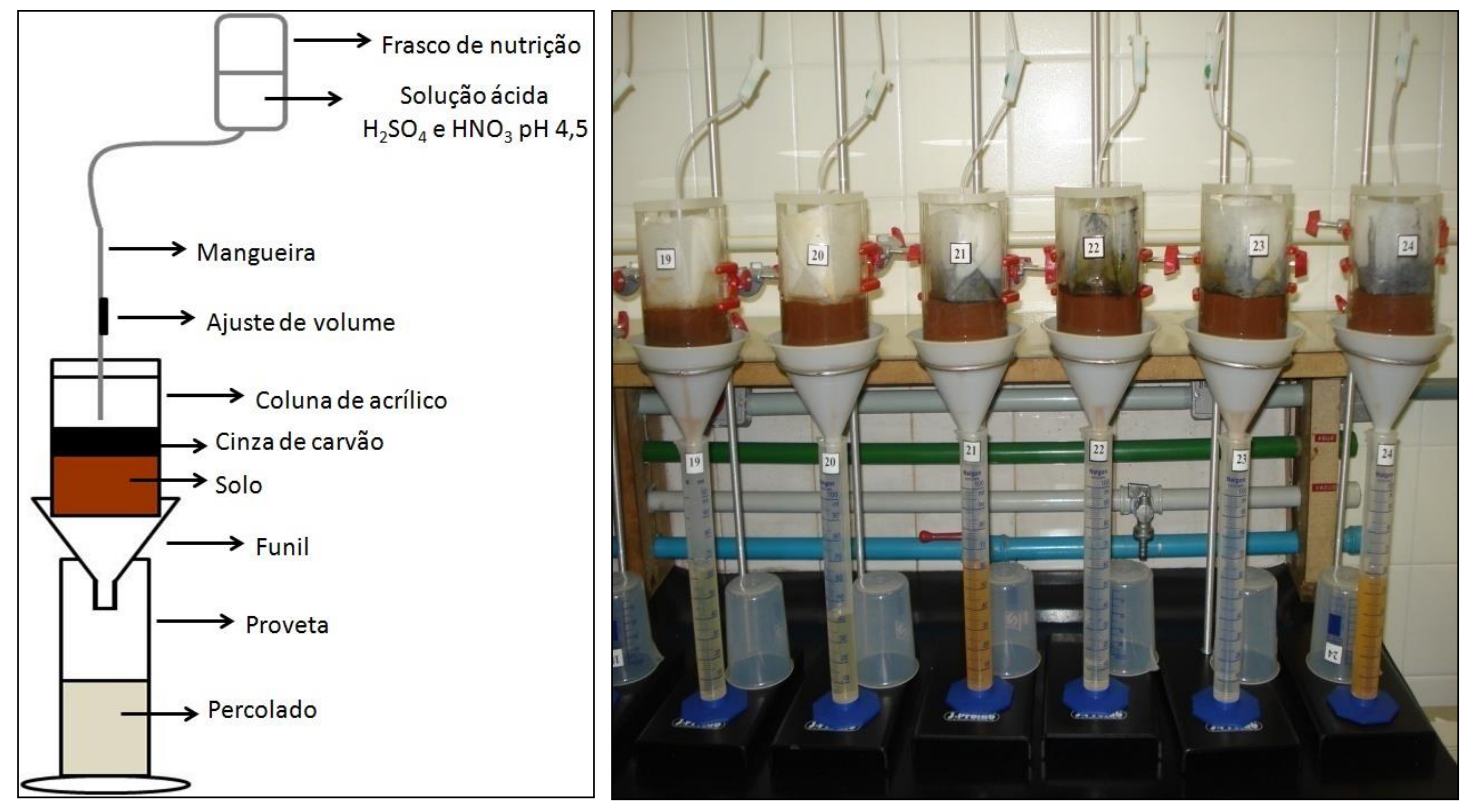

FIGURA 19 - Sistema de percolação das colunas de solo e as colunas no laboratório

\subsection{Determinação da vazão e do coeficiente de permeabilidade das colunas}

A vazão das colunas foi calculada pela razão entre o volume $(\mathrm{mL})$ do percolado da coluna e o tempo (min). O volume foi medido a cada 30 minutos pela proveta adicionada abaixo do funil no sistema de percolação (FIG.19) conforme descrito por Lange, 2012.

O coeficiente de permeabilidade foi calculado por meio da equação da Lei de Darcy (equação 2):

$\mathrm{Q}=\mathrm{k} . \mathrm{i} . \mathrm{A}$ 
Em que: $\mathrm{Q}=$ vazão da coluna; $\mathrm{k}=$ coeficiente de permeabilidade; $\mathrm{i}=$ gradiente hidráulico; A= área da secção transversal da coluna.

O gradiente hidráulico foi estabelecido igual a um, pois foi considerado que a perda de carga hidráulica foi totalmente devida à perda de altura e a pressão neutra no sistema foi nula, ou seja, igual a pressão atmosférica (Lange, 2012). O volume de entrada da solução na coluna foi aproximadamente o mesmo volume de saída do percolado, indicando que não houve acúmulo de percolado no topo da coluna e confirmando a hipótese do gradiente unitário (Lange, 2012).

\subsection{Desmontagem das colunas}

Após o período de percolação, as colunas foram desmontadas e o solo e a areia inerte foram separados da cinza de carvão cuidadosamente. Na FIG. 20 foi apresentado o solo após separação deste da cinza de carvão. O solo e a cinza de carvão foram espalhados em um recipiente de polietileno, separadamente, para secarem em temperatura ambiente. Após a secagem, as amostras foram homogeneizadas e quarteadas para posterior determinação das características químicas e da concentração dos elementos.

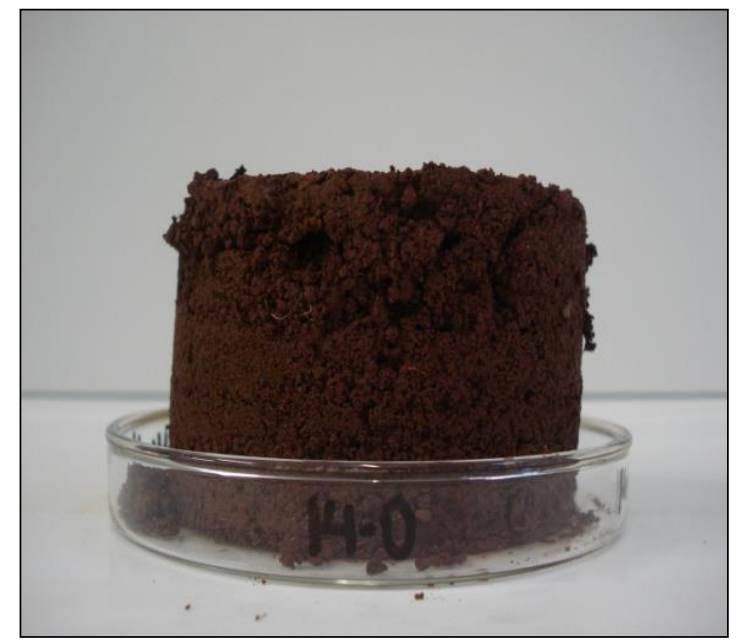

FIGURA 20 - Solo da coluna desmontada após separação da cinza de carvão 


\subsection{Caracterização física, química e mineralógica das amostras}

As características das amostras de solo, cinza de carvão e percolado das colunas foram determinadas no CQMA do IPEN/CNEN-SP. Algumas características foram determinadas também pela Escola Superior de Agricultura "Luiz Queiroz" da Universidade de São Paulo (ESALQ-USP) e pelo Laboratório de Caracterização Tecnológica da Escola Politécnica da Universidade de São Paulo (LCT-POLI-USP), pois estes laboratórios prestam serviço de análises químicas rotineiramente.

\subsubsection{Caracterização física do solo}

As características físicas determinadas na amostra de solo foram condutividade elétrica, densidade da partícula, densidade do solo, porosidade, granulometria, umidade atual e residual e cor do solo.

Os métodos adotados para determinar as características físicas do solo foram apresentados na TAB. 9.

TABELA 9 - Características físicas do solo e métodos adotados pelos laboratórios de análise

\begin{tabular}{ccc}
\hline Característica física do solo & Laboratório & Método \\
\hline Condutividade elétrica & ESALQ-USP & Condutivímetro (1:2,5) \\
\hline Densidade de partículas (Dp) & CQMA-IPEN & Balão volumétrico e álcool etílico ${ }^{1}$ \\
\hline Densidade do solo (Ds) & ESALQ-USP & Picnômetro \\
\hline Granulometria & CQMA-IPEN & Gravimetria com anel volumétrico $^{1}$ \\
\hline Porosidade (P) & CQMA-IPEN & Densímetro de Bouyoucos ${ }^{1}$ \\
\hline Umidade atual e residual & ESALQ-USP & Classe de diâmetro $^{1}$ \\
\hline 1. Fonte - EMBRAPA, 1997. & CQMA-IPEN & Razão entre Dp e Ds $^{1}$ \\
\hline
\end{tabular}

A cor do solo foi determinada utilizando a Carta de Munsell. 


\subsubsection{Caracterização química da cinza de carvão, solo e percolado das colunas}

A composição química da cinza e do solo foi determinada pelo laboratório LCT-POLI-USP, por meio da fluorescência de raios-X, utilizando um espectrômetro por fluorescência de raios-X modelo Axios Advanced, da marca PANalytical. O pH da cinza e do solo foi medido no pHmetro digital MPA 210P, marca CAAL, em duplicata. A metodologia para determinação do $\mathrm{pH}$ da cinza de carvão de Figueira foi em meio aquoso na proporção cinza:água 1:50, conforme descrito por Lange (2012).

Os métodos adotados para determinar as características químicas do solo foram apresentados na TAB. 10.

TABELA 10 - Características químicas do solo e métodos adotados pelos laboratórios de análise

\begin{tabular}{|c|c|c|}
\hline Característica química do solo & Laboratório & Método \\
\hline \multirow{2}{*}{$\mathrm{pH}$} & CQMA-IPEN & Solução $\mathrm{KCl}$ e $\mathrm{H}_{2} \mathrm{O}$ proporção $1: 2,5^{1}$ \\
\hline & ESALQ & Soluções de $\mathrm{KCl}, \mathrm{CaCl}_{2}$ e $\mathrm{H}_{2} \mathrm{O}$, proporção $1: 2,5$ \\
\hline \multirow{2}{*}{ Matéria orgânica (MO) } & CQMA-IPEN & Combustão em mufla a $375^{\circ} \mathrm{C}^{3}$ \\
\hline & ESALQ & Dicromato/titulométrico \\
\hline \multirow[b]{2}{*}{ Capacidade de troca catiônica (CTC) } & CQMA-IPEN & Troca compulsiva com $\mathrm{BaCl}_{2}$ e $\mathrm{MgSO}_{4}{ }^{1}$ \\
\hline & ESALQ-USP & $\begin{array}{c}\mathrm{T}=\mathrm{S}(\text { soma dos cátions trocáveis })+\left(\mathrm{H}^{+}+\right. \\
\left.\qquad \mathrm{Al}^{+++}\right)\end{array}$ \\
\hline Óxidos $\mathrm{Al}, \mathrm{Fe}$ e $\mathrm{Mn}$ & CQMA-IPEN & Ataque sulfúrico 1,2 \\
\hline Óxidos Al, Fe, Mn, Si e Ti & ESALQ & $\begin{array}{c}\mathrm{Al} \text { - complexometria com EDTA; } \\
\text { Fe e } \mathrm{Mn} \text { - ataque sulfúrico }\left(\mathrm{H}_{2} \mathrm{SO}_{4} \text { a } 50 \%\right) \\
\mathrm{Si} \text { - extração com } \mathrm{NaOH}_{2} \mathrm{O} \text { e determinação por } \\
\text { gravimetria; } \\
\mathrm{Ti} \text { - oxidação da matéria orgânica - } \\
\text { colorimetria; }\end{array}$ \\
\hline
\end{tabular}

A MO do solo foi queimada na mufla Q-318M24, marca Quimis, e foi medida em quadruplicata. Para a determinação dos óxidos, a concentração dos elementos Al, Fe e Mn nos extratos do solo foi medida no espectrômetro de emissão atômica com fonte de plasma acoplada indutivamente ICP/OES, modelo M120E, da marca Spectroflame, e posteriormente foi calculada a concentração dos óxidos respectivos por regra de três. 
Os coeficientes $\mathrm{Ki}$ e $\mathrm{Kr}$, relacionados com a intemperização do solo, foram calculados inserindo a porcentagem de alguns óxidos nas equações 3 e 4 (EMBRAPA, 1999):

$$
\begin{aligned}
& \mathrm{Ki}=1,7 \frac{\%{\mathrm{de} \mathrm{SiO}_{2}}}{\%{\mathrm{de} \mathrm{Al}_{2} \mathrm{O}_{3}}} \\
& \mathrm{Kr}=1,7 \frac{\%{\operatorname{de~} \mathrm{SiO}_{2}}^{\% \operatorname{de~} \mathrm{Al}_{2} \mathrm{O}_{3}+0,64 \mathrm{Fe}_{2} \mathrm{O}_{3}}}{}
\end{aligned}
$$

Nas amostras de percolado das colunas de solo, com ou sem cinza, o pH, a condutividade elétrica e o carbono dissolvido foram medidos no percolado coletado de cada coluna a cada 28 dias. $\mathrm{O}$ pH foi medido no mesmo pHmetro descrito anteriormente, a condutividade elétrica no condutivímetro W12D da marca BEL Engineering e o carbono dissolvido no equipamento TOC $-\mathrm{V}_{\mathrm{CPH}}$ da marca Shimadzu.

\subsubsection{Caracterização mineralógica de cinza de carvão e solo}

A mineralogia da cinza e do solo foi determinada no difratômetro de raiosX, X'Pert PRO com detector X'Celerator, marca PANalytical, utilizando o método do pó. Esta determinação foi realizada no laboratório LCT-POLI-USP.

\subsubsection{Determinação da concentração dos elementos majoritários e tóxicos}

Os elementos majoritários $\mathrm{Al}, \mathrm{Ca}, \mathrm{Fe}, \mathrm{K}, \mathrm{Mg}, \mathrm{Mn}, \mathrm{Na}$ e $\mathrm{Si}$ e os elementos tóxicos $\mathrm{As}, \mathrm{Cd}, \mathrm{Mo}, \mathrm{Pb}$ e $\mathrm{Zn}$ foram determinados nos extratos das amostras de solo e de cinza de carvão por digestão ácida e nos percolados das colunas no equipamento de espectrometria de emissão óptica por plasma acoplado indutivamente - ICP/OES. Este equipamento já foi descrito anteriormente no item 4.7.2.

A digestão ácida foi realizada com base no método EPA 3051 A, utilizando $\mathrm{HNO}_{3}(9 \mathrm{~mL})$ e $\mathrm{HCl}(3 \mathrm{~mL})$ concentrados para $500 \mathrm{mg}$ de solo ou cinza de carvão e após a digestão no forno micro-ondas modelo DGT 100 Plus, da marca Provecto Analítica, o extrato foi diluído para $50 \mathrm{~mL}$. O extrato foi filtrado com papel de filtro 
faixa branca de porosidade $6 \mu \mathrm{m}$, refrigerado a $5^{\circ} \mathrm{C}$ e posteriormente determinado no ICP-OES.

Os elementos tóxicos $\mathrm{As}, \mathrm{Cd}, \mathrm{Mo}, \mathrm{Pb}$ e $\mathrm{Zn}$ também foram determinados nos extratos do solo obtidos por extração com EDTA e extração com $\mathrm{Ca}\left(\mathrm{NO}_{3}\right)_{2}$.

A extração dos elementos no solo com EDTA foi obtida pela mistura e agitação do solo com EDTA- $\mathrm{NH}_{4}$ 0,05 mol L ${ }^{-1}$, em uma proporção solo:solução 1:20, com base no método de Ure (1996).

A extração dos elementos no solo foi obtida pela mistura e agitação com $\mathrm{Ca}\left(\mathrm{NO}_{3}\right)_{2}$ 0,1 mol L${ }^{-1}$, em proporção solo:solução 1:20 (Conder et al., 2001).

Os extratos do solo obtidos por extração com EDTA e $\mathrm{Ca}\left(\mathrm{NO}_{3}\right)_{2}$ e o percolado das colunas foram filtrados a vácuo em filtro de membrana 0,45 $\mu \mathrm{m}$, acidificados a $\mathrm{pH} 2$ e refrigerados a $5^{\circ} \mathrm{C}$.

As amostras foram analisadas em duplicata e uma amostra branco foi acrescentada a cada grupo de digestão ou extração de amostras. Para as amostras de solo tratadas por digestão ácida foram utilizados dois materiais de referência do National Institute for Standard and Technology: NIST 2711, Montana soil, e NIST 2709, San Joaquin soil. Para as amostras de solo tratadas por extração com EDTA foi utilizado o material de referência para solos BCR 484 da Community Bureau of Reference.

No percolado das colunas e nos extratos de solo e cinza de carvão foram determinadas as concentrações de $\mathrm{As}$ e $\mathrm{Pb}$ no espectrômetro de absorção atômica (AASGF), modelo AAS-GF 800, com forno de grafite modelo HGA 400 da Perkin Elmer, e as concentrações de $\mathrm{Cd}$, Mo e Zn no espectrômetro de emissão atômica com fonte de plasma acoplada indutivamente (ICP/OES) com especificações descritas no item 4.7.2.

A concentração dos elementos foi denominada de concentração parcial nos extratos obtidos por digestão ácida, concentração biodisponível nos extratos obtidos por extração com EDTA e concentração trocável nos extratos obtidos por extração com $\mathrm{Ca}\left(\mathrm{NO}_{3}\right)_{2}$. 


\subsubsection{Determinação da concentração dos ânions}

A concentração dos ânions fluoreto, cloreto, nitrito, nitrato, fosfato e sulfato foram determinados nos percolados das colunas coletados a cada 28 dias de percolação. Os percolados foram filtrados a vácuo em filtro de membrana $0,45 \mu \mathrm{m}$ e a determinação foi realizada por meio do cromatógrafo de íons modelo DX120, marca DIONEX, com detecção condutimétrica e separação em colunas de troca aniônica IONPAC AS14-HC (4X250 mm).

\subsection{Tratamento de dados}

\subsubsection{Cálculo da porcentagem de lixiviação dos elementos da cinza de carvão}

A quantidade dos elementos lixiviados da cinza de carvão foi calculada por dois métodos: o primeiro método foi pela subtração entre a concentração do elemento na cinza e a concentração do elemento na cinza ap das CSC e o segundo método foi pela somatória das massas do elemento nos percolados das CC no período de 336 dias de percolação. A massa do elemento lixiviado da cinza no percolado foi calculada pela multiplicação entre a concentração do elemento no percolado da CC e o volume percolado.

A porcentagem de lixiviação do elemento na cinza de carvão foi calculada com base nas equações 5 e 6 que consideram a quantidade dos elementos lixiviados da cinza calculada pelos métodos, um e dois, respectivamente.

$$
\text { Lixiviação do elemento }=\frac{\text { Cec-Cecap }}{\text { Cec }} \times 100 \%
$$

Em que Cec é a concentração do elemento na cinza e Cecap é a concentração do elemento na cinza após percolação.

$$
\text { Lixiviação do elemento }=\frac{\sum_{\mathrm{t}=28}^{336} \operatorname{mepCC}}{\operatorname{mec}} \times 100 \%
$$


Em que mepCC é a massa do elemento no percolado das $\mathrm{CC}$ e mec é a massa do elemento na cinza.

A massa do elemento no percolado das $\mathrm{CC}$ foi calculada multiplicando-se a concentração do elemento no percolado $\left(\mu \mathrm{g} \mathrm{mL}^{-1}\right)$ pelo volume do percolado da coluna $(\mathrm{mL})$.

A massa do elemento na cinza foi calculada multiplicando-se a concentração do elemento por $0,05 \mathrm{~kg}$, massa de cinza adicionada no topo das colunas de solo e areia inerte.

\subsubsection{Cálculo da porcentagem de retenção dos elementos no solo}

A porcentagem de retenção dos elementos no solo foi calculada com base nas equações 7 e 8, considerando a quantidade do elemento lixiviado da cinza calculada pelos métodos um e dois, respectivamente:

$$
\text { Retenção do elemento }=\frac{\text { mers }}{\text { mec }- \text { mecap }} \times 100 \%
$$

Em que mers é a massa do elemento retido no solo, mec é a massa do elemento na cinza e mecap é a massa do elemento na cinza ap.

A massa do elemento retido no solo foi calculada subtraindo-se a massa do elemento no solo da CSC da massa do elemento no solo da CS. A massa do elemento no solo das CS e CSC foi calculada pela multiplicação entre a concentração do elemento no solo, em $\mathrm{mg} \mathrm{kg}^{-1}$, e a massa do solo compactado na coluna, 0,279 kg.

A massa do elemento na cinza e na cinza ap das CSC e CC foi calculada multiplicando-se a concentração do elemento por $0,05 \mathrm{~kg}$.

$$
\text { Retenção do elemento }=\frac{\text { mers }}{\sum_{\mathrm{t}=28}^{336} \operatorname{mepCC}} \times 100 \%
$$

Em que mepCC é a massa do elemento no percolado das CC. 


\subsubsection{Balanço de massa}

O balanço de massa foi avaliado pela equivalência entre a massa dos elementos lixiviados da cinza de carvão e a somatória da massa do elemento retido no solo e da massa do elemento no percolado da coluna (FIG.21).

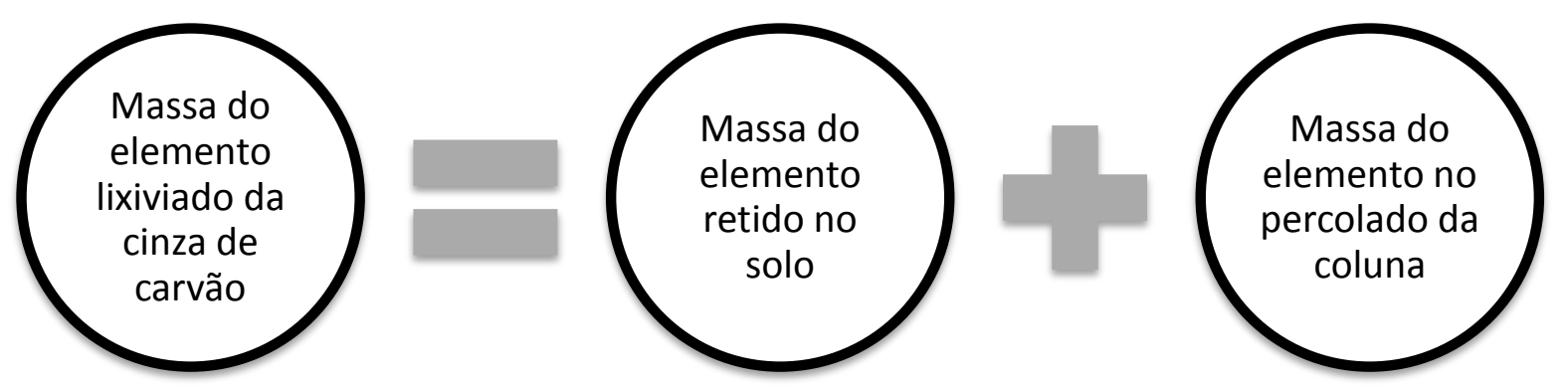

FIGURA 21 - Esquema do balanço de massa

A massa do elemento lixiviado da cinza de carvão foi calculada por dois métodos: método um, pela subtração entre as massas do elemento na cinza e na cinza após percolação (cinza ap); método dois, pela somatória das massas do elemento nos percolados das CC gerados no período de 336 dias de percolação, conforme descrito no item 4.8.1. A massa do elemento na cinza e na cinza ap foi calculada conforme descrito no item 4.8.2.

A massa do elemento retido no solo foi calculada conforme descrito no item 4.8.2.

A massa dos elementos presentes no percolado foi calculada pela subtração entre a massa do elemento no percolado da CSC e a massa do percolado da CS. A massa do elemento no percolado das CSC e CS foi obtida pela multiplicação entre a concentração do elemento no percolado $\left(\mu \mathrm{g} \mathrm{mL}^{-1}\right)$ e o volume do percolado da coluna $(\mathrm{mL})$, conforme descrito no item 4.8.1.

\subsubsection{Cálculo de Kp}

O coeficiente de partição, Kp, foi calculado pelas equações 9 e 10 


$$
\begin{gathered}
\text { Kp EDTA }=\frac{\text { Concentração parcial do elemento no solo }}{\text { Concentração biodisponível do elemento no solo }} \\
\mathrm{Kp} \mathrm{Ca(NO3)2}=\frac{\text { Concentração parcial do elemento no solo }}{\text { Concentração trocável do elemento no solo }}
\end{gathered}
$$

\subsubsection{Cálculo da porcentagem de extração dos elementos no solo}

A porcentagem da extração com EDTA do elemento no solo foi calculada com base nas concentrações das extrações com EDTA e com a digestão ácida do elemento no solo após a percolação.

$$
\text { Extração EDTA do elemento }=\frac{\text { cee }}{\text { ceda }} \times 100 \%
$$

Em que cee é a concentração do elemento obtida por extração com EDTA e ceda a concentração do elemento obtida por meio da digestão ácida. 


\section{RESULTADOS E DISCUSSÃO}

As características físicas, químicas e mineralógicas e a concentração dos elementos nas amostras de cinza de carvão, solo e percolado das colunas foram determinadas para avaliar a mobilidade dos elementos As, Cd, Mo, Pb e Zn no solo e a contaminação do solo.

\subsection{Cinza de Carvão}

A cinza de carvão foi caracterizada quanto à composição química, pH e mineralogia por Lange (2012) e estas características foram apresentadas abaixo.

A composição química da cinza de carvão foi apresentada na TAB. 11.

TABELA 11 - Composição química da cinza de carvão obtida por fluorescência de raios-X, expressa em \% de óxidos

\begin{tabular}{|c|c|c|c|c|c|c|c|c|c|}
\hline $\mathrm{SiO}_{2}$ & $\mathbf{A l}_{2} \mathbf{O}_{3}$ & $\mathrm{Fe}_{2} \mathrm{O}_{3}$ & $\mathbf{K}_{2} \mathbf{O}$ & $\mathrm{SO}_{3}$ & $\mathrm{TiO}_{2}$ & $\mathrm{Na}_{2} \mathrm{O}$ & $\mathrm{CaO}$ & MgO & $\mathbf{P}_{2} \mathbf{O}_{5}$ \\
\hline 54,4 & 18,0 & 8,08 & 2,63 & 2,39 & 1,09 & 1,07 & 1,07 & 0,87 & 0,23 \\
\hline $\mathbf{A s}_{2} \mathbf{O}_{3}$ & $\mathrm{ZnO}$ & $\mathrm{ZrO}_{2}$ & BaO & PbO & $\mathbf{V}_{2} \mathbf{O}_{5}$ & MnO & SrO & $\mathrm{Cr}_{2} \mathrm{O}_{3}$ & $\mathbf{U}_{3} \mathbf{O}_{8}$ \\
\hline 0,19 & 0,16 & 0,12 & 0,07 & 0,06 & 0,06 & 0,05 & 0,05 & 0,03 & 0,03 \\
\hline $\mathbf{Y}_{2} \mathbf{O}_{3}$ & Cl & $\mathbf{R} \mathbf{b}_{2} \mathbf{O}$ & $\mathrm{MoO}_{3}$ & $\mathrm{NiO}$ & $\mathrm{CuO}$ & $\mathrm{GeO}_{2}$ & $\mathrm{Co}_{3} \mathrm{O}_{4}$ & $\mathrm{Nb}_{2} \mathbf{O}_{5}$ & PF \\
\hline 0,02 & 0,02 & 0,01 & 0,01 & 0,01 & 0,01 & 0,01 & nd & nd & 9,30 \\
\hline
\end{tabular}

Foi observado que a maior parte da cinza é composta por Si e Al, seguido de Fe, K, S, Ti, Na, Ca e Mg (TAB.11), o que corresponde aos dados de cinzas de carvão de Figueira e de outros municípios do sul do Brasil descritos por Izidoro (2008) e Rohde et al. (2006). Os demais elementos estão em concentração inferior na cinza e dentre estes, As e Zn são os elementos tóxicos que estão em maior concentração quando comparados, por exemplo, com Mo e $\mathrm{Pb}$ (TAB.11). O cádmio não foi detectado por esse método por causa da concentração ser menor que $0,005 \%$.

Levandowski e Kalkreuth (2009) analisaram as cinzas de carvão da usina de Figueira coletadas em período diferente do ano de coleta do presente trabalho (2001- 
2002, item 4.1) e os resultados obtidos foram semelhantes com os descritos na TAB. 11, no qual as concentrações de As e $\mathrm{Zn}$ também foram superiores às concentrações dos outros elementos traço. Depoi (2007) analisou a cinza leve de carvão de Figueira e observou que em comparação com outras usinas termoelétricas a concentração de Ba e $\mathrm{Cd}$ foi maior e a dos elementos $\mathrm{As}, \mathrm{Pb}, \mathrm{Zn}$ e Mo foi 100 vezes maior. Flues et al. (2013) determinaram a concentração de elementos tóxicos nas cinzas pesada (do fundo de caldeira) e leves (dos filtros ciclone e manga) da usina termoelétrica de Figueira e observaram uma concentração dos elementos mais elevada na cinza leve do filtro manga quando comparada com as outras cinzas. Os elementos da cinza leve do filtro manga apresentaram a seguinte concentração total decrescente: $\mathrm{Zn}>\mathrm{As}>\mathrm{Pb}>\mathrm{Mo}>\mathrm{Cd}$.

Dos elementos presentes na cinza de carvão da Usina Termoelétrica de Figueira foram selecionados os elementos $\mathrm{As}, \mathrm{Cd}, \mathrm{Mo}, \mathrm{Pb}$ e $\mathrm{Zn}$ com base na sua toxicidade, concentração desses elementos na cinza de carvão e na contaminação do solo analisado ao redor da usina termoelétrica de Figueira (Camargo, 2005; Flues et al., 2008; Flues et al., 2013).

Outros elementos tóxicos como o $\mathrm{Ba}, \mathrm{Cu}, \mathrm{Cr}$ e $\mathrm{Ni}$ também foram detectados na cinza de carvão (TAB. 11), mas não foram considerados para o presente estudo porque o solo de Figueira não apresentou contaminação em relação aos elementos $\mathrm{Cu}$, Cr e Ni (Flues et al., 2008) e Ba foi pouco lixiviado da cinza leve de Figueira (Depoi et al., 2008).

$\mathrm{O} \mathrm{pH}_{\mathrm{H} 2 \mathrm{O}} 7,4$ da cinza de carvão de Figueira utilizada neste presente trabalho já foi descrito por Lange (2012). Este $\mathrm{pH}$ mostra que a cinza é alcalina. $\mathrm{O} \mathrm{pH}$ da cinza influencia na mobilidade dos elementos que são mais lixiviados da cinza em meio ácido (Flues et al., 2013). De acordo com Ferret (2004), o pH da cinza de carvão depende do carvão do qual foi gerada, e de um modo geral variam entre 4,5 e 12.

A composição mineral da cinza de carvão foi determinada por difração de raios-X pelo LCT-POLI-USP e já foi descrita por Lange (2012). Os minerais identificados na cinza foram quartzo $\left(\mathrm{SiO}_{2}\right)$, mulita $\left(\mathrm{Al}_{4,59} \mathrm{Si}_{1,41} \mathrm{O}_{9,7}\right)$, hematita $\left(\mathrm{Fe}_{2} \mathrm{O}_{3}\right)$ e magnesioferrita $\left(\mathrm{MgFe}_{2} \mathrm{O}_{4}\right)$. 


\subsection{Solo}

As características físicas, químicas e mineralógicas foram determinadas no solo antes da percolação e após percolação, denominados de solo e solo ap, respectivamente.

\subsubsection{Caracterização física do solo}

A condutividade elétrica, densidade da partícula, densidade do solo, porosidade, granulometria, umidade atual e residual e cor do solo foram analisadas no solo.

Na TAB. 12 foram apresentadas as características físicas do solo.

TABELA 12 - Características físicas do solo

\begin{tabular}{|c|c|c|c|c|c|c|}
\hline $\begin{array}{c}\text { Laboratório de } \\
\text { análise }\end{array}$ & $\begin{array}{c}\mathrm{CE} \\
\left(\mathrm{dS} \mathrm{m}^{-1}\right)\end{array}$ & $\begin{array}{c}\mathrm{Dp} \\
\left(\mathrm{g} \mathrm{cm}^{-3}\right)\end{array}$ & $\begin{array}{c}\text { Ds } \\
\left(\mathrm{g} \mathrm{cm}^{-3}\right)\end{array}$ & Porosidade & $\begin{array}{c}\text { Umidade } \\
\text { atual } \\
(\%)\end{array}$ & $\begin{array}{c}\text { Umidade } \\
\text { residual } \\
(\%)\end{array}$ \\
\hline IPEN & nd & $\begin{array}{l}2,73 \pm 0,03 \\
\quad(n=2)\end{array}$ & $\begin{array}{c}0,92 \pm 0,08 \\
(n=7)\end{array}$ & 0,66 & $\begin{array}{c}18,55 \pm 0,96 \\
(n=7)\end{array}$ & $\begin{array}{c}9,13 \pm 0,17 \\
(n=4)\end{array}$ \\
\hline ESALQ & 170,5 & 2,62 & nd & nd & nd & nd \\
\hline
\end{tabular}

O solo apresentou densidade da partícula igual a 2,73 $\mathrm{g} \mathrm{cm}^{-3}$. De acordo com Brady (1989), a densidade da partícula para solos minerais geralmente apresenta valores entre 2,60 a $2,75 \mathrm{~g} \mathrm{~cm}^{-3}$.

A densidade do solo foi $0,92 \mathrm{~g} \mathrm{~cm}^{-3}$. Geralmente solos de textura fina possuem densidade menor do que solos arenosos (Brady, 1989), fato que pode ser observado quando a densidade do solo analisado no presente trabalho foi comparada com a densidade $1,14 \mathrm{~g} \mathrm{~cm}^{-3}$ de um Latossolo de textura franco arenosa (Lange, 2012).

Na TAB. 13 foi apresentada a granulometria do solo. 
TABELA 13 - Granulometria do solo

\begin{tabular}{|c|c|c|c|c|c|c|c|c|}
\hline \multirow[t]{2}{*}{$\begin{array}{l}\text { Laboratório } \\
\text { de análise }\end{array}$} & \multicolumn{6}{|c|}{$\begin{array}{c}\text { Areia } \\
\left(\mathrm{mg} \mathrm{kg}^{-1}\right)\end{array}$} & \multirow{2}{*}{$\begin{array}{c}\text { Silte } \\
\text { (mg kg- } \\
1 \text { । }\end{array}$} & \multirow[t]{2}{*}{$\begin{array}{c}\text { Argila } \\
\left(\mathrm{mg} \mathrm{kg}^{-1}\right)\end{array}$} \\
\hline & MG & $\mathbf{G}$ & $\mathbf{M}$ & $\mathbf{F}$ & MF & AT & & \\
\hline IPEN & - & - & - & - & - & $35 \%(\mathrm{n}=1)$ & $9 \%(n=1)$ & $56 \%(n=1)$ \\
\hline ESALQ & 20 & 12 & 58 & 130 & 32 & 252 & 121 & 627 \\
\hline
\end{tabular}

Os valores de argila, silte e areia total do solo (TAB.13) obtidos no presente trabalho foram semelhantes aos valores determinados pela ESALQ que presta serviço de análises químicas e físicas rotineiramente.

O solo apresentou maior quantidade de partículas de argila quando comparado com as partículas de areia e silte (TAB.13), podendo favorecer a retenção de cátions devido ao comportamento coloidal, a área de exposição e a capacidade de adsorção na superfície das partículas de argila, conforme descrito no item 3.2.1. Esta retenção está relacionada com a maior área superficial da partícula da argila quando comparada com a área das outras partículas e com as cargas elétricas negativas não neutralizadas que adsorvem os cátions presentes na solução do solo (Lepsch, 2002).

Os valores de areia total, silte e argila (TAB.13) foram aplicados no triângulo adotado pela Sociedade Brasileira de Ciência do Solo para classificar a textura do solo. Na FIG. 22 foi apresentada a textura do solo. 


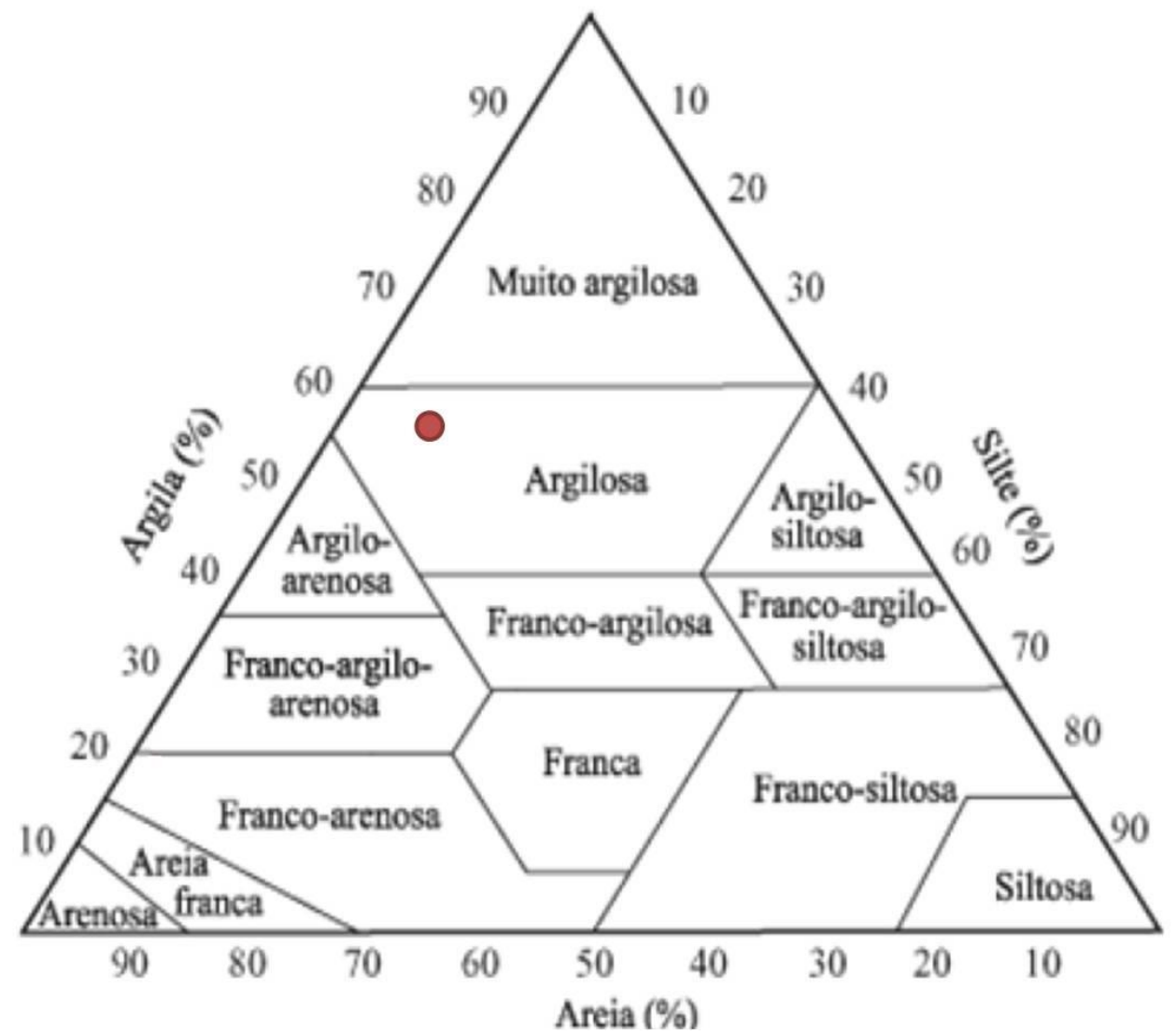

FIGURA 22 - Textura do solo de acordo com o diagrama adotado pela Sociedade

Brasileira de Ciência do Solo

Fonte - Resende et al., 2002.

A textura do solo foi classificada como solo argiloso (FIG.22).

A cor do solo foi determinada utilizando a carta de Munsell e foram obtidos os seguintes valores para o solo: matiz 2,5YR, valor 3 e croma 4. Matiz é o nome da cor e matiz igual a 2,5YR significa ter $62,5 \%$ de $\mathrm{R}$ (red), cor vermelha, e $37,5 \%$ de $\mathrm{Y}$ (yellow), cor amarela. Valor está relacionado com o brilho ou a tonalidade, é o número de partes de cor branca em combinação com a preta, varia de 0 (preto absoluto) a 10 (branco puro). Valor 3 corresponde a 3 partes de branco para 7 de preto. Croma é a intensidade ou pureza do matiz, a soma da cor cinza e da matiz equivale a vinte. Croma 4 são 4 partes da matiz para 16 de cinza (Hypolito et al., 2011). Na FIG. 23 foi destacada a matiz para o solo obtida por meio da carta de Munsell. 


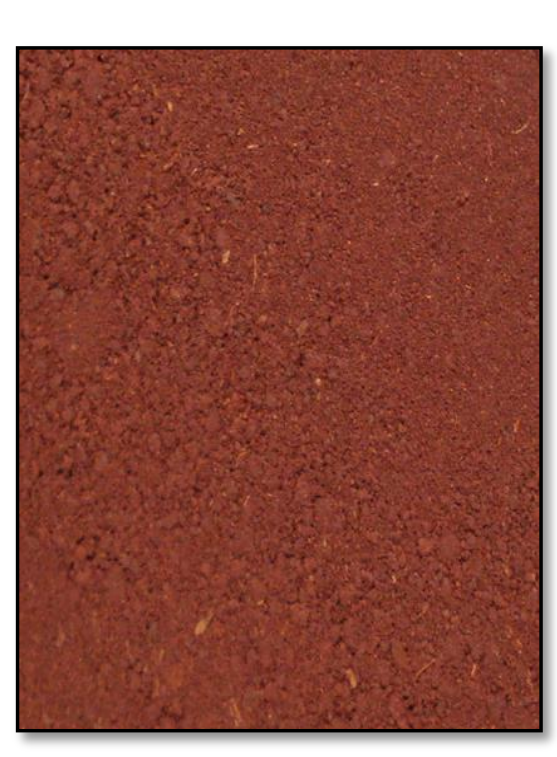

(a)

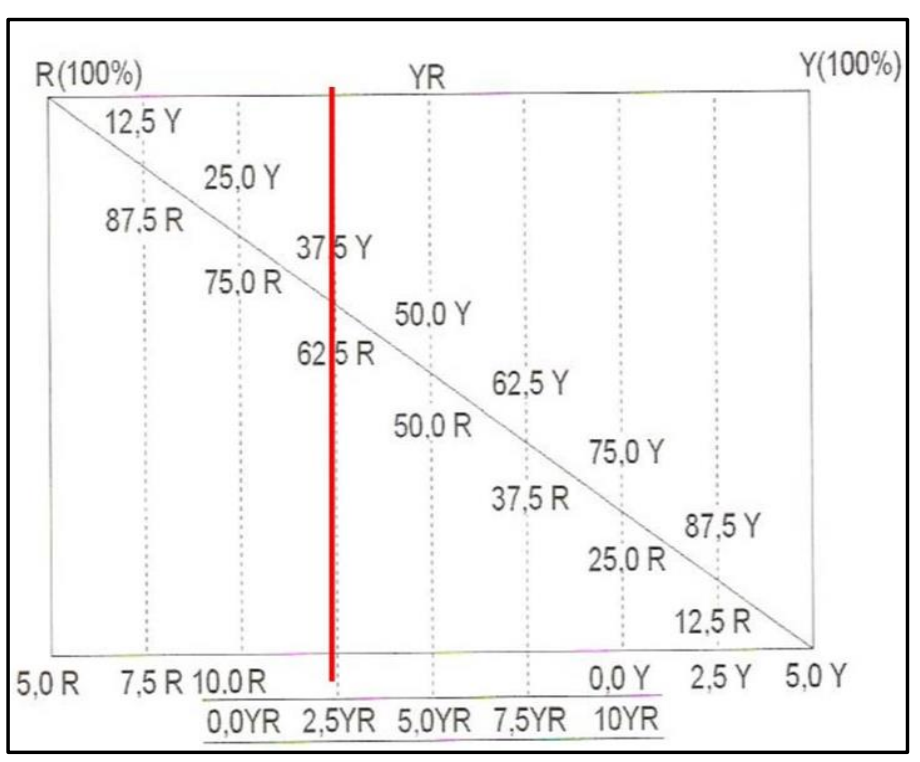

(b)

FIGURA 23 - (a) Cor do solo em estudo e a (b) classificação da matiz do Sistema de Munsell, linha vermelha Fonte - Hypolito et al., 2011.

\subsubsection{Caracterização química do solo}

As características químicas determinadas no solo foram composição química, pH, MO, CTC, óxidos, Ki e Kr.

A composição química do solo foi determinada por fluorescência de raiosX. Os resultados foram expressos em \% de óxidos na TAB. 14.

TABELA 14 - Composição química do solo obtida por fluorescência de raios-X, expressos em \% de óxidos

\begin{tabular}{|c|c|c|c|c|c|c|c|c|c|}
\hline $\mathrm{SiO}_{2}$ & $\mathbf{A l}_{2} \mathbf{O}_{3}$ & $\mathrm{Fe}_{2} \mathrm{O}_{3}$ & $\mathrm{TiO}_{2}$ & $\mathrm{Co}_{3} \mathrm{O}_{4}$ & $\mathrm{CaO}$ & $\mathbf{K}_{2} \mathbf{O}$ & MgO & $\mathbf{P}_{2} \mathbf{O}_{5}$ & $\mathrm{SO}_{3}$ \\
\hline 39,9 & 27,6 & 14,5 & 2,40 & 0,76 & 0,34 & 0,24 & 0,23 & 0,20 & 0,14 \\
\hline $\mathrm{ZrO}_{2}$ & MnO & $\mathbf{V}_{2} \mathbf{O}_{5}$ & $\mathrm{Cr}_{2} \mathrm{O}_{3}$ & $\mathrm{Na}_{2} \mathrm{O}$ & $\mathrm{CuO}$ & $\mathrm{Nb}_{2} \mathrm{O}_{5}$ & $\mathrm{SrO}$ & $\mathrm{ZnO}$ & PbO \\
\hline 0,08 & 0,06 & 0,05 & 0,03 & 0,03 & 0,01 & 0,01 & 0,01 & 0,01 & 0,01 \\
\hline $\mathbf{R} \mathbf{b}_{2} \mathbf{O}$ & $\mathbf{Y}_{2} \mathbf{O}_{3}$ & $\mathrm{As}_{2} \mathbf{O}_{3}$ & $\mathbf{B a O}$ & Cl & $\mathrm{GeO}_{2}$ & $\mathrm{MoO}_{3}$ & $\mathrm{NiO}$ & $\mathbf{U}_{3} \mathbf{O}_{8}$ & PF \\
\hline$<0,01$ & $<0,01$ & $<0,01$ & $<0,01$ & $<0,01$ & $<0,01$ & $<0,01$ & $<0,01$ & $<0,01$ & 13,4 \\
\hline
\end{tabular}


Os elementos mais abundantes no solo foram $\mathrm{Si}, \mathrm{Al}$ e $\mathrm{Fe}$. Dos elementos tóxicos selecionados para o presente estudo, $\mathrm{As}, \mathrm{Cd}, \mathrm{Mo}, \mathrm{Pb}$ e $\mathrm{Zn}$, com base no item 5.1, foram detectados no solo os elementos $\mathrm{Zn}$ e $\mathrm{Pb}$ em concentrações $0,01 \%$ (TAB.14).

Na TAB. 15 foram descritas as características químicas do solo.

TABELA 15 - Características químicas do solo

\begin{tabular}{|c|c|c|c|c|c|c|}
\hline $\begin{array}{l}\text { Laboratório } \\
\text { de análise }\end{array}$ & $\mathrm{pH}\left(\mathrm{H}_{2} \mathrm{O}\right)$ & pH (KCl) & MO (\%) & $\operatorname{CTC} \underset{1}{\left(\operatorname{mmol}_{\mathrm{c}}\right.} \mathrm{kg}^{-}$ & $\mathbf{K i}$ & $\mathbf{K r}$ \\
\hline IPEN & $6,2 \pm 0,1(\mathrm{n}=2)$ & $\begin{array}{c}5,1 \pm 0,2 \\
(\mathrm{n}=6)\end{array}$ & $8,0 \pm 0,7(\mathrm{n}=4)$ & $163,0 \pm 4,6(\mathrm{n}=8)$ & 0,16 & 0,13 \\
\hline ESALQ & 6,1 & 4,8 & 3,7 & 108,8 & 0,15 & 0,12 \\
\hline $\begin{array}{l}\text { Laboratório } \\
\text { de análise }\end{array}$ & $\mathrm{Al}_{2} \mathrm{O}_{3}(\%)$ & $\mathrm{Fe}_{2} \mathrm{O}_{3}(\%)$ & $\operatorname{MnO}(\%)$ & $\mathrm{SiO}_{2}(\%)$ & \multicolumn{2}{|c|}{$\mathrm{TiO}_{2}(\%)$} \\
\hline IPEN & $18,7(\mathrm{n}=1)$ & $7,4(\mathrm{n}=1)$ & $0,03(\mathrm{n}=1)$ & nd & \multicolumn{2}{|c|}{ nd } \\
\hline ESALQ & 21,01 & 8,39 & 0,04 & 1,80 & \multicolumn{2}{|c|}{13,25} \\
\hline
\end{tabular}

$\mathrm{O}$ pH e os óxidos de $\mathrm{Al}, \mathrm{Fe}$ e $\mathrm{Mn}$ (TAB.15) apresentaram valores semelhantes aos determinados pela ESALQ, que presta serviço de análises químicas rotineiramente. No entanto, a MO e a CTC apresentaram valores diferentes quando comparados com os da ESALQ (TAB.15) que podem ser atribuídos às diferentes metodologias utilizadas entre os laboratórios de análise. Para a determinação da MO no IPEN foi utilizado o método de combustão na mufla a $375^{\circ} \mathrm{C}$ e na ESALQ o método dicromato/titulação. Para a determinação da CTC no IPEN foi utilizado o método de troca compulsiva e na ESALQ foi utilizado o método de soma dos cátions trocáveis, $\mathrm{H}^{+}$ $\mathrm{e} \mathrm{Al}^{+++}$.

$\mathrm{O}$ solo apresentou valor de $\mathrm{pH}_{\mathrm{KCl}} 5,1$ (TAB.15) que classifica-o como um solo ácido. Fadigas et al. (2002) analisaram 162 amostras das principais classes de solos brasileiros e observaram que $89 \%$ das amostras apresentaram valores de $\mathrm{pH} \leq 6,0$, ou seja, a maior parte dos solos brasileiros são ácidos.

$\mathrm{O} \mathrm{pH}$ do solo é uma característica muito importante, pois, influencia no comportamento de cátions e ânions. Os cátions tendem a ser mais móveis no solo em 
meio ácido e os ânions tendem a ser mais móveis em meio alcalino (Alloway, 1990; McBride, 1994). Arsênio e Mo se encontram em forma de ânion e $\mathrm{Cd}, \mathrm{Pb}$ e $\mathrm{Zn}$ em forma de cátion (Alloway, 1990). Considerando que o solo é ácido poderia ser esperado que a mobilidade de $\mathrm{Cd}, \mathrm{Pb}$ e $\mathrm{Zn}$ fosse maior que a do As e Mo.

No entanto, a mobilidade dos elementos no solo não depende somente do $\mathrm{pH}$, mas também de outras características, tais como, matéria orgânica, óxidos de $\mathrm{Al}, \mathrm{Fe}$ e Mn, argila.

O solo apresentou 8,0\% de MO (TAB.15). Segundo Moniz et al. (1972), solos com MO inferior a $20 \%$ podem ser classificados como solo mineral e com porcentagem superior a 20\% como solo orgânico. Brady (1989) classifica os solos com 12 a 18 \% de MO como solos orgânicos. Portanto, o solo pode ser considerado como um solo mineral. Fadigas et al. (2002) analisou diversas classes de solo do Brasil e observou na maior parte dos solos uma quantidade de MO menor que 2\%. Soares (2005) por meio do método Walkley-Black (oxidação do carbono com dicromato de potássio) encontrou valores de MO entre $0,6 \%$ e 21,34\% para solos do estado de São Paulo de diversas classes, e dentre essas os Latossolos apresentaram valores entre $1,24 \%$ e $9,56 \%$.

O solo apresentou concentração de óxidos de $\mathrm{Al}(18,7 \%)$ e $\mathrm{Fe}(7,4 \%)$ superiores ao valor determinado para óxido de Mn (0,03\%) (TAB.15), sendo a concentração do óxido de Al mais alta que a concentração do Fe. No estudo de Fadigas et al. (2002) $90 \%$ das amostras dos solos brasileiros apresentaram menos de $4 \%$ de Fe e valores menores que 0,04\% para o Mn. No estudo de Soares (2005) foram obtidos valores para óxidos de Al 1,0-24,8\%, de Fe 0,7-33,2\% e de Mn 0,01-0,32\% para solos do estado de São Paulo utilizando o método com ácido sulfúrico, similar ao método adotado no presente trabalho.

Os valores de CTC obtidos para o solo (TAB.15) foram 163,0 $\mathrm{mmol}_{\mathrm{c}} \mathrm{kg}^{-1}$ (IPEN) e 108,8 mmol $_{\mathrm{c}} \mathrm{kg}^{-1}$ (ESALQ). Os solos brasileiros apresentam em geral baixa CTC, considerando o valor de 100 mmol $_{\mathrm{c}} \mathrm{kg}^{-1}$ uma CTC baixa e $250 \mathrm{mmol}_{\mathrm{c}} \mathrm{kg}^{-1} \mathrm{CTC}$ 
alta (Melfi et al., 2004). O valor obtido para o solo do presente trabalho foi um valor médio.

Fadigas et al. (2006) analisaram 256 amostras das principais classes de solo do Brasil e o intervalo de CTC determinado para as amostras foi de $27-171 \mathrm{mmol}_{\mathrm{c}} \mathrm{kg}^{-1}$. Os valores da CTC do solo obtidos pelos laboratórios de análise, IPEN e ESALQ, estão dentro do intervalo da CTC obtido para outros solos brasileiros.

Os valores obtidos de $\mathrm{Ki}$ e $\mathrm{Kr}$ obtidos para o solo foram 0,16 e 0,13, respectivamente (TAB.15). O Ki é determinado por meio das porcentagens de $\mathrm{SiO}_{2} \mathrm{e}$ $\mathrm{Al}_{2} \mathrm{O}_{3}$ no solo e o $\mathrm{Kr}$ por meio das porcentagens de $\mathrm{SiO}_{2}, \mathrm{Al}_{2} \mathrm{O}_{3}$ e $\mathrm{Fe}_{2} \mathrm{O}_{3}$, conforme descrito anteriormente nas equações 3 e 4 do item 4.7.2. Para calcular os valores de Ki e $\mathrm{Kr}$ foram considerados os valores de óxidos de $\mathrm{Al}$ e Fe determinados pelo laboratório do IPEN e o valor de óxido de Si determinado pelo laboratório da ESALQ (TAB.15).

De acordo com o Manual Técnico de Pedologia do IBGE (2007) solos com $\mathrm{Ki}$ e $\mathrm{Kr} \leq 0,75$ são gibbsíticos, ou seja, solos onde predominam a gibbsita.

O solo foi classificado como um Latossolo com base no valor de Ki e no Mapa Pedológico do Estado de São Paulo (Oliveira et al., 1999).

Tomando-se como base a coordenada geográfica 22०37’2.73” S e 47³6’6.74” O descrita em materiais e métodos (item 4.2), o Mapa Pedológico do Estado de São Paulo (Oliveira et al., 1999) e o auxílio do geógrafo Pinheiro o ponto de coleta foi localizado no mapa da FIG. 24. 


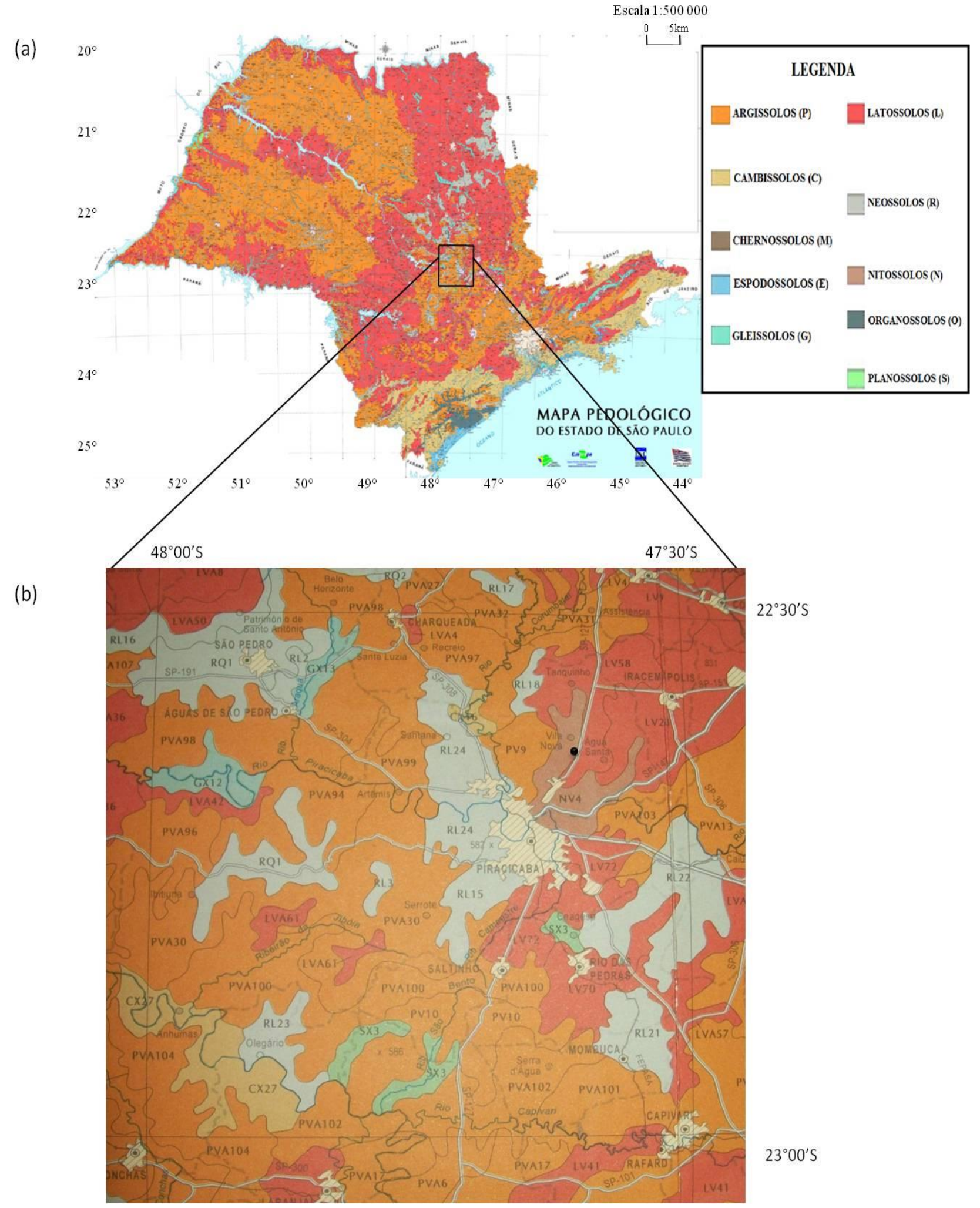

FIGURA 24 - (a) Mapa Pedológico do Estado de São Paulo; (b) Foto da área selecionada no Mapa Pedológico do Estado de São Paulo e localização do ponto de coleta do solo

Fonte - Adaptado de Rossi e Oliveira, 2000; Oliveira et al. 1999. 
Foi observado que neste ponto de coleta (FIG. 24b) o solo está numa área de transição entre duas classes de solo, Latossolo e Nitossolo. Segundo o geógrafo Gildo Pinheiro (comunicação pessoal), o fato do ponto de coleta do solo estar localizado entre duas classes de solo (FIG.24b), o solo coletado deve apresentar características do Latossolo e Nitossolo, pois na natureza não há uma linha que determina o início e o término de uma classe de solo, sendo uma transição gradativa.

Os Nitossolos são frequentemente associados aos Latossolos, pois esses solos têm características em comum (Lepsch, 2002). Os Latossolos são solos bem intemperizados (Ker, 1998; Lepsch, 2002), nos quais quanto menor o $\mathrm{Ki}$, maior o intemperismo do solo. $\mathrm{O} \mathrm{Ki}$ do Nitossolo é maior do que o Ki do Latossolo, devido ao estado de intemperismo menos avançado (Dias et al, 2001).

Dias et al. (2001) estudaram a adsorção de $\mathrm{Cd}$ em dois Latossolos e um Nitossolo em camadas superficiais e subsuperficiais, e os valores de Ki para Nitossolo $(1,42-1,62)$ foram maiores do que para o Latossolo $(0,75-0,79)$.

Considerando o ponto de coleta do solo (FIG.24b) numa área de transição de classes de solo, Latossolo e Nitossolo, e um Ki do solo igual a 0,16 (TAB.15), o solo coletado assemelha-se mais a um Latossolo do que a um Nitossolo, pois o valor de Ki é baixo e isso mostra que é um solo muito intemperizado, como o Latossolo.

\subsubsection{Caracterização química do solo após percolação}

As características químicas $\mathrm{pH}$ e óxidos de $\mathrm{Al}, \mathrm{Fe}$ e Mn foram determinadas no solo após a percolação (solo ap) com a finalidade de avaliar alguma alteração nos valores destas características após período de percolação das colunas de solo.

$\mathrm{O}$ pH foi selecionado para determinação no solo após a percolação por ser uma característica importante na sorção dos elementos nas frações do solo (matéria orgânica, argila e óxidos de $\mathrm{Al}, \mathrm{Fe}$ e $\mathrm{Mn}$ ) como discutido na revisão de literatura, no item 3.2.2. Na TAB. 16 foi apresentado o pH do solo após 168 e 336 dias de percolação das colunas. 
TABELA $16-\mathrm{pH}$ do solo e solo ap

\begin{tabular}{ccccc}
\hline Tempo (dias) & Solo & $\mathbf{p H}_{\mathbf{K C l}}$ & $\mathbf{p H}_{\mathbf{H 2 O}}$ & $\Delta \mathbf{p H}$ \\
\hline 0 & $\mathrm{~S}$ & $5,1 \pm 0,2(\mathrm{n}=6)$ & $6,2 \pm 0,1(\mathrm{n}=2)$ & 1,1 \\
\hline 168 & $\mathrm{CS}(\mathrm{n}=4)$ & 5,0 & $5,9 \pm 0,1$ & 0,9 \\
336 & & $4,9 \pm 0,1$ & $5,9 \pm 0,1$ & 1,0 \\
\hline 168 & $\mathrm{CSC}(\mathrm{n}=4)$ & 5,3 & $6,3 \pm 0,1$ & 0,9 \\
336 & 5,1 & 6,0 & \\
\hline $\mathrm{S}-$ solo; $\mathrm{CS}-$ coluna de solo; $\mathrm{CSC}-$ coluna de solo com cinza; $\mathrm{n}$ - número de amostras.
\end{tabular}

$\mathrm{S}$ - solo; CS - coluna de solo; CSC - coluna de solo com cinza; $\mathrm{n}$ - número de amostras.

Foi observado que não houve diferença representativa no valor do $\mathrm{pH}$ do solo entre os períodos de 168 e 336 dias de percolação (TAB.16), e também não houve diferença entre o solo e solo ap.

$\mathrm{O} \Delta \mathrm{pH}$ foi determinado para avaliar a carga da superfície da partícula coloidal do solo. O valor positivo indica que a carga da superfície é negativa e o valor negativo indica que a carga é positiva (Tan, 1993). O $\Delta \mathrm{pH}$ é calculado pela diferença entre os valores de $\mathrm{pH}$ obtidos em extratos de solo em $\mathrm{KCl}$ e $\mathrm{H}_{2} \mathrm{O}$ conforme a equação 9:

$$
\Delta \mathrm{pH}=\mathrm{pH}_{\mathrm{H} 2 \mathrm{O}}-\mathrm{pH}_{\mathrm{KCl}}
$$

Os valores de $\Delta \mathrm{pH}$ para o solo foram positivos (TAB.16) o que indica a tendência do solo para adsorver cátions como $\mathrm{Cd}, \mathrm{Pb}$ e $\mathrm{Zn}$.

Os óxidos foram determinados no solo após a percolação pelo fato de ter sido observado nos percolados das colunas uma coloração marrom e partículas, que poderiam representar solubilidade ou transporte dos óxidos. Na FIG. 25 foram ilustrados os percolados das CS, que apresentaram uma coloração marrom mais intensa nos tempos iniciais da percolação, tornando-se mais clara ao longo dos 168 dias de percolação. 

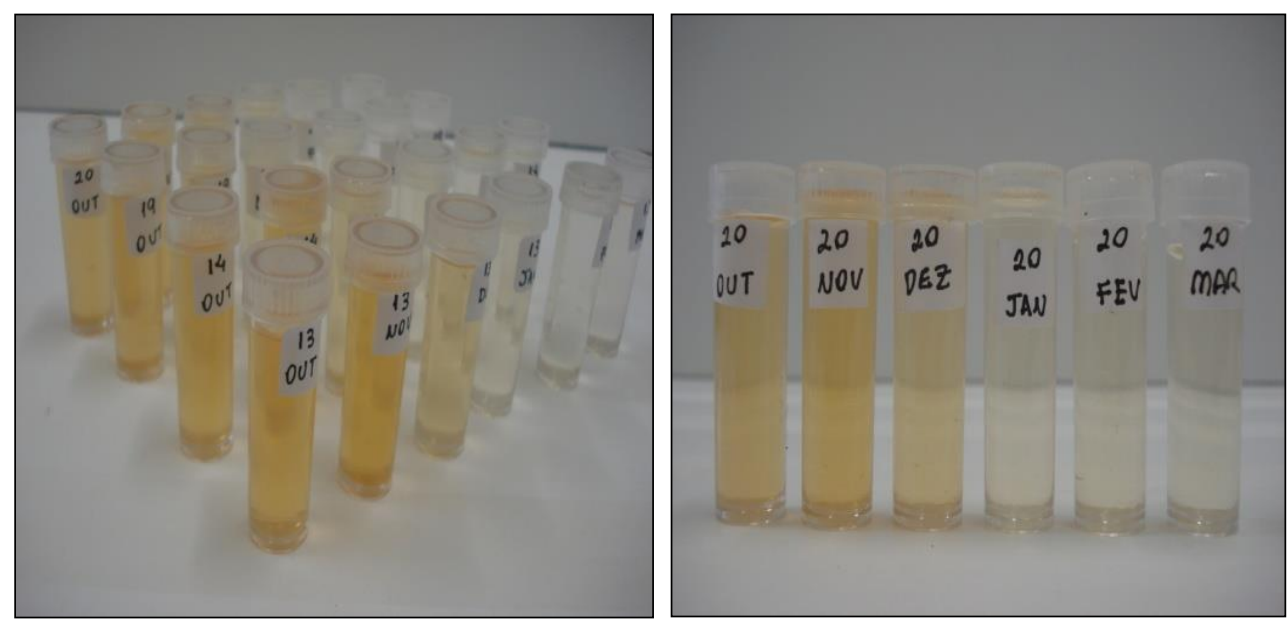

FIGURA 25 - Percolados das colunas de solo ao longo de 168 dias de percolação

Os óxidos são uma característica importante porque estão relacionados com a sorção dos elementos no solo. Na TAB. 17 foram apresentados os valores de óxidos de Al, Fe e Mn no solo e solo ap.

TABELA 17 - Valores de óxidos no solo e solo ap expressos em \%

\begin{tabular}{cccc}
\hline Solo & $\mathbf{A l}_{2} \mathbf{O}_{\mathbf{3}}$ & $\mathbf{F e}_{2} \mathbf{O}_{3}$ & $\mathbf{M n O}$ \\
\hline $\mathrm{S}$ & 18,7 & 7,4 & 0,03 \\
$\mathrm{CS}$ & 17,9 & 7,6 & 0,03 \\
$\mathrm{CSC}$ & 18,6 & 7,7 & 0,03 \\
\hline
\end{tabular}

S - solo, CS - coluna de solo, CSC - coluna de solo com cinza.

Foi observado na TAB. 17 que a porcentagem dos óxidos no solo não foi alterada após a percolação das colunas de solo.

\subsubsection{Caracterização mineralógica do solo}

A composição mineralógica do solo foi determinada por difratometria de raios-X (FIG.26). 

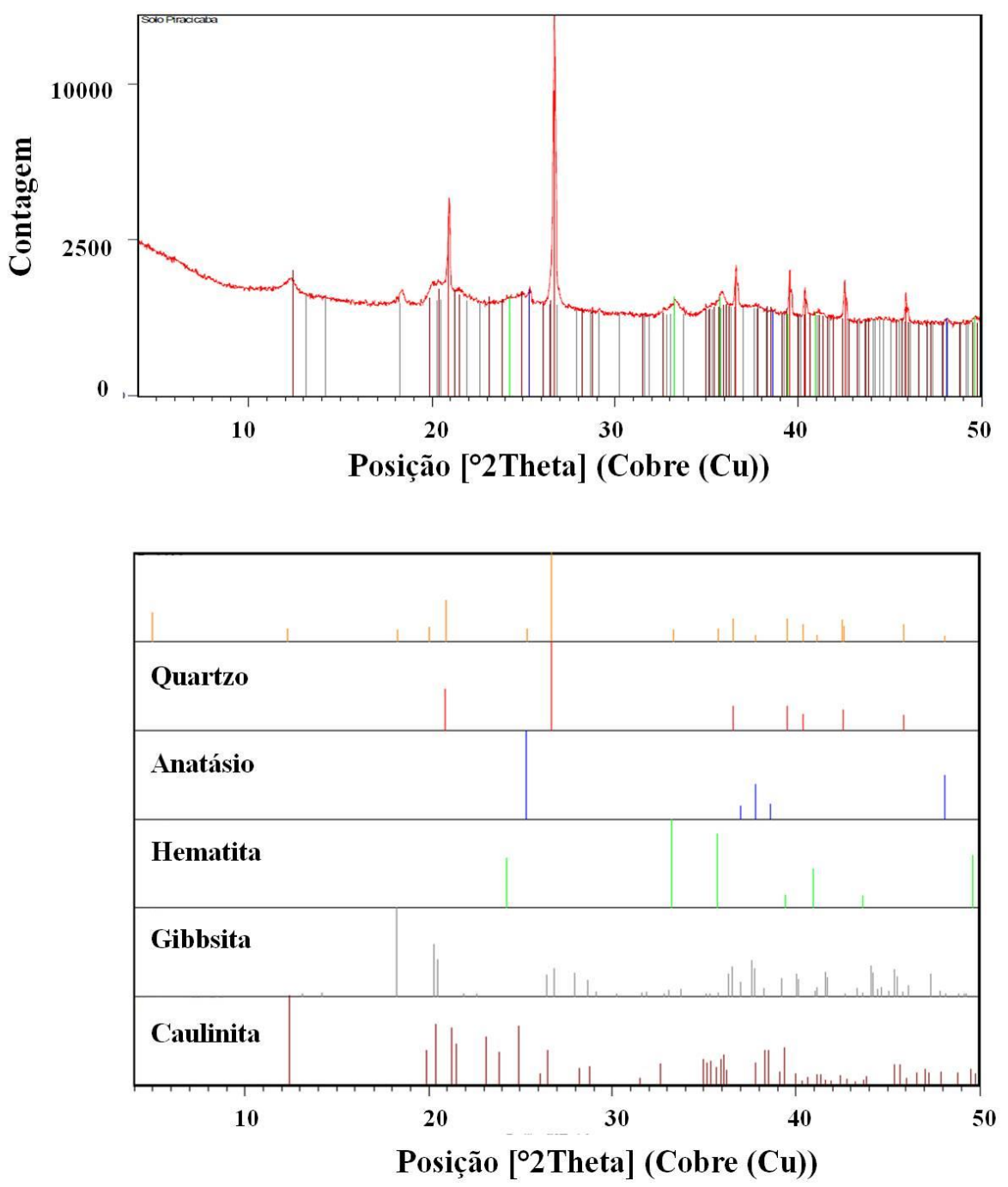

FIGURA 26 - Difratograma do solo obtido no laboratório LCT-POLI-USP

$\mathrm{Na}$ análise da composição mineral do solo foram detectados os minerais anatásio $\left(\mathrm{Ti}_{0,784} \mathrm{O}_{2}\right)$, caulinita $\left(\mathrm{Al}_{2}\left(\mathrm{Si}_{2} \mathrm{O}_{5}\right)(\mathrm{OH})_{4}\right)$, gibbsita $\left(\mathrm{Al}(\mathrm{OH})_{3}\right)$, hematita $\left(\mathrm{Fe}_{2} \mathrm{O}_{3}\right)$ e quartzo $\left(\mathrm{SiO}_{2}\right)$ (FIG.26). No solo foi detectado gibbsita, que está de acordo com os valores de $\mathrm{Ki}$ e $\mathrm{Kr}$ discutidos no item 5.2.2.

\subsubsection{Concentração parcial dos elementos majoritários no extrato do solo obtido por digestão ácida}

A concentração parcial dos elementos majoritários nos extratos do solo foi obtida por digestão ácida descrita em materiais e métodos, item 4.7.4. Na TAB. 18 foi apresentada a concentração dos elementos majoritários. 
TABELA 18 - Concentração dos elementos majoritários no extrato do solo obtido por digestão ácida após 336 dias de percolação

\begin{tabular}{|c|c|c|c|c|c|c|c|c|}
\hline Solo & Al & \multicolumn{7}{|c|}{$\%$} \\
\hline \multicolumn{9}{|l|}{ Solo $(n=2)$} \\
\hline Média & 7,06 & 0,161 & 5,58 & 0,066 & 0,019 & 0,041 & 0,027 & 0,089 \\
\hline Intervalo & $\begin{array}{l}6,78- \\
7,33\end{array}$ & $\begin{array}{c}0,160- \\
0,161\end{array}$ & $\begin{array}{c}5,37- \\
5,78\end{array}$ & $\begin{array}{c}0,060- \\
0,072\end{array}$ & $\begin{array}{c}0,019- \\
0,020\end{array}$ & $\begin{array}{c}0,040- \\
0,042\end{array}$ & $\begin{array}{c}0,026- \\
0,029\end{array}$ & $\begin{array}{r}0,083- \\
0,094\end{array}$ \\
\hline \multicolumn{9}{|l|}{$\mathrm{CS}(\mathrm{n}=8)$} \\
\hline Média & 7,69 & 0,145 & 5,50 & 0,063 & 0,019 & 0,045 & 0,024 & 0,085 \\
\hline Intervalo & $\begin{array}{c}6,79- \\
9,52\end{array}$ & $\begin{array}{c}0,132- \\
0,155\end{array}$ & $\begin{array}{c}5,19- \\
5,83\end{array}$ & $\begin{array}{c}0,053- \\
0,070\end{array}$ & $\begin{array}{c}0,017- \\
0,021\end{array}$ & $\begin{array}{c}0,036- \\
0,050\end{array}$ & $\begin{array}{c}0,018- \\
0,032\end{array}$ & $\begin{array}{c}0,064- \\
0,110\end{array}$ \\
\hline \multicolumn{9}{|l|}{$\operatorname{CSC}(n=8)$} \\
\hline Média & 7,57 & 0,18 & 5,57 & 0,058 & 0,019 & 0,043 & 0,012 & 0,079 \\
\hline Intervalo & $\begin{array}{l}5,63- \\
10,29\end{array}$ & $\begin{array}{c}0,16- \\
0,19\end{array}$ & $\begin{array}{c}5,10- \\
6,12\end{array}$ & $\begin{array}{c}0,048- \\
0,072\end{array}$ & $\begin{array}{c}0,018- \\
0,021\end{array}$ & $\begin{array}{c}0,033- \\
0,052\end{array}$ & $\begin{array}{c}0,008- \\
0,019\end{array}$ & $\begin{array}{r}0,059- \\
0,103\end{array}$ \\
\hline
\end{tabular}

As maiores concentrações de todos os extratos de solo foram para $\mathrm{Al}$ e Fe, e as menores concentrações foram de Mn e Si. Foi observado que os valores médios e os intervalos da concentração dos elementos majoritários $\mathrm{Al}, \mathrm{Fe}, \mathrm{Mg}, \mathrm{Na}$ e K (TAB. 18) do solo e das CS e CSC não apresentaram diferença representativa. A concentração do Ca apresentou um pequeno aumento na CSC quando comparada com a do solo e da CS. Por outro lado, a concentração do Si apresentou uma pequena diminuição na CSC quando comparada com a do solo e da CS.

\subsection{Percolado da coluna}

Nas amostras do percolado das colunas foram determinadas as características químicas, tais como, $\mathrm{pH}$, condutividade elétrica, carbono dissolvido e concentração de elementos majoritários e ânions. A vazão das colunas e o coeficiente de permeabilidade do solo também foram determinados. 


\subsubsection{Características químicas do percolado da coluna}

Na FIG. 27 foi apresentado o pH dos percolados das CS, CSC e CC para os 336 dias de percolação.

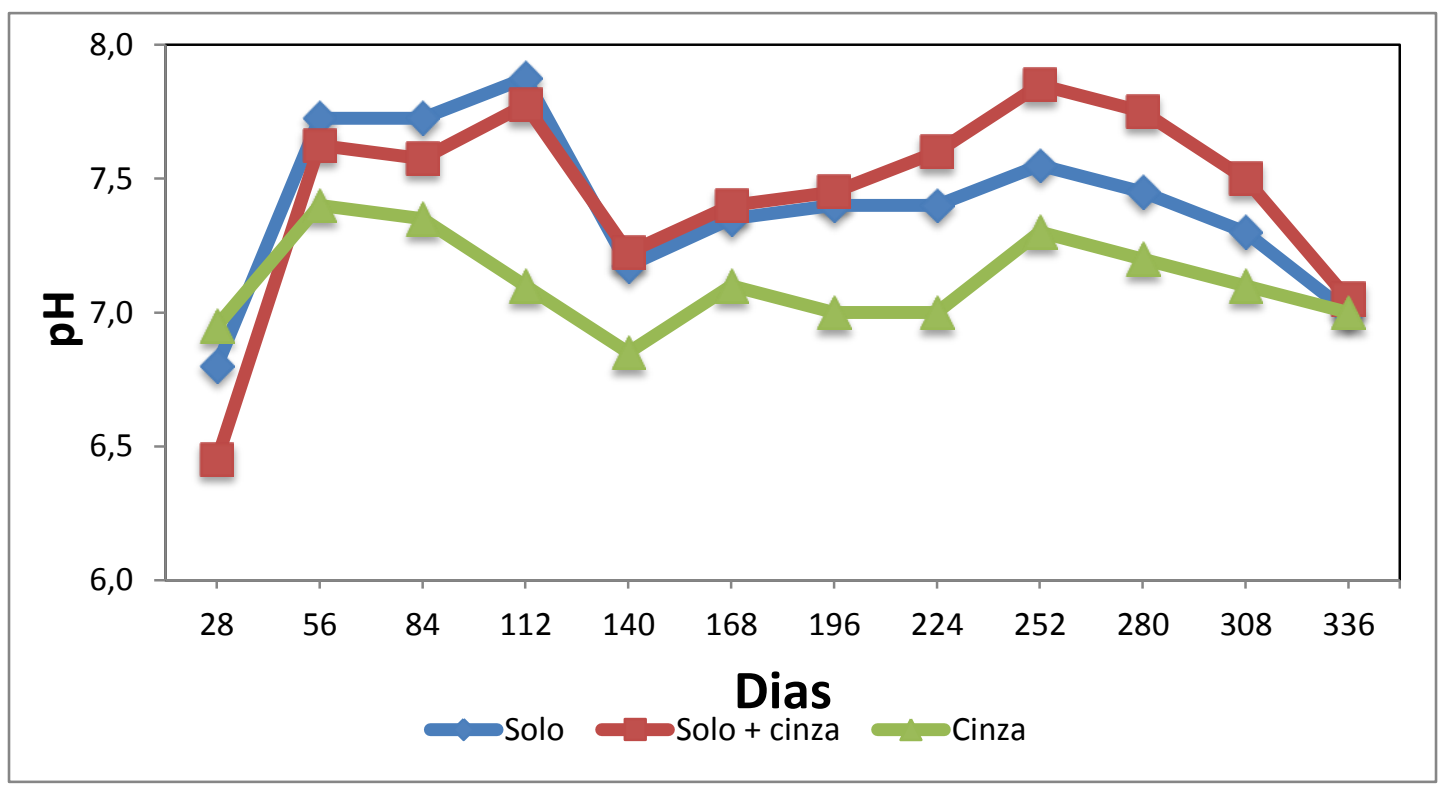

FIGURA 27 - pH dos percolados das colunas ao longo de 336 dias de percolação

Os valores de $\mathrm{pH}$ dos percolados das colunas coletados a cada 28 dias variaram entre 6,5 e 7,9 (FIG.27). Os valores de $\mathrm{pH}$ dos percolados das CC já foram apresentados por Lange (2012), com um valor médio de $\mathrm{pH} 7,1$. Os valores de $\mathrm{pH}$ do percolado das CS e CSC apresentaram média de 7,4 e para alguns percolados das CS o $\mathrm{pH}$ foi ligeiramente maior que os valores do percolado das $\mathrm{CC}$ que apresentou média de 7,1. O valor médio do $\mathrm{pH}$ do percolado das CS e CSC ao longo dos 336 dias de percolação indicou um caráter básico, exceto nos primeiros 28 dias no qual o pH foi ligeiramente ácido (FIG.27).

Na FIG. 28 foi apresentada a condutividade elétrica dos percolados das CS, CSC e CC para os 336 dias de percolação. 


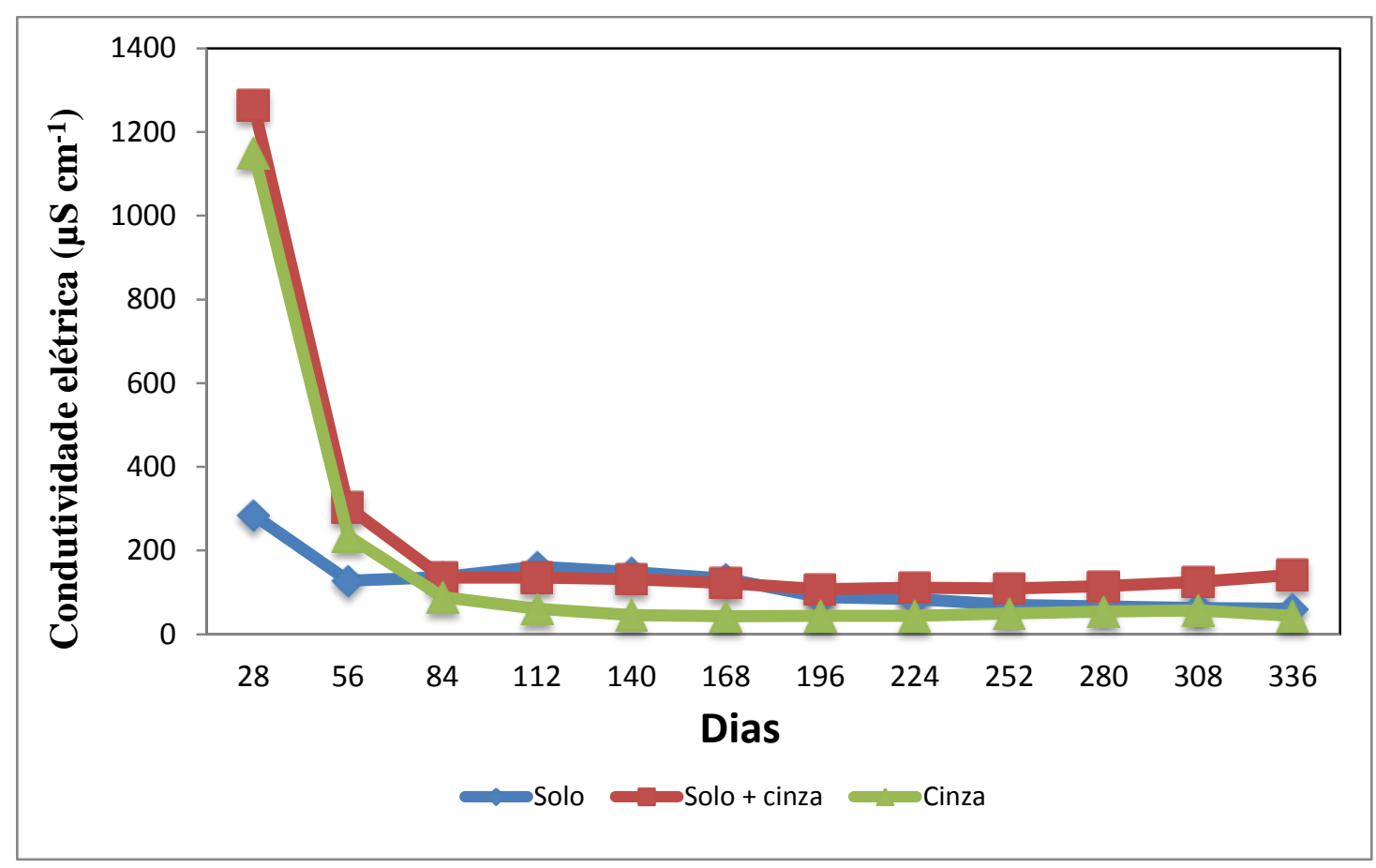

FIGURA 28 - Condutividade elétrica dos percolados das colunas ao longo de 336 dias de percolação

Os valores de condutividade elétrica dos percolados das CC já foram apresentados por Lange (2012). A condutividade elétrica nos percolados das colunas foi maior nos primeiros 28 dias de percolação para todas as colunas, diminuindo e se mantendo relativamente constante ao longo dos outros 336 dias de percolação. Isso indica que há uma maior concentração de íons nos primeiros 28 dias (FIG.28).

Na TAB. 19 foi apresentada a concentração do carbono no percolado das colunas.

TABELA 19 - Concentração de carbono COD, CID e CT no percolado das colunas ao longo de 336 dias

\begin{tabular}{cccc}
\hline $\begin{array}{c}\text { Percolado da } \\
\text { coluna }\end{array}$ & COD & $\begin{array}{c}\text { CID } \\
\mathbf{m g ~ L}^{-1}\end{array}$ & CT \\
\hline $\mathbf{C C}(\mathbf{n = 1 8})$ & $0,9-13,7$ & $1,7-4,4$ & $2,76-18,1$ \\
$\mathbf{C S}(\mathbf{n}=\mathbf{3 6})$ & $3,6-36,5$ & $2,8-16,9$ & $6,8-39,3$ \\
$\mathbf{C S C}(\mathbf{n}=\mathbf{3 6})$ & $3,8-28,0$ & $1,7-12,0$ & $6,5-34,1$ \\
\hline
\end{tabular}

COD - carbono orgânico dissolvido; CID - carbono inorgânico dissolvido; CT - carbono total; CS - coluna de solo; CSC - coluna de solo com cinza; CC- coluna de cinza; $\mathrm{n}$ - número de amostras. 
Os valores de concentração do carbono orgânico, inorgânico e total dos percolados das CC já foram apresentados por Lange (2012). Foi observado que o percolado das CS apresentou mais carbono total do que no percolado das CC, ou seja, a maior parte do carbono total é proveniente do próprio solo. A concentração de carbono orgânico foi maior que a de carbono inorgânico nos percolados de todas as colunas, ou seja, o carbono orgânico foi mais lixiviado da cinza e do solo que o carbono inorgânico.

A concentração dos elementos majoritários foi determinada no percolado das colunas e apresentada na TAB. 20.

TABELA 20 - Concentração dos elementos majoritários no percolado das colunas

\begin{tabular}{|c|c|c|c|c|c|c|c|c|}
\hline $\begin{array}{l}\text { Percolado } \\
\text { da coluna }\end{array}$ & Al & Mn & $\mathrm{Fe}$ & $\begin{array}{l}\text { Na } \\
\quad \text { mg L }\end{array}$ & Mg & $\mathbf{S i}$ & $\mathbf{K}$ & $\mathrm{Ca}$ \\
\hline$C C(n=18)$ & $<0,01-0,03$ & $<0,005-0,1$ & $<0,02$ & $0,2-47,9$ & $0,1-11,9$ & $3,9-7,4$ & $0,1-19,9$ & $5,7-248,0$ \\
\hline $\operatorname{CS}(n=36)$ & $<0,01-6,2$ & $<0,005-0,9$ & $<0,02-3,2$ & $<0,01-1,0$ & $0,9-7,8$ & $3,8-9,7$ & $1,3-12,2$ & $0,5-36,4$ \\
\hline $\operatorname{CSC}(n=36)$ & $<0,01-6,4$ & $<0,005-0,6$ & $<0,02-4,9$ & $0,4-41,6$ & $1,6-40,5$ & $4,1-11,9$ & $1,4-38,4$ & $11,4-194,0$ \\
\hline VI & 0,2 & 0,4 & 0,3 & - & - & - & - & - \\
\hline
\end{tabular}

Entre os elementos majoritários determinados no percolado das colunas, o Ca apresentou a maior concentração (TAB.20), principalmente no percolado das CC, ao passo que $\mathrm{Mn}, \mathrm{Fe}$ e $\mathrm{Al}$ apresentaram as menores concentrações no percolado das colunas. Isso mostra que $\mathrm{Ca}$ foi o elemento mais lixiviado da cinza e do solo e $\mathrm{Mn}, \mathrm{Fe}$ e Al foram os elementos menos lixiviados.

As concentrações dos elementos majoritários Al, Mn e Fe nos percolados da CSC foram comparadas com os valores de intervenção para água subterrânea (CETESB, 2005). Para isso a concentração desses elementos (TAB. 20) foi dividida por 10 que é um fator adotado pela CETESB (2001) para atenuação natural das substâncias no solo. A concentração dos elementos Al e Fe nos percolados das colunas de solo foi maior que o valor de intervenção e a maior parte desta concentração é proveniente do próprio solo. 


\subsubsection{Concentração dos ânions}

A concentração dos ânions no percolado das colunas foi descrita na TAB.

21.

TABELA 21 - Concentração de ânions no percolado das colunas

\begin{tabular}{|c|c|c|c|c|c|c|}
\hline $\begin{array}{l}\text { Percolado da } \\
\text { coluna }\end{array}$ & $\mathbf{F}^{-}$ & \multicolumn{4}{|c|}{$\operatorname{mg~} L^{-1}$} & $\mathrm{SO}_{4}{ }^{2-}$ \\
\hline$C C(n=18)$ & $0,15-1,61$ & $<0,09-1,7$ & $<0,05$ & $<0,1-2,9$ & $<0,15-0,32$ & $7,4-696,6$ \\
\hline $\operatorname{CS}(n=36)$ & $<0,05-2,50$ & $<0,09-4,3$ & $<0,05-1,2$ & $0,08-467,8$ & $<0,15$ & $0,1-16,2$ \\
\hline $\operatorname{CSC}(n=36)$ & $<0,05-0,33$ & $<0,09-3,3$ & $<0,05-1,75$ & $0,4-111,1$ & $<0,15$ & $0,9-759,4$ \\
\hline VMP & 1,5 & 250,0 & 1,0 & 10,0 & - & 250,0 \\
\hline
\end{tabular}

Os ânions que apresentaram maiores concentrações foram o nitrato $\left(\mathrm{NO}_{3}{ }^{-}\right)$ no percolado das CS e CSC e o sulfato $\left(\mathrm{SO}_{4}{ }^{2-}\right)$ no percolado das $\mathrm{CC}$ e CSC (TAB.21). Isso mostra que o nitrato é proveniente do solo e o sulfato da cinza.

A concentração dos ânions obtida nos percolados das CS e CSC (TAB.21) foi comparada com o valor máximo permitido para o consumo humano (VMP) estabelecido pelo Conselho Nacional do Meio Ambiente (CONAMA, 2008). No entanto, esta comparação não pode ser realizada diretamente, pois os ânions podem ser atenuados ao longo do perfil do solo. Então, a concentração dos ânions foi dividida por 10 que é um fator adotado pela CETESB (2001) para atenuação natural das substâncias no solo, e posteriormente foi comparada com o VMP. Apenas o nitrato apresentou concentração acima do VMP $\left(10 \mathrm{mg} \mathrm{L}^{-1}\right)$, ressaltando que o nitrato é proveniente do próprio solo e não da lixiviação da cinza de carvão.

\subsubsection{Vazão da coluna e coeficiente de permeabilidade}

As colunas foram percoladas com a solução simuladora de água de chuva com o volume previamente descrito na TAB. 8, e os volumes percolados das colunas foram apresentados na FIG. 29. 


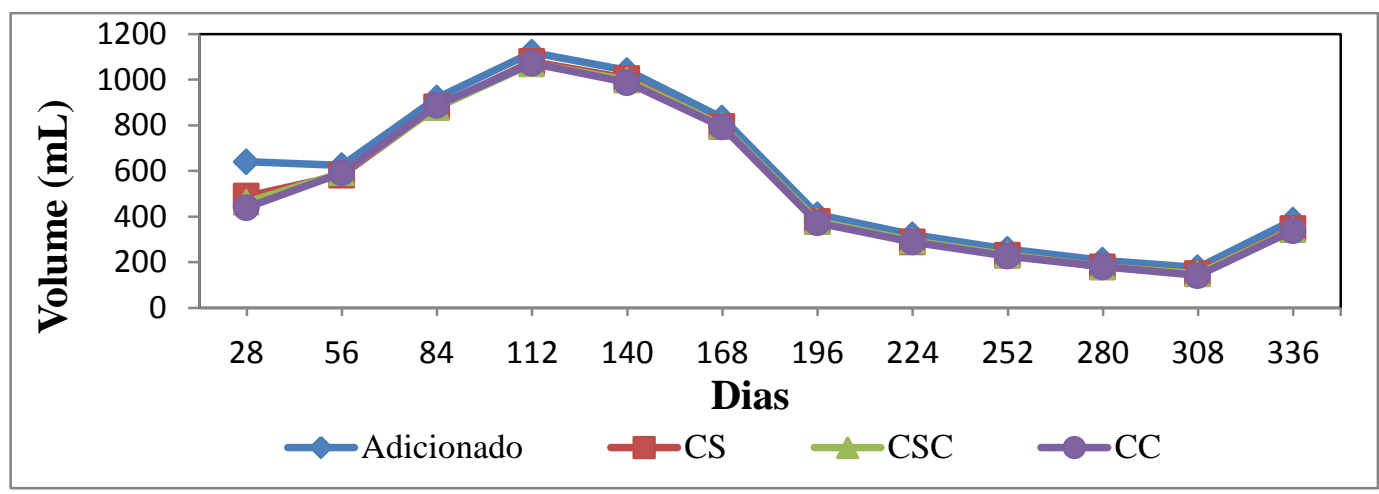

FIGURA 29 - Volume adicionado e percolado nas colunas

Fonte - Fonte de CC Lange (2012)

O volume obtido no percolado de todas as colunas ficou bem próximo do volume adicionado nas colunas com exceção dos primeiros 28 dias (FIG.29).

A vazão das colunas foi calculada e apresentada na FIG. 30.

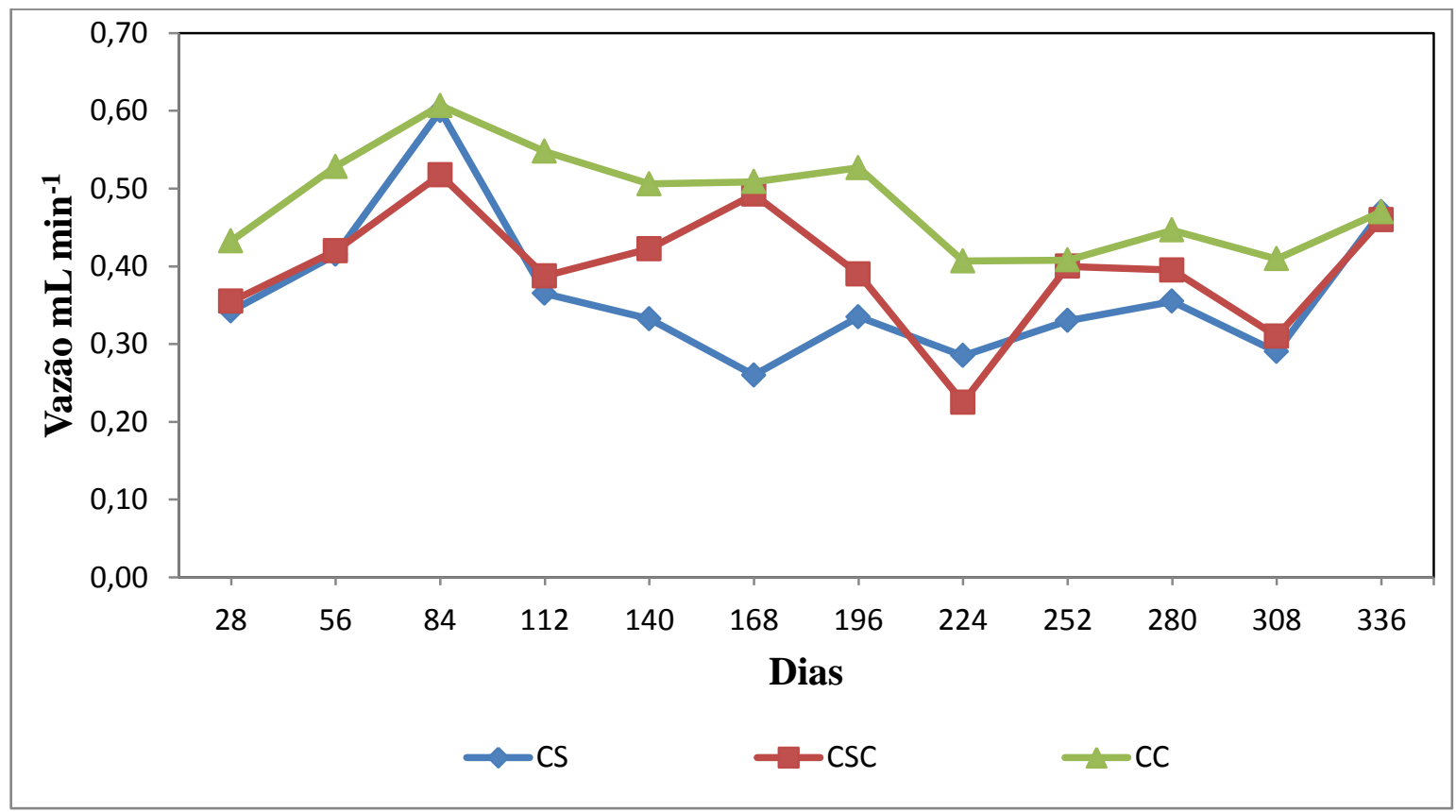

FIGURA 30 - Vazão das colunas para 336 dias

Fonte - Fonte de CC Lange (2012)

A vazão das CC foi a maior conforme foi observado na FIG. 30 e durante o experimento. A vazão das CS e CSC foi menor, a areia inerte das CC é um meio que permite uma maior vazão, e o solo é um meio que permite menor vazão e pelo fato do 
solo ser argiloso fica menor a vazão. Os valores da vazão ficaram entre $0,23 \mathrm{~mL} \mathrm{~min}^{-1}$ (CSC) e $0,61 \mathrm{~mL} \mathrm{~min}^{-1}(\mathrm{CC})$.

Por meio dos valores de vazão das colunas foi calculado o coeficiente de permeabilidade e apresentado na FIG. 31.

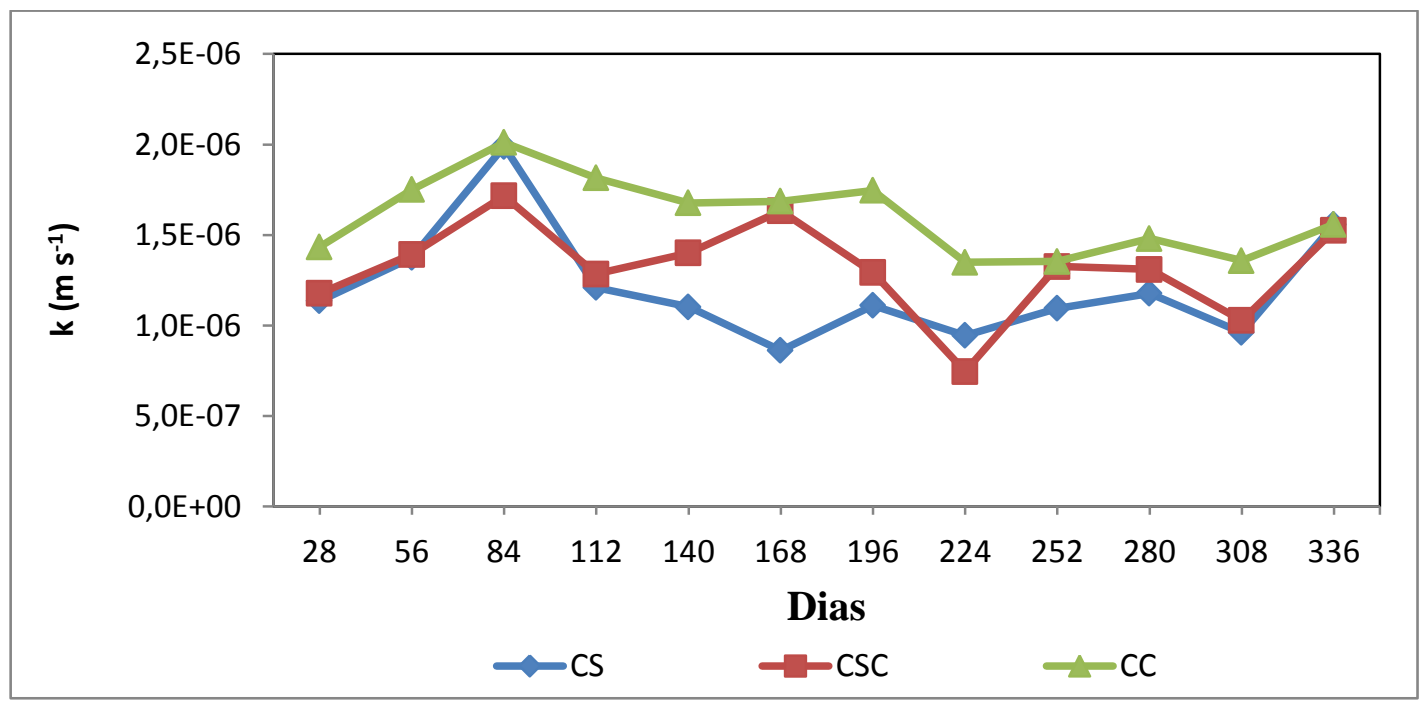

FIGURA 31 - Coeficiente de permeabilidade das colunas para 336 dias Fonte - Fonte de CC Lange (2012)

$\mathrm{O}$ coeficiente de permeabilidade $(\mathrm{k})$ foi maior para as $\mathrm{CC}$ e menor para as CS. Os valores ficaram entre 7,5E-07 $\mathrm{m} \mathrm{s}^{-1}$ (CSC) e 2,0E-06 $\mathrm{m} \mathrm{s}^{-1}$ (CS e CC).

\subsection{Concentração dos elementos tóxicos}

A concentração dos elementos tóxicos foi determinada na cinza de carvão, solo e percolado das colunas.

\subsubsection{Concentração dos elementos tóxicos na cinza de carvão}

A concentração parcial dos elementos tóxicos foi determinada na cinza antes da percolação (denominada de cinza) e após percolação (denominada de cinza ap) das CC e CSC, conforme apresentado na TAB. 22. Os valores de concentração parcial dos elementos na cinza de carvão foram descritos por Lange (2012). 
TABELA 22 - Concentração parcial dos elementos tóxicos no extrato da cinza de carvão obtido por digestão ácida

\begin{tabular}{cccccc} 
& As & Cd & Mo & Pb & Zn \\
& & & & \\
mg kg-1 & & & \\
\hline Cinza (n=2) & & & & & \\
\hline Média & 1635 & 37 & 82 & 154 & 778 \\
Intervalo & $1590-1680$ & $36,6-37,4$ & $80-83$ & $151-157$ & $765-791$ \\
DPR (\%) & 3,9 & 1,5 & 2,3 & 2,8 & 2,4 \\
\hline Cinza ap - 168 dias (n=6) & & & & & \\
\hline Média & 1025 & 21 & 25 & 135 & 538 \\
Intervalo & $944-1110$ & $15-29$ & $22-29$ & $111-162$ & $493-607$ \\
DPR (\%) & 7,1 & 32,5 & 9,8 & 15,4 & 10,4 \\
\hline Cinza ap - 336 dias (n=6) & & & & & \\
\hline Média & 1098 & 27 & 24 & 153 & 523 \\
Intervalo & $1010-1170$ & $26-28$ & $23-26$ & $140-164$ & $492-540$ \\
DPR (\%) & 5,5 & 3,5 & 3,4 & 5,9 & 3,6 \\
\hline DPR - desvio padrão relativo; n - número de amostras & & & &
\end{tabular}

O desvio padrão relativo das amostras de cinza de carvão variou de 1,5 a $15,4 \%$, indicando que a reprodutibilidade do método foi satisfatória. A concentração de Cd na cinza de carvão ap 168 dias apresentou uma variabilidade maior, com DPR $32,5 \%$.

As concentrações dos elementos As e $\mathrm{Zn}$ foram maiores que as concentrações dos outros elementos na cinza (TAB.22) e o Cd apresentou a menor concentração. Isso está coerente com os resultados de Flues et al. (2013) que também determinaram a concentração dos elementos na cinza leve de Figueira.

A concentração média dos elementos foi reduzida da cinza para a cinza ap (TAB.22), indicando que os elementos foram lixiviados da cinza, exceto para o $\mathrm{Pb}$.

Para avaliar se a concentração dos elementos na cinza de carvão ap foi diferente entre os dois períodos de percolação, 168 e 336 dias (TAB.22), foi realizado o teste estatístico de Wilcoxon com um nível de significância 0,05. De acordo com os 
resultados do teste, a concentração dos elementos $\mathrm{As}, \mathrm{Cd}$, Mo, $\mathrm{Pb}$ e $\mathrm{Zn}$ não apresentou diferença nos dois períodos de percolação, ou seja, a lixiviação dos elementos da cinza de carvão ocorreu no primeiro período de percolação (168 dias). Portanto, a concentração média dos elementos foi calculada com base nos valores de concentração obtidos nos dois períodos de percolação.

A razão entre a concentração média da cinza e da cinza ap foi calculada para avaliar a lixiviação de cada elemento na cinza de carvão. Os valores obtidos para a razão da concentração dos elementos foram próximos de 1,0 com exceção do Mo que apresentou valor igual a 3,3 para os 336 dias de percolação, indicando que o Mo foi o elemento mais lixiviado da cinza de carvão. Os valores da razão da concentração dos elementos As, Cd e Zn foram iguais a 1,5 para os 336 dias de percolação. A sequência de lixiviação dos elementos na cinza ap foi $\mathrm{Mo}>\mathrm{As}=\mathrm{Cd}=\mathrm{Zn}$. O Pb apresentou razão igual a 1,1, indicando que esse elemento não foi lixiviado da cinza de carvão e, portanto, o $\mathrm{Pb}$ não contribui para um aumento deste elemento no solo.

\subsubsection{Concentração dos elementos tóxicos no solo}

No solo foram determinadas as concentrações dos elementos tóxicos nos extratos obtidos por digestão ácida e por extrações com EDTA e $\mathrm{Ca}\left(\mathrm{NO}_{3}\right)_{2}$.

\subsubsection{Concentração parcial dos elementos no extrato do solo obtido por digestão ácida}

A concentração parcial dos elementos nos extratos do solo obtidos por digestão ácida foi descrita em materiais e métodos, item 4.7.4. Essa concentração representa os elementos ligados nas frações solúvel, trocável, orgânica e óxidos do solo (TAB.5).

A viabilidade da metodologia adotada para a determinação dos elementos nos extratos do solo foi avaliada pelos extratos dos materiais de referência para solos (NIST-2711 e NIST-2709) obtidos pelo procedimento descrito em materiais e métodos, item 4.7.4. A concentração dos elementos obtida nos extratos destes materiais de referência para solos foi descrita por Lange (2012). A metodologia foi considerada 
satisfatória, pois os valores de concentração dos elementos apresentaram-se dentro ou próximos do intervalo estabelecido para os materiais de referência e com boa reprodutibilidade (desvio padrão relativo entre 0,5 e 9,7\%).

Na TAB. 23 foram apresentados os valores de concentração parcial dos elementos no extrato do solo obtido por digestão ácida.

TABELA 23 - Concentração parcial dos elementos nos extratos do solo e solo ap obtido por digestão ácida

\begin{tabular}{|c|c|c|c|c|c|c|}
\hline \multirow{3}{*}{ Elemento } & & \multirow{3}{*}{ Solo (n=2) } & \multicolumn{4}{|c|}{ Solo ap $\left(\mathrm{mg} \mathrm{kg}^{-1}\right)$} \\
\hline & & & \multicolumn{2}{|c|}{$\operatorname{CS}(n=4)$} & \multicolumn{2}{|c|}{$\operatorname{CSC}(n=4)$} \\
\hline & & & 168 dias & 336 dias & 168 dias & 336 dias \\
\hline \multirow[t]{3}{*}{ As } & Média & $<5$ & $<5$ & $<5$ & $95,0 \pm 1,9$ & $82,0 \pm 9,9$ \\
\hline & Intervalo & - & - & - & $93,0-96,7$ & $73,0-91,0$ \\
\hline & DPR (\%) & - & - & - & 2,0 & 12,0 \\
\hline \multirow[t]{3}{*}{ Cd } & Média & $<1$ & $<1$ & $<1$ & $1,9 \pm 0,1$ & $1,7 \pm 0,2$ \\
\hline & Intervalo & - & - & - & $<1-2,0$ & $1,5-1,9$ \\
\hline & DPR (\%) & - & - & - & 3,0 & 12,3 \\
\hline \multirow[t]{3}{*}{ Mo } & Média & $<20$ & $<20$ & $<20$ & $<20$ & $<20$ \\
\hline & Intervalo & - & - & - & - & - \\
\hline & DPR (\%) & - & - & - & - & - \\
\hline \multirow[t]{3}{*}{$\mathbf{P b}$} & Média & $31,6 \pm 0,3$ & $32,5 \pm 2,7$ & $31,6 \pm 2,4$ & $34,6 \pm 2,2$ & $29,1 \pm 1,6$ \\
\hline & Intervalo & $31,4-31,9$ & $29,8-36,1$ & $29,3-34,2$ & $31,7-37,1$ & $27,6-30,7$ \\
\hline & DPR (\%) & 1,1 & 8,2 & 7,6 & 6,4 & 5,4 \\
\hline \multirow[t]{3}{*}{$\mathbf{Z n}$} & Média & $33,9 \pm 1,6$ & $38,6 \pm 1,0$ & $37,1 \pm 1,7$ & $40,0 \pm 4,8$ & $44,0 \pm 7,6$ \\
\hline & Intervalo & $32,7-35,0$ & $37,5-39,6$ & $35,3-38,6$ & $34,7-45,8$ & $39,9-55,4$ \\
\hline & DPR (\%) & 4,8 & 2,7 & 4,5 & 12,0 & 17,3 \\
\hline
\end{tabular}

O desvio padrão relativo (TAB.23) indicou que houve reprodutibilidade entre as amostras de solo, pois estes valores variaram entre $1,1 \%$ e $17,3 \%$.

$\mathrm{O} \mathrm{Pb}$ e o $\mathrm{Zn}$ foram detectados no solo (TAB.23), ou seja, parte destes elementos são provenientes do próprio solo. A concentração do Zn no solo ap da CSC 
aumentou quando comparada com a do solo e solo ap da CS, mas a maior parte do $\mathrm{Zn}$ provém do próprio solo (TAB.23). Para avaliar estatisticamente a contribuição do Zn lixiviado da cinza de carvão para o solo com base na diferença entre a concentração do Zn no solo da CSC e a concentração no solo e solo ap da CS foi aplicado o teste Wilcoxon com nível de significância 0,05. O resultado mostrou que existe diferença entre as concentrações do $\mathrm{Zn}$ no solo, mostrando que houve uma contribuição deste elemento no solo devido à lixiviação dele na cinza de carvão.

A diferença entre a concentração do $\mathrm{Pb}$ no solo e solo ap (TAB.23) não foi representativa. Para avaliar estatisticamente essa diferença foi utilizado o teste KruskalWallis com nível de significância 0,05 , no qual foi observado que não existe diferença entre a concentração do $\mathrm{Pb}$ no solo e solo ap, ou seja, não houve contribuição do $\mathrm{Pb}$ lixiviado da cinza para o solo. Isso é coerente com o descrito no item 5.5.1 no qual foi discutido que o $\mathrm{Pb}$ não foi lixiviado da cinza de carvão.

Embora o Mo tenha sido lixiviado da cinza de carvão (item 5.5.1), este elemento não apresentou concentrações no solo acima do valor de quantificação do método (TAB.23).

O As e Cd não foram detectados no solo e no solo das CS acima do valor de quantificação do método, mas foram detectados no solo das CSC (TAB.23). Isso mostra que o As e Cd são provenientes da cinza de carvão. A concentração do As no solo da CSC aumentou significativamente quando comparada com a do solo.

Foi observado que a concentração média do As, Cd e Zn no solo das CSC após os dois períodos de percolação, 168 e 336 dias, foi próxima (TAB.23). Para avaliar estatisticamente a diferença da concentração dos elementos As, $\mathrm{Cd}$ e $\mathrm{Zn}$ no solo das CSC após os dois períodos de lixiviação (168 e 336 dias) foi realizado o teste Wilcoxon com nível de significância 0,05 . Os resultados do teste mostraram que as concentrações do $\mathrm{Cd}$ e $\mathrm{Zn}$ nos dois períodos de percolação não são estatisticamente diferentes, ou seja, a retenção dos elementos $\mathrm{Cd}$ e Zn ocorreu no primeiro período de percolação (168 dias). No entanto, a concentração do As no solo ap no período de 168 dias é diferente da concentração deste elemento no período de 336 dias de percolação, sendo a 
concentração do As no solo ap no período de 168 dias maior que no período de 336 dias. Isso indica que o As retido no solo poderia ser lixiviado do solo num período maior de percolação.

A concentração parcial do As e Cd no solo ap das CSC (TAB.23) mostra que estes elementos foram retidos no solo. Conforme descrito na revisão de literatura item 3.2.4, provavelmente o As ficou retido nos óxidos de $\mathrm{Fe}$ e $\mathrm{Al}$, especialmente nos óxidos de $\mathrm{Fe}$, e $\mathrm{Cd}$ pode ter sido retido na argila, $\mathrm{MO}$ e óxidos de $\mathrm{Fe}$ e $\mathrm{Mn}$ e o $\mathrm{pH}$ médio 7,4 do percolado das CSC (FIG. 27) pode ter favorecido a retenção do Cd no solo.

Embora a maior parte do $\mathrm{Zn}$ seja proveniente do próprio solo, houve contribuição deste elemento no solo ap das CSC conforme discutido anteriormente, ou seja, o Zn também ficou retido no solo como o As e o Cd, embora seja um elemento de alta mobilidade em pH menor que 5 (Scokart et al., 1983). Conforme descrito na revisão de literatura item 3.2.4, provavelmente o $\mathrm{Zn}$ ficou retido na $\mathrm{MO}$ e argila e $\mathrm{pH}$ médio 7,4 do percolado das CSC (FIG. 27) pode ter favorecido a retenção do Zn no solo.

Souza et al. (2006) estudaram a adsorção de $\mathrm{Zn}$ em 11 solos do estado da Paraíba com diferentes propriedades físicas e químicas. A CTC foi a propriedade que apresentou melhor correlação (correlação positiva) com a adsorção desse elemento no solo. Considerando que os solos apresentaram CTC entre 137,4 e 198,4 $\mathrm{mmol}_{\mathrm{c}} \mathrm{kg}^{-1}$ e a CTC do solo do presente estudo foi de $163,0 \mathrm{mmol}_{\mathrm{c}} \mathrm{kg}^{-1}$ (TAB.15), essa poderia ser uma das propriedades pelo qual o $\mathrm{Zn}$ foi retido no solo.

\subsubsection{Comparação entre a concentração parcial dos elementos no solo ap e os valores de referência ambiental}

Para comparar a concentração parcial dos elementos As, Cd e Zn no solo ap com os valores orientadores para solos estabelecidos pela CETESB (2005) foi calculada a média das concentrações destes elementos considerando os valores de concentração obtidos nos dois períodos de percolação, 168 e 336 dias (TAB.23). Embora a concentração do As no solo ap após os dois períodos de percolação seja diferente, conforme discutido anteriormente, a média das concentrações deste elemento 
no solo ap, considerando os dois períodos de percolação, também foi calculada, pois a concentração média de As nos dois períodos (TAB.23) foi próxima. Na TAB. 24 foram apresentados os valores de concentração parcial dos elementos e os valores orientadores para solos estabelecidos pela CETESB (2005).

TABELA 24- Concentração parcial dos elementos no extrato do solo ap obtido por digestão ácida e valores orientadores para solos estabelecidos pela CETESB (2005)

\begin{tabular}{|c|c|c|c|c|}
\hline & & \multirow{2}{*}{$\begin{array}{c}\text { Solo } \\
\operatorname{CSC}(n=8)\end{array}$} & \multicolumn{2}{|c|}{ Valores orientadores para solos } \\
\hline & & & Referência & Intervenção* \\
\hline \multicolumn{2}{|l|}{ Elemento } & \multicolumn{3}{|c|}{$\mathrm{mg} \mathrm{kg}^{-1}$} \\
\hline \multirow[t]{2}{*}{ As } & Média & 88,5 & \multirow[b]{2}{*}{3,5} & \multirow[b]{2}{*}{35} \\
\hline & Intervalo & $73,0-96,7$ & & \\
\hline \multirow[t]{2}{*}{ Cd } & Média & 1,8 & \multirow[b]{2}{*}{$<0,5$} & \multirow[b]{2}{*}{3} \\
\hline & Intervalo & $<1-2,0$ & & \\
\hline \multirow[t]{2}{*}{ Mo } & Média & $<20$ & \multirow[t]{2}{*}{$<4$} & \multirow[t]{2}{*}{50} \\
\hline & Intervalo & - & & \\
\hline \multirow[t]{2}{*}{$\mathbf{P b}$} & Média & 31,8 & \multirow[b]{2}{*}{17} & \multirow[b]{2}{*}{180} \\
\hline & Intervalo & $27,6-37,1$ & & \\
\hline \multirow[t]{2}{*}{$\mathbf{Z n}$} & Média & 42,0 & \multirow{2}{*}{60} & \multirow[b]{2}{*}{450} \\
\hline & Intervalo & $34,7-55,4$ & & \\
\hline
\end{tabular}

CSC - coluna de solo com cinza; $\mathrm{n}$ - número de amostras; * valor de intervenção para área agrícola.

O valor de referência é uma concentração do elemento nos solos do estado de São Paulo, determinada por meio de um estudo realizado pela CETESB, para diversos elementos, em que pode se atribuir que o solo está limpo. E o valor de intervenção é uma concentração que acima da qual existe risco potencial à saúde humana (CETESB, 2005).

$\mathrm{O} \mathrm{As}, \mathrm{Cd}$ e $\mathrm{Pb}$ apresentaram concentrações superiores ao valor de referência, com exceção do $\mathrm{Zn}$. Portanto, o $\mathrm{Zn}$ não representa uma preocupação ambiental nas condições do presente estudo. 
Embora a concentração do $\mathrm{Pb}$ tenha sido superior ao valor de referência, o $\mathrm{Pb}$ também não representa uma preocupação ambiental nas condições do presente estudo, sendo que a concentração deste elemento é natural do próprio solo coletado em área com pouca perturbação antropogênica.

O As foi o único elemento que apresentou concentração maior que o valor de intervenção (TAB.24), ou seja, o As representa preocupação ambiental nas condições do estudo.

O Cd apresentou concentração no solo acima do valor de referência e abaixo do valor de intervenção (TAB.24), porém a concentração do $\mathrm{Cd}$ foi próxima ao valor de intervenção. Isso indica que $\mathrm{Cd}$ pode representar uma preocupação ambiental se a proporção cinza:solo $(1: 5,5)$ estabelecida no presente estudo fosse reduzida. Sendo assim, a massa de Cd lixiviado da cinza e introduzida no solo poderia ser maior e consequentemente a concentração do $\mathrm{Cd}$ no solo seria maior também.

O Mo não foi avaliado porque a concentração deste elemento no solo foi abaixo do limite de quantificação do método.

\subsubsection{Concentração biodisponível dos elementos no extrato do solo obtido por extração com EDTA}

A concentração biodisponível dos elementos nos extratos do solo obtidos por extração com EDTA foi descrita em materiais e métodos, item 4.7.4. Essa concentração representa os elementos ligados nas frações solúvel, trocável, orgânica, e parcialmente ligados aos óxidos do solo (TAB.5).

A viabilidade da metodologia adotada para a determinação dos elementos nos extratos do solo foi avaliada pelos extratos do material de referência para solo (BCR 484) obtido pelo procedimento descrito em materiais e métodos, item 4.7.4. A concentração dos elementos obtida nos extratos deste material de referência para solo foi descrita por Lange (2012). A metodologia foi considerada satisfatória para $\mathrm{Cd}$ e $\mathrm{As}$, pois os valores de concentração destes elementos apresentaram-se dentro ou próximo do intervalo estabelecido para o material de referência e com boa reprodutibilidade (desvio 
padrão relativo entre 9,5 e 12,7\%). A metodologia não foi avaliada para o As e Mo, pois o material de referência BCR 484 não apresenta valores de concentração para estes elementos.

Na TAB. 25 foi apresentada a concentração biodisponível do $\mathrm{Zn}$ determinada no extrato do solo ap por extração com EDTA.

TABELA 25 - Concentração biodisponível do Zn no extrato do solo ap obtido por extração com EDTA

\begin{tabular}{cccc}
\hline Elemento & & \multicolumn{2}{c}{ Solo ap $\left(\mathbf{m g ~ k g}^{-\mathbf{1}}\right)$} \\
& & $\mathbf{C S}(\mathbf{n}=\mathbf{4})$ & $\mathbf{C S C}(\mathbf{n = 8})$ \\
\hline Zn & Média & 3,6 & 27,1 \\
& Intervalo & $3,2-4,1$ & $24,1-30,6$ \\
& DPR $(\%)$ & 11,0 & 9,9 \\
\hline CS - coluna de solo; CSC - coluna de solo com cinza; $\mathrm{n}$ - número de amostras.
\end{tabular}

O desvio padrão relativo foi entre 9,9 e $11,0 \%$, indicando uma reprodutibilidade do método satisfatória. O As, Cd e Mo não foram apresentados na TAB. 25 porque a concentração destes elementos foi menor que o limite de quantificação do método, e o $\mathrm{Pb}$ porque é proveniente do próprio solo.

O As e Cd apresentaram concentrações no extrato do solo ap obtido por digestão ácida (TAB.23), no entanto, estes elementos não foram detectados no extrato do solo ap obtido por extração com EDTA (TAB.25). Considerando que a extração com EDTA solubiliza os elementos das frações solúvel, trocável, orgânica e parcialmente da fração óxidos do solo (Alloway, 1990) e a digestão ácida solubiliza os elementos destas frações mais a fração óxidos do solo, poderia-se esperar que As e Cd lixiviados da cinza de carvão ficariam retidos na fração óxidos do solo.

Para o Zn, foi possível calcular a porcentagem de extração deste elemento no solo ap com EDTA em relação à digestão ácida porque a concentração biodisponível (TAB.25) e a concentração parcial (TAB.23) foram medidas. Esta porcentagem de extração foi calculada com base na equação 11 (descrita em materiais métodos, item 4.8.5) e apresentada na TAB.26. 
TABELA 26 - Porcentagem de extração do Zn no solo ap com EDTA em relação à digestão ácida

\section{Zn}

\begin{tabular}{ccc} 
& CS & CSC \\
\hline Digestão ácida $\left(\mathbf{m g ~ k g}^{-1}\right)$ & 37,9 & 42,0 \\
Extração com EDTA $\left(\mathbf{m g ~ k g}^{-1}\right)$ & 3,6 & 27,1 \\
Porcentagem de extração EDTA $(\boldsymbol{\%})$ & 9,5 & 64,6 \\
\hline CS - coluna de solo, CSC - coluna de solo com cinza. &
\end{tabular}

A porcentagem de extração EDTA para o Zn no solo ap da CS, 9,5\%, mostra que o $\mathrm{Zn}$ foi pouco extraído do solo e isso indica que a maior parte do $\mathrm{Zn}$ no solo ap está ligado na fração óxidos ou residual considerando que a digestão ácida é parcial. No entanto, a porcentagem de extração EDTA para o Zn no solo ap da CSC, 64,6\% (TAB.26), mostra que o $\mathrm{Zn}$ foi bem mais extraído do solo ap da CSC que o do solo ap da CS. Isso indica que a maior parte do Zn no solo ap da CSC foi ligado nas frações trocável e orgânica e parcialmente na fração óxidos, e que a cinza de carvão influenciou na extração do Zn no solo com EDTA.

\subsubsection{Concentração trocável dos elementos no extrato do solo obtido por extração com $\mathrm{Ca}\left(\mathrm{NO}_{3}\right)_{2}$}

A concentração trocável dos elementos nos extratos do solo obtidos por extração com $\mathrm{Ca}\left(\mathrm{NO}_{3}\right)_{2}$ foi descrita em materiais e métodos, item 4.7.4. Essa concentração representa os elementos ligados nas frações solúvel e trocável do solo (TAB.5). A concentração trocável do $\mathrm{Zn}$ no extrato do solo ap obtido por extração com $\mathrm{Ca}\left(\mathrm{NO}_{3}\right)_{2}$ foi apresentada na TAB. 27.

TABELA 27 - Concentração trocável do Zn no extrato do solo ap obtido por extração $\operatorname{com~} \mathrm{Ca}\left(\mathrm{NO}_{3}\right)_{2}$

\begin{tabular}{cccc}
\hline \multirow{2}{*}{ Elemento } & & \multicolumn{2}{c}{ Solo ap $\left(\mathbf{m g ~ k g}^{-\mathbf{1}}\right)$} \\
& & $\mathbf{C S}(\mathbf{n}=\mathbf{4})$ & $\mathbf{C S C}(\mathbf{n}=\mathbf{8})$ \\
\hline \multirow{2}{*}{$\mathbf{Z n}$} & Média & 0,76 & 0,54 \\
& Intervalo & $0,46-0,92$ & $0,32-1,18$ \\
& DPR $(\%)$ & 27,4 & 56,9 \\
\hline
\end{tabular}

CS - coluna de solo; CSC - coluna de solo com cinza; $\mathrm{n}$ - número de amostras. 
O método não apresentou uma boa reprodutibilidade, pois, os desvios padrões relativos, $27,4 \%$ e 56,9\% (TAB.27) foram elevados. Isso poderia ser explicado pela baixa concentração do $\mathrm{Zn}$ no extrato do solo obtido por extração com $\mathrm{Ca}\left(\mathrm{NO}_{3}\right)_{2}$.

Os elementos As, Cd e Mo não foram apresentados na TAB. 27, pois não foram detectados no solo acima do limite de quantificação do método, e o Pb por ser proveniente do próprio solo.

As concentrações de Zn no solo ap das CS e CSC (TAB.27) apresentaram intervalos próximos. Isso indica que o Zn lixiviado da cinza de carvão não ficou retido na fração trocável do solo, pois a extração com $\mathrm{Ca}\left(\mathrm{NO}_{3}\right)_{2}$ solubiliza elementos das frações solúvel e trocável do solo.

A porcentagem de extração do $\mathrm{Zn}$ com $\mathrm{Ca}\left(\mathrm{NO}_{3}\right)_{2}$ no solo ap em relação à digestão ácida foi calculada com base na equação 12 descrita em materiais métodos, item 4.8.5. Essa porcentagem de extração foi apresentada na TAB. 28.

TABELA 28 - Porcentagem de extração do $\mathrm{Zn}$ no solo (ap) com $\mathrm{Ca}\left(\mathrm{NO}_{3}\right)_{2}$ em relação à digestão ácida

\begin{tabular}{ccc}
\cline { 2 - 3 } & $\mathbf{Z n}$ & \\
& $\mathbf{C S}$ & $\mathbf{C S C}$ \\
\hline Digestão ácida $\left(\mathbf{m g ~ k g}^{-1}\right)$ & 37,9 & 42,0 \\
Extração com $\mathbf{C a}\left(\mathbf{N O}_{\mathbf{3}}\right)_{\mathbf{2}}\left(\mathbf{m g ~ k g}^{-1}\right)$ & 0,76 & 0,54 \\
Porcentagem de extração $\mathbf{C a}\left(\mathbf{N O}_{\mathbf{3}}\right)_{\mathbf{2}}(\%)$ & 2,0 & 1,3 \\
\hline
\end{tabular}

CS - coluna de solo, CSC - coluna de solo com cinza.

A baixa porcentagem de extração do $\mathrm{Zn}$ com $\mathrm{Ca}\left(\mathrm{NO}_{3}\right)_{2}, 2,0$ para o solo ap da CS e 1,3 para o solo ap da CSC, mostrou que a maior parte do Zn não foi ligado na fração trocável do solo, como foi discutido anteriormente.

Scokart et al. (1983) determinaram a concentração total dos metais $\mathrm{Cd}, \mathrm{Cu}$, $\mathrm{Pb}$ e $\mathrm{Zn}$ com uma mistura de $\mathrm{HCl}$ e $\mathrm{HNO}_{3}$ e a concentração trocável com $\mathrm{NH}_{4} \mathrm{Ac}$ em solos contaminados, com pH entre 3,3 e 4,9 e MO entre 0,5 e 1,8\%. O Cd e o $\mathrm{Zn}$ foram os elementos mais encontrados na fração trocável. 
Kabala e Singh (2001) analisaram quatro solos contaminados, com $\mathrm{pH}_{\mathrm{H} 2 \mathrm{O}}$ entre 5,36 e 8,12, com diferentes texturas e MO entre 0,09 e 2,18\%. Nesses solos foi realizado extração sequencial para os elementos $\mathrm{Cu}, \mathrm{Pb}$ e $\mathrm{Zn}$. Nos solos de estrutura fina os elementos ficaram ligados principalmente na fração residual e em menor quantidade na fração óxidos, e nos solos arenosos os elementos ficaram ligados principalmente à fração residual e orgânica.

\subsubsection{Concentração dos elementos tóxicos no percolado das colunas}

As concentrações dos elementos tóxicos nos percolados das $\mathrm{CC}$ ao longo de 336 dias de percolação foram apresentadas na FIG. 32. Estes valores de concentração dos elementos tóxicos dos percolados das CC já foram apresentados por Lange (2012).

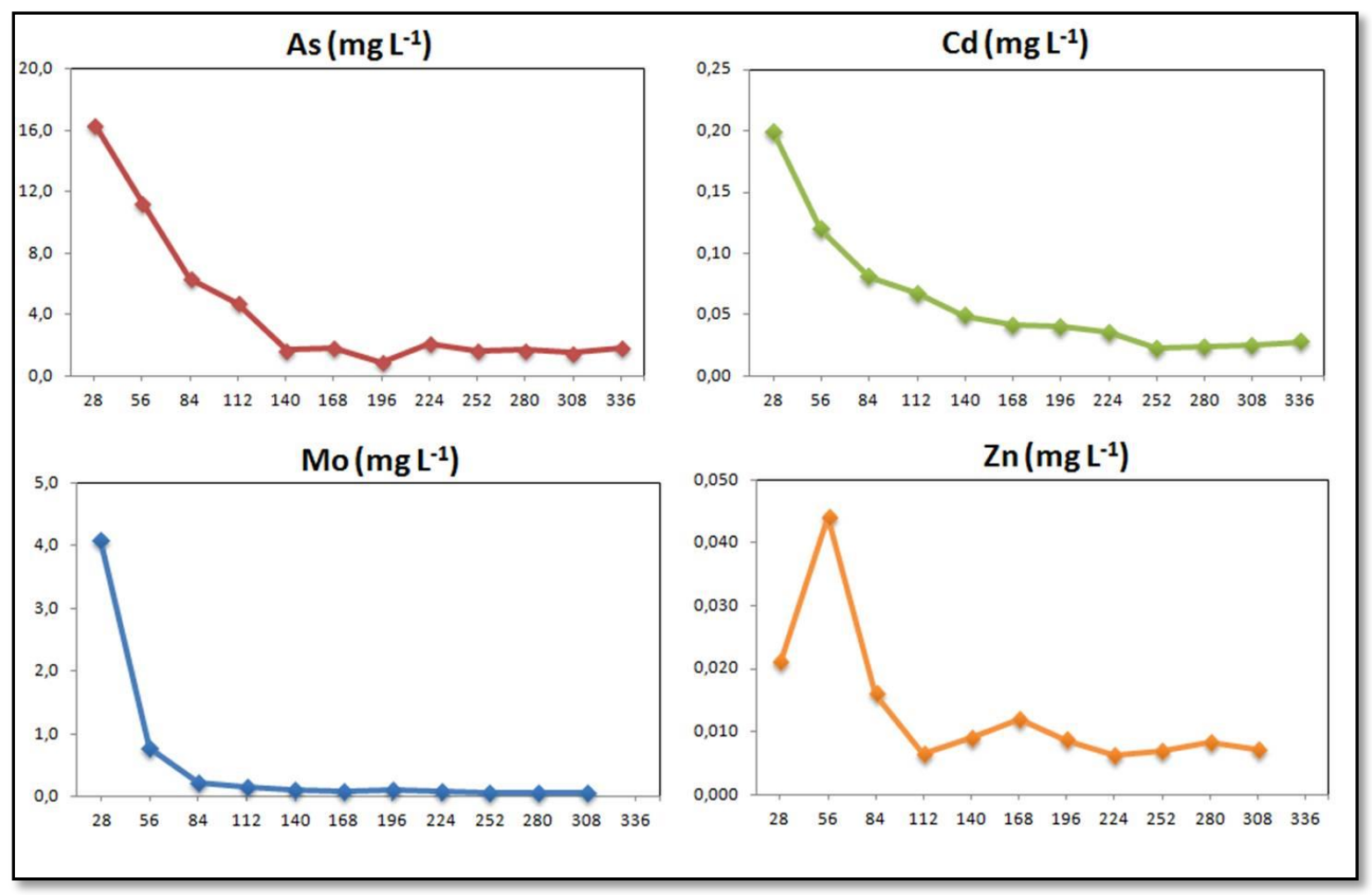

FIGURA 32 - Concentração dos elementos tóxicos $\left(\mathrm{mg} \mathrm{L}^{-1}\right)$ no percolado das colunas de cinza durante 336 dias de percolação

A concentração dos elementos tóxicos no percolado das $\mathrm{CC}$ foi maior nos primeiros dias de percolação (FIG.32) e foi diminuindo ao longo de 336 dias, para concentrações próximas aos limites de quantificação do método. De um modo geral, 
esse comportamento foi similar ao comportamento da curva da condutividade elétrica (FIG.27). A concentração do As e Cd diminuíram gradativamente quando comparada com a do Mo.

$\mathrm{O} \mathrm{Pb}$ não foi detectado no percolado das $\mathrm{CC}$ porque a concentração deste elemento foi abaixo do limite de quantificação do método. Portanto, $\mathrm{o} \mathrm{Pb}$ não foi lixiviado da cinza de carvão como os demais elementos. Isso está coerente com o descrito no item 5.5.1, que o Pb não foi lixiviado da cinza.

No percolado das CS apenas o $\mathrm{Zn}$ foi detectado acima do limite de quantificação do método, mas muito próximo do valor limite $\left(<0,010 \mu \mathrm{g} \mathrm{mL}^{-1}\right)$ e no percolado das CSC somente o $\mathrm{Zn}$ e o As foram detectados acima do limite de quantificação do método, mas também muito próximo do valor limite, no caso do As o limite foi $<0,001 \mathrm{~g} \mathrm{~mL}^{-1}$.

Embora os elementos As, $\mathrm{Cd}$, Mo e $\mathrm{Zn}$ tenham sido quantificados no percolado das CC (FIG.32), Cd e Mo não foram detectados no percolado das CSC, e As e Zn apresentaram concentrações baixas e próximas dos limites de quantificação do método no percolado destas colunas. Isto indica que As, Cd, Mo e $\mathrm{Zn}$ foram retidos pelo solo nas condições deste estudo.

Na FIG. 33 foi apresentado um resumo do comportamento dos elementos nas amostras de cinza de carvão, solo e percolado da coluna no sistema de percolação das colunas. 


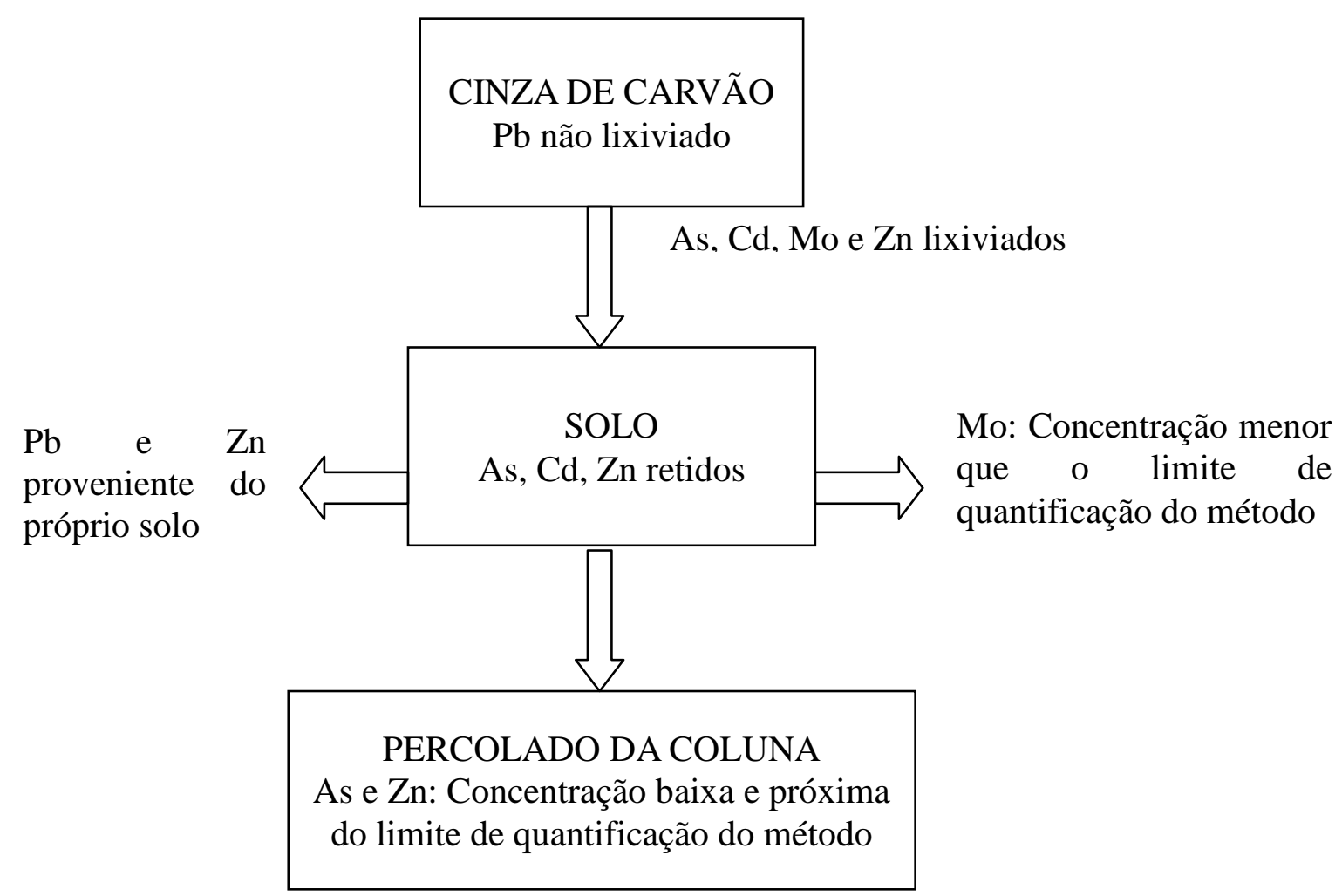

FIGURA 33 - Comportamento dos elementos nas amostras de cinza de carvão, solo e percolado da coluna no sistema de percolação das colunas

\subsection{Tratamento de dados}

Os dados obtidos para as amostras de solo, cinza e percolado das colunas foram utilizados para avaliar o balanço de massa, a lixiviação dos elementos da cinza de carvão, a retenção dos elementos no solo e a determinação do Kp.

\subsubsection{Lixiviação dos elementos da cinza de carvão}

A porcentagem de lixiviação dos elementos na cinza de carvão foi determinada com base nos dois métodos de cálculo da quantidade dos elementos lixiviados da cinza de carvão conforme descrito em materiais e métodos, item 4.8.2.

A porcentagem de lixiviação dos elementos da cinza de carvão com base no método um foi calculada pela equação 5 descrita em materiais e métodos (item 4.8.1), inserindo a média da concentração dos elementos na cinza e a média dos valores de 
concentração dos elementos na cinza ap considerando os dois períodos de percolação das colunas (TAB.22). Na TAB. 29 foi apresentada a porcentagem de lixiviação dos elementos da cinza de carvão com base no método um.

TABELA 29 - Porcentagem de lixiviação dos elementos da cinza de carvão com base no método um

\begin{tabular}{ccccc}
\cline { 2 - 5 } & As & Cd & Mo & Zn \\
\cline { 2 - 5 } & \multicolumn{5}{c}{$\mathbf{~ m g ~ k g ~}^{-1}$} \\
\hline Cinza $(\mathbf{n}=\mathbf{2})$ & 1635 & 37 & 82 & 778 \\
Cinza percolada $(\mathbf{n = 1 2})$ & 1062 & 24 & 25 & 531 \\
\hline Porcentagem de lixiviação (\%) & 35,1 & 35,1 & 70,1 & 31,8 \\
\hline
\end{tabular}

O Mo foi o elemento mais lixiviado da cinza de carvão e a sequência da lixiviação dos elementos foi Mo>Cd As>Zn para 336 dias de percolação das colunas. No trabalho de Lange (2012) a mesma cinza de carvão foi percolada sobre colunas de solo franco arenoso e a sequência e porcentagem de lixiviação foi Mo (65\%)>Cd (47\%)>As (35\%)>Zn (30\%), ou seja, a sequência de lixiviação dos elementos foi a mesma em ambos os trabalhos. $\mathrm{O} \mathrm{Pb}$ não foi considerado nesta sequência, pois este elemento não foi lixiviado da cinza de carvão conforme discutido no item 5.5.1.

A porcentagem de lixiviação dos elementos lixiviados da cinza de carvão com base no método dois foi calculada pela equação 6 descrita em materiais e métodos (item 4.8.1), inserindo a somatória das massas do elemento nos percolados das CC no período de 336 dias de percolação e a massa do elemento na cinza. Na TAB. 30 foi apresentada a porcentagem de lixiviação dos elementos da cinza de carvão com base no método 2 . 
TABELA 30 - Porcentagem de lixiviação dos elementos da cinza de carvão com base no método dois

\begin{tabular}{ccccc}
\cline { 2 - 5 } & As & Cd & Mo & Zn \\
Cinza (n=2) & \multicolumn{2}{c}{$\mathbf{~ m g ~}$} \\
\hline Somatória do percolado & 30,12 & 0,43 & 2,79 & 0,08 \\
\hline Porcentagem de lixiviação (\%) & 36,84 & 22,63 & 68,05 & 0,21 \\
\hline
\end{tabular}

A sequência de lixiviação dos elementos foi $\mathrm{Mo}>\mathrm{As}>\mathrm{Cd}>\mathrm{Zn}$, similar à sequência obtida com base no método um (TAB.29). No entanto, a porcentagem de lixiviação dos elementos da cinza calculada com base nos dois métodos foi próxima (TAB.29 e TAB.30), exceto para o Zn. Essa diferença pode estar relacionada com a formação de um precipitado de Zn que teria ficado retido no papel de filtro adicionado entre a cinza de carvão e o solo ou a areia inerte, como foi discutido por Lange (2012). A lixiviação do elemento da cinza calculada pelo método um considera apenas a cinza do sistema de percolação das CSC ao passo que pelo método dois o sistema de percolação das $\mathrm{CC}$ é considerado como um todo, cinza e percolado da $\mathrm{CC}$, e entre a cinza e o percolado da CC foi adicionado o papel de filtro.

O método dois é o mais adequado, pois leva em consideração o sistema de percolação como um todo, ou seja, considera a quantidade do elemento lixiviado da cinza de carvão, retida no papel de filtro e percolada para o solo.

\subsubsection{Retenção dos elementos no solo}

A porcentagem de retenção dos elementos no solo foi calculada pelas equações 7 e 8 descritas em materiais e métodos (item 4.8.2), inserindo a massa do elemento lixiviado da cinza e a massa do elemento retido no solo ap. Na TAB. 31 foi apresentada a porcentagem de retenção dos elementos no solo. 
TABELA 31 - Porcentagem de retenção dos elementos no solo

\begin{tabular}{ccc}
\multirow{2}{*}{ Método } & \multicolumn{2}{c}{ Porcentagem de retenção no solo (\%) } \\
\cline { 2 - 3 } & As & Cd \\
\hline Um: subtração das massas & 68,2 & 63,0 \\
Dois: somatória das massas & 64,9 & 93,0 \\
\hline
\end{tabular}

A porcentagem de retenção do As no solo ap das CSC foi similar, ao passo que para $\mathrm{Cd}$ foi maior quando calculada pelo método dois do que quando calculada pelo método um. Embora a porcentagem de lixiviação de Cd, 35,1\% (TAB.29), calculada com base no método um, foi considerada próxima da porcentagem de lixiviação 22,63 (TAB.30), calculada pelo método dois, a porcentagem de lixiviação calculada pelo método dois foi um pouco menor. Isso é coerente, pois o método dois considera o sistema de percolação como um todo, ou seja, considera a quantidade de Cd lixiviado da cinza de carvão, retida no papel de filtro e percolada para o solo.

Considerando que o método dois é o mais adequado, conforme já discutido no item 5.5.1, a porcentagem de retenção mostra que boa parte do Cd ficou retida no solo e que este elemento foi mais retido no solo que o As.

A porcentagem de retenção do $\mathrm{Zn}$ no solo ap não foi calculada devido à diferença de porcentagem de lixiviação deste elemento na cinza calculada com base nos métodos um (TAB.29) e dois (TAB.30) descrita no item 5.5.1. A porcentagem de retenção do Mo não foi calculada porque a concentração deste elemento no solo foi menor que o limite de quantificação do método como descrito no item 5.4.2.1. A porcentagem de retenção do $\mathrm{Pb}$ no solo não foi calculada porque o $\mathrm{Pb}$ não foi lixiviado da cinza de carvão como descrito no item 5.4.1.

\subsubsection{Balanço de massa}

O balanço de massa foi realizado para avaliar se a massa do elemento lixiviado da cinza de carvão foi equivalente à somatória da massa do elemento retido no solo mais a massa do elemento no percolado da coluna. 
As massas dos elementos As e Cd lixiviados da cinza de carvão, retidos no solo e no percolado das CSC foram apresentadas na TAB. 32. Estas massas foram calculadas conforme descrito em materiais e métodos, no item 4.8.1. A massa dos elementos lixiviados da cinza de carvão foi calculada pelos dois métodos descritos no item 4.8.1. A massa dos elementos retidos no solo foi calculada pela subtração entre as massas do elemento nas CSC e CS. A massa dos elementos no percolado das CSC correspondente ao período de 336 dias de percolação foi calculada pela somatória das massas do elemento nos percolados gerados a cada 28 dias.

TABELA 32 - Balanço de massa dos elementos

\begin{tabular}{ccc}
\hline Elemento & \multicolumn{2}{c}{ Massa do elemento (mg) } \\
\hline Lixiviado da cinza (método um) & As & Cd \\
Lixiviado da cinza (método dois) & 28,68 & 0,64 \\
Retido no solo & 30,12 & 0,43 \\
Percolado da coluna & 19,55 & 0,40 \\
\hline nd - não determinado & 0,013 & nd \\
\hline
\end{tabular}

A massa do As lixiviado da cinza de carvão não representa a somatória das massas desse elemento no solo e no percolado da coluna. Isso indica que o As lixiviado da cinza que não ficou retido no solo pode ter precipitado e este ficou retido no papel de filtro adicionado na parte inferior da coluna de solo.

$\mathrm{O}$ balanço de massa para o $\mathrm{Cd}$ apresentou valores próximos entre a massa do Cd lixiviado da cinza e a massa do Cd retido no solo, considerando o método dois de cálculo da massa do elemento lixiviado da cinza de carvão. Isso indica que o $\mathrm{Cd}$ lixiviado da cinza de carvão foi retido no solo e não foi lixiviado para o percolado da CSC. No entanto, isso não foi observado quando a massa do elemento lixiviado da cinza de carvão foi calculada pelo método um.

A massa dos elementos Mo e $\mathrm{Pb}$ não foi apresentada na TAB. 32, pois o Mo não foi detectado no solo das CSC acima do limite de quantificação do método e o $\mathrm{Pb}$ não foi lixiviado da cinza de carvão (item 5.4.1). 
Considerando o que foi descrito anteriormente que o método dois é o método mais adequado para o cálculo de balanço de massa (item 5.5.1), os resultados para Cd no balanço de massa (TAB.32) foram satisfatórios nas condições de estudo.

\subsubsection{Determinação do Kp}

O coeficiente de partição, Kp, é a razão entre a concentração do elemento na fase sólida do solo e a concentração do elemento na fase líquida (solução do solo), conforme descrito na revisão da literatura, item 3.2.3.

O Kp foi determinado somente para o $\mathrm{Zn}$, pois foi o elemento que apresentou concentração acima do limite de quantificação nos extratos do solo obtidos por extração com EDTA e $\mathrm{Ca}\left(\mathrm{NO}_{3}\right)_{2}$. O valor de $\mathrm{Kp}$ foi calculado com base nas equações 9 e 10 descritas em materiais e métodos (item 4.8.4), inserindo a concentração parcial do elemento no solo ap (TAB.23) e a concentração biodisponível do elemento no solo ap (TAB.25) ou concentração trocável no solo ap (TAB.27). Na TAB. 33 foram apresentados os valores de Kp para o Zn.

TABELA 33 - Valores calculados de Kp para Zn

\section{$\operatorname{Zn}\left(\mathbf{L ~ k g}^{-1}\right)$}

Solo ap da CS

Solo ap da CSC

\begin{tabular}{ccc}
\hline Kp \\
EDTA & 10,5 & 1,6 \\
$\mathbf{K p}_{\text {Ca(NO3)2 }}$ & 49,8 & 77,8 \\
\hline CS - coluna de solo; CSC - coluna de solo com cinza
\end{tabular}

$\mathrm{O}$ valor de $\mathrm{Kp}_{\mathrm{Ca}(\mathrm{NO} 3) 2}$ foi superior ao valor de $\mathrm{Kp}$ EDTA, apresentando uma razão de 4,7 para o solo ap da CS e 48,6 para o solo ap da CSC. Isso é coerente com o fato de $\mathrm{Ca}\left(\mathrm{NO}_{3}\right)_{2}$ extrair somente elementos da fração trocável do solo ao passo que EDTA extrai elementos das frações trocável, orgânica e parcialmente da fração óxidos (TAB.5). Além disso, conforme discutido nos itens 5.4.2.3 e 5.4.2.4, o Zn provavelmente foi retido nas frações orgânica e óxidos do solo. Portanto, se o $\mathrm{Ca}\left(\mathrm{NO}_{3}\right)_{2}$ extrai menos $\mathrm{Zn}$ que o EDTA, então, o $\mathrm{Kp}_{\mathrm{Ca}(\mathrm{NO} 3) 2}$ será maior que o $\mathrm{Kp}$ EDTA. 
Os valores de $\mathrm{Kp}$ Ca(NO3)2 para os solos ap das CS e CSC foram próximos apresentando uma razão entre eles de 1,6. Por outro lado, o valor de $\mathrm{Kp}$ EDTA para o solo ap da CS foi maior que o valor para o solo ap da CSC (TAB.33), apresentando uma razão entre eles de 6,6. Isso indica que a cinza de carvão diminui a capacidade de retenção do Zn no solo.

\subsection{Comparação entre os dados dos solos argiloso e franco arenoso}

Os ensaios de colunas do solo argiloso de Piracicaba deste presente estudo foram realizados em paralelo com os ensaios de colunas do solo franco arenoso coletado entre Conchal e Araras descritos por Lange (2012). Ambos os estudos tem como objetivo avaliar a mobilidade dos elementos $\mathrm{As}, \mathrm{Cd}, \mathrm{Mo}, \mathrm{Pb}$ e $\mathrm{Zn}$ no solo, mas cada solo apresenta características físicas e químicas diferentes. Estes estudos fazem parte de um projeto financiado pela FAPESP como foi descrito em materiais e métodos (item 4).

Na FIG. 34 foram apresentadas fotos das amostras dos solos argiloso e franco arenoso com estrutura não deformada.

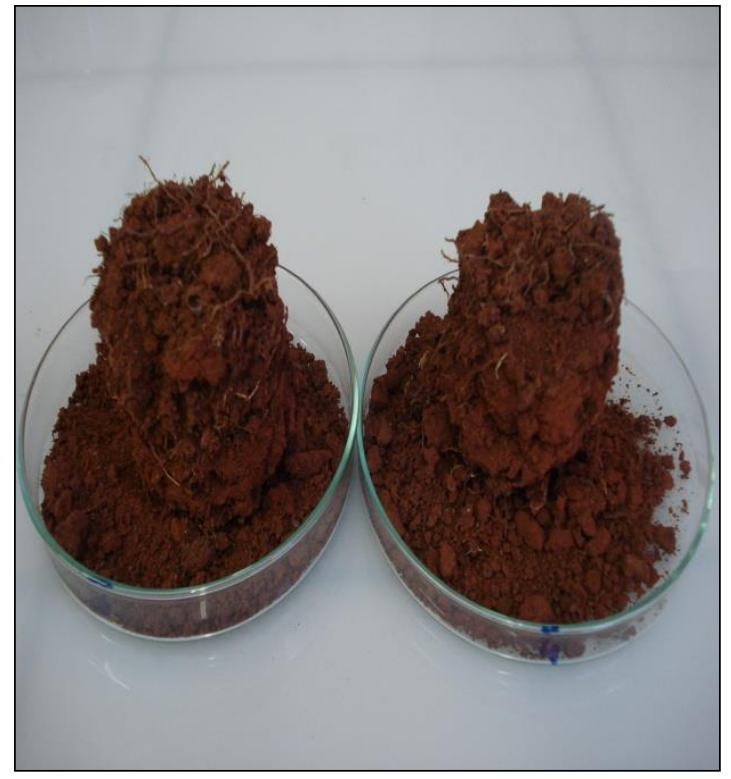

(a)

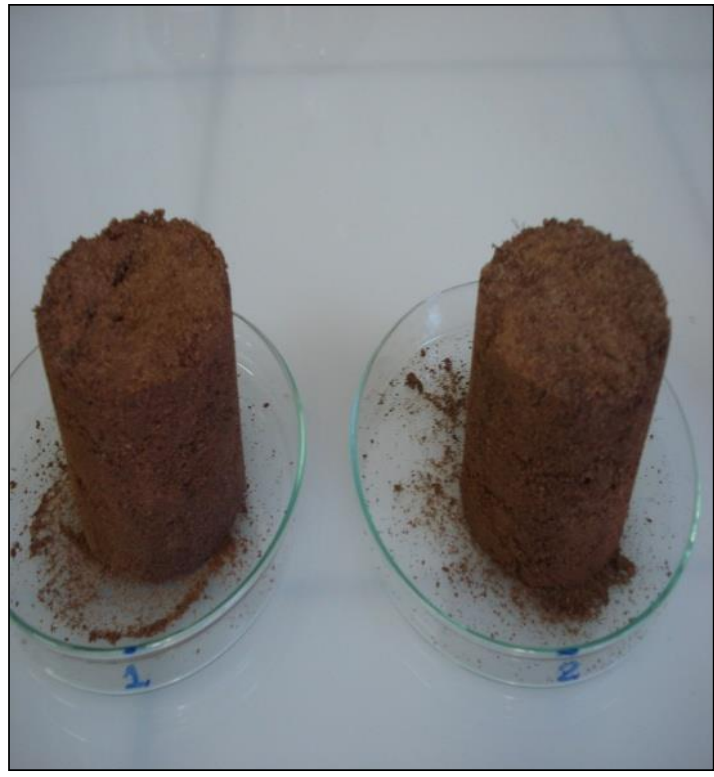

(b)

FIGURA 34 - Amostras dos solos com estrutura não deformada (a) Solo argiloso; (b)

Solo franco arenoso 
O solo argiloso é um solo de cor mais avermelhada do que o solo franco arenoso, apresentando mais raízes de plantas e agregados maiores das partículas do solo (FIG.34).

As principais características físicas e químicas dos solos argiloso e franco arenoso foram descritas na TAB. 34.

TABELA 34 - Características físicas e químicas dos solos argiloso e franco arenoso

\begin{tabular}{ccc}
\hline Características & Solo argiloso & Solo franco arenoso* \\
\hline Areia (\%) & 35 & 80 \\
Argila (\%) & 56 & 18 \\
Silte (\%) & 9 & 2 \\
$\mathrm{MO}(\%)$ & 8,0 & 2,66 \\
$\mathrm{CTC}\left(\mathrm{mmolc} \mathrm{kg}^{-1}\right)$ & 163,0 & 72,0 \\
$\mathrm{pH} \mathrm{KCl}$ & 5,1 & 3,7 \\
$\mathrm{pH} \mathrm{H}$ & 6,2 & 4,8 \\
$\mathrm{Al}_{2} \mathrm{O}_{3}(\%)$ & 18,7 & 5,9 \\
$\mathrm{Fe}_{2} \mathrm{O}_{3}(\%)$ & 7,4 & 1,6 \\
$\mathrm{MnO}_{2}(\%)$ & 0,03 & $<0,0065$ \\
\hline MO - matéria orrânica; CTC - capacidade de troca catiônica. & &
\end{tabular}

Fonte* - Lange, 2012

O solo argiloso apresentou $56 \%$ de argila e o solo franco arenoso apresentou $80 \%$ de areia e $18 \%$ de argila (TAB.34). A quantidade de óxidos de $\mathrm{Al}, \mathrm{Fe}$ e $\mathrm{Mn}$ presente no solo argiloso (TAB.34) foi maior que a do solo franco arenoso, apresentando uma razão de 3,2 para o $\mathrm{Al}_{2} \mathrm{O}_{3}$ e 4,6 para o $\mathrm{Fe}_{2} \mathrm{O}_{3}$. A quantidade de $\mathrm{MO}$ presente no solo argiloso (TAB.34) foi três vezes maior que a do solo franco arenoso. A CTC do solo argiloso (TAB.34) também foi maior que a do solo franco arenoso, apresentando uma razão de 2,3. Além disso, o pH do solo franco arenoso é mais ácido que o do solo argiloso. As características de ambos os solos indicam que o solo argiloso tem uma capacidade de retenção dos elementos maior que a do solo franco arenoso.

A concentração dos elementos retidos no solo das colunas de solo com cinza foi apresentada na TAB. 35 para avaliar a retenção dos elementos de ambos os solos. 
TABELA 35 - Concentração dos elementos nos solos argiloso e franco arenoso após o período de 336 dias de percolação das colunas

\begin{tabular}{ccccc}
\hline \multicolumn{5}{c}{ Concentração $\left(\mathbf{m g ~ k g}^{-1}\right)$} \\
\hline \multirow{2}{*}{ Elemento } & \multicolumn{2}{c}{ Solo argiloso } & \multicolumn{2}{c}{ Solo franco arenoso } \\
& Solo & Solo ap da CSC & Solo & Solo ap da CSC \\
\hline As & $<5(\mathrm{n}=2)$ & $88,5(\mathrm{n}=8)$ & $<5(\mathrm{n}=2)$ & $60,5(\mathrm{n}=8)$ \\
$\mathrm{Cd}$ & $<1(\mathrm{n}=2)$ & $1,8(\mathrm{n}=8)$ & $<1(\mathrm{n}=2)$ & $1,2(\mathrm{n}=8)$ \\
$\mathrm{Zn}$ & $33,9(\mathrm{n}=2)$ & $42(\mathrm{n}=8)$ & $5,4(\mathrm{n}=2)$ & $8,5(\mathrm{n}=8)$ \\
\hline
\end{tabular}

CSC - coluna de solo com cinza de carvão.

*Fonte - Lange 2012

O solo argiloso apresentou maiores concentrações de $\mathrm{Zn}$ que as do solo franco arenoso, sendo a maior parte proveniente do próprio solo. Ambos os solos não apresentaram concentrações naturais de As e Cd e a concentração destes elementos após a percolação das colunas foi maior no solo argiloso. $\mathrm{O}$ Mo e o $\mathrm{Pb}$ não foram apresentados na TAB. 35 porque a concentração do Mo nos solos foi menor que o limite de quantificação do método e o $\mathrm{Pb}$ não foi lixiviado da cinza de carvão conforme descrito no item 5.5.1

A porcentagem de retenção dos elementos nos diferentes solos (TAB.36) foi calculada com base na equação 8 descrita em materiais e métodos, item 4.8.2.

TABELA 36 - Retenção dos elementos no solo argiloso e franco arenoso

\begin{tabular}{lccccc}
\cline { 2 - 5 } & \multicolumn{2}{c}{ Solo argiloso } & \multicolumn{2}{c}{ Solo franco } \\
\hline \multirow{2}{*}{ \% retenção no solo } & As & Cd & As & Cd \\
& 64,9 & 93 & 58 & 81 \\
\hline
\end{tabular}

A retenção de As e Cd no solo argiloso foi maior que a no solo franco arenoso (TAB.36), possivelmente devido a maior porcentagem de óxidos de $\mathrm{Fe}, \mathrm{Al}$ e Mn, matéria orgânica e argila no solo argiloso (TAB.34).

Uma das características que poderia ter favorecido uma maior retenção do Cd no solo argiloso $\left(\mathrm{pH}_{\mathrm{KCl}} 5,1\right)$ em relação ao solo franco arenoso $\left(\mathrm{pH}_{\mathrm{KCl}} 3,7\right)$ é o $\mathrm{pH}$, 
pois com base no estudo de Pierangeli et al. (2005) descrito na revisão de literatura item 3.2.4, a adsorção do Cd em Latossolos de $\mathrm{pH}$ 6,5 foi maior que de $\mathrm{pH}$ 4,5. 


\section{CONCLUSÕES}

- A concentração dos elementos As e Zn na cinza de carvão foi maior que a do $\mathrm{Cd}$, Mo e Pb.

- Os elementos As, Cd, Mo e Zn foram lixiviados da cinza de carvão e, embora a concentração do As e $\mathrm{Zn}$ tenha sido maior que a do Mo, este elemento foi o mais lixiviado.

- $\mathrm{O} \mathrm{Pb}$ não foi lixiviado da cinza de carvão.

- A concentração dos elementos $\mathrm{As}, \mathrm{Cd}, \mathrm{Mo}, \mathrm{Pb}$ e $\mathrm{Zn}$ na cinza ap não apresenta diferença nos dois períodos de percolação, ou seja, a lixiviação dos elementos da cinza ocorre no primeiro período de percolação (168 dias).

- Os elementos As, $\mathrm{Cd}$, e $\mathrm{Zn}$ lixiviados da cinza de carvão ficaram retidos no solo.

- Embora o Mo tenha sido lixiviado da cinza de carvão, este elemento não foi detectado no solo ap e no percolado das colunas de solo, pois o Mo não apresentou concentração nestas amostras acima do valor de quantificação do método.

- $\mathrm{O} \mathrm{Pb}$ detectado no solo foi proveniente do próprio solo.

- A maior parte do Zn detectado no solo é proveniente do próprio solo.

- O As apresentou concentração no solo acima do valor de intervenção, sendo o único elemento crítico do ponto de vista ambiental.

- O Zn no solo ap das colunas CSC foi provavelmente mais ligado nas frações orgânica e parcialmente na fração óxidos do solo e o Zn no solo das colunas CS na fração óxidos e residual.

- A retenção do As e Cd no solo argiloso foi um pouco maior que a do solo franco arenoso. 


\section{REFERÊNCIAS BIBLIOGRÁFICAS}

ADHIKARI, T.; SINGH, M. V. Remediation of cadmium pollution in soils by different amendments: A column study. Comunications in soil science and plant analysis, v. 39, n. 3-4, p. 386-396, 2008.

AGÊNCIA EMBRAPA DE INFORMAÇÃO TECNOLÓGICA - AGEITEC. Disponível em: <http://www.agencia.cnptia.embrapa.br/>. Acesso em: 29 nov. 2012.

AGÊNCIA NACIONAL DE ENERGIA ELÉTRICA - ANEEL. Banco de Informações de Geração. Disponível em: <htttp:// www.aneel.gov.br/15.htm/>. Acesso em: 18 out. 2011.

AGOURAKIS, D. C.; CAMARGO, I. M. C.; COTRIM, M. B.; FLUES, M. Comportamento de zinco e manganês de pilhas alcalinas em uma coluna de solo. Química Nova, v. 29, n. 5, p. 960-964, 2006.

ALLOWAY, B. J. Heavy metals in soils. 1.ed. New York: John Wiley \& Sons, 1990.

ALMEIDA, T. L. Implicações ambientais dos processos de atenuação de lixiviado em locais de disposição de resíduos sólidos urbanos. 2009. Tese (Doutorado). Escola de Engenharia de São Carlos - USP, São Carlos, São Paulo.

AMARAL SOBRINHO, N. M. B.; VELLOSO, A. C. X.; COSTA, L. M.; OLIVEIRA, C. Mobilidade de metais pesados em solo tratado com resíduo siderúrgico ácido. Revista Brasileira de Ciência do Solo, v. 22, n. 2, p. 345-353, 1998.

ANTONIADIS, V.; ALLOWAY B. J. Leaching of cadmium, nickel, and zinc down the profile of sewage sludge-treated soil. Communications in Soil Science and Plant Analysis, v. 33, n. 1-2, p. 273-286, 2002.

ARAÚJO, A. R.; CARVAlHO, J. L.N.; GUILHERME, L. R. G.; CURI, N.; MARQUES, J. J. Movimentação de nitrato e amônio em colunas de solo. Ciência e Agrotecnologia, v. 28, n. 3, p. 537-541, 2004.

AREDES, S.; KLEIN, B.; PAWLIK, M. The removal of arsenic from water using natural iron oxide minerals. Journal of Cleaner Production, v. 29-30, p. 208-213, 2012.

ASHWORTH, D. J.; ALLOWAY, B. J. Soil mobility of sewage sludge-derived dissolved organic matter, copper, nickel and zinc. Environmental Pollution, v. 127, p. 137-144, 2004.

ASSIS, I. R. Adsorção e disponibilidade de As em solos com diferentes composições mineralógicas. 2010. Tese (Doutorado) - Universidade Federal de Viçosa, Minas Gerais. 
ASSOCIAÇÃO BRASILEIRA DE NORMAS TÉCNICAS. Rochas e solos. Rio de Janeiro: ABNT, 1995. (NBR 6502).

ASSOCIAÇÃO BRASILEIRA DE NORMAS TÉCNICAS. Solo - Determinação do teor de matéria orgânica por queima a 440 ${ }^{\circ}$. . Rio de Janeiro: ABNT, 1996. (NBR 13600).

BEESLEY, L.; MORENO-JIMÉNEZ, E.; CLEMENTE, R.; LEPP, N.; DICKINSON, N. Mobility of arsenic, cadmium and zinc in a multi-element contaminated soil profile assessed by in-situ soil pore water sampling, column leaching and sequencial extraction. Environmental Pollution, v. 158, p. 155-160, 2010.

BIASIOLI, M.; FABIETTI, G.; BARBERIS, R.; AJMONE-MARSAN, F. An appraisal of soil diffuse contamination in an industrial district in northern Italy. Chemosphere, v. 88, n. 10, p. 1241-1249, 2012.

BRASIL - MINISTÉRIO DE MINAS E ENERGIA. Matriz Energética Nacional 2030. Colaboração Empresa de Pesquisa Energética. Brasília: MME: EPE, 2007.

BRADY, N. C. Natureza e propriedades dos solos. 7.ed. Rio de Janeiro: Freitas Bastos, 1989.

BRAZ, A. M. S. Coeficiente de distribuição de metais pesados em solos paraenses. 2011. Dissertação (Mestrado) - Escola Superior de Agricultura "Luiz de Queiroz", São Paulo.

CAMARGO, I. M. C. Estudo da influência do coeficiente de partição de metais no solo de Figueira, Paraná, no cálculo do risco à saúde humana, utilizando o modelo C-Soil. 2005. Tese (Doutorado) - Instituto de Pesquisas Energéticas e Nucleares, São Paulo.

CAMARGO, I. M. C.; HIROMOTO, G.; FLUES, M. Heavy metal partition in acid soils contaminated by coal power plant. Journal of the Brazilian Chemical Society, v. 18, n. 4, p. 831-837, 2007.

CAMARGO, O.A.; MONIZ, A.C.; JORGE, J.A.; VALADARES, J.M.A.S. Métodos de Analise Química, Mineralógica e Física de Solos do Instituto Agronômico de Campinas. Campinas, Instituto Agronômico, 2009. 77 p. (Boletim técnico, 106, Edição revista e atualizada).

CAMOBRECO, V. J.; RICHARDS, B. K.; STEENHUIS, T. S.; PEVERLY, J. H.; McBRIDE, M. B. Movement of heavy metals through undisturbed and homogenized soil columns. Soil Science, v. 161, p.740-750, 1996.

CAMPOS, M. L.; GUILHERME, L. R. G.; LOPES, R. S.; ANTUNES, A. S.; GRANATE DE SÁ; J. J.; CURI, N. Teor e capacidade máxima de adsorção de arsênio 
em Latossolos brasileiros. Revista Brasileira de Ciência do Solo, v. 31, n. 6, p. 13111318, 2007.

CARBONÍFERA DO CAMBUÍ. Disponível em: http://www.carboniferadocambui.com.br/modules/mastop_publish/?tac=A_Empresa/.

Acesso em: 18 out. 2011.

CAVALLARO, N.; McBRIDE, M. B. Copper and cadmium adsorption characteristics of selected acid and calcareous soils. Soil Science Society of America Journal, v. 42, n. 4, p. 550-556, 1978.

CERQUEIRA, B.; COVELO, E. F.; ANDRADE, L.; VEGA, F. A. The influence of soil properties on the individual and competitive sorption and desorption of $\mathrm{Cu}$ and $\mathrm{Cd}$. Geoderma, v. 162, p. 20-26, 2011.

CHATURVEDI, P. K.; SETH, C. S.; MISRA, V. Selectivity sequences and sorption capacities of phosphatic clay and humus rich soil towards the heavy metals present in zinc mine tailing. Journal of Hazardous Materials, v. 147, p. 698-705, 2007.

CHAVES, E. V. Absorção de metais pesados de solos contaminados do aterro sanitário e pólo industrial de Manaus pelas espécies de plantas Senna multijuga, Schizolobium amazonicum E Caesalpinia echinata. 2008. Tese (Doutorado) Universidade Federal do Amazonas, Manaus.

CHIRENJE, T.; RIVERO, C.; MA, L. Q. Leachability of $\mathrm{Cu}$ and $\mathrm{Ni}$ in wood ashamended soil as impacted by humic and fulvic acid. Geoderma, v. 108, p. 31- 47, 2002.

CHOTPANTARAT, S., ONG, S. K.; SUTTHIRAT, C.; OSATHAPHAN, K. Competitive sorption and transport of $\mathrm{Pb}^{2+}, \mathrm{Ni}^{2+}, \mathrm{Mn}^{2+}$ and $\mathrm{Zn}^{2+}$ in lateritic soil columns. Journal of Hazardous Materials, v. 190, p. 391-396, 2011.

COMPANHIA DE TECNOLOGIA DE SANEAMENTO AMBIENTAL - CETESB. Relatório de estabelecimento de Valores Orientadores para Solos e Águas Subterrâneas no Estado de São Paulo, R321, 2001.

COMPANHIA DE TECNOLOGIA DE SANEAMENTO AMBIENTAL - CETESB. Decisão de Diretoria $N^{o}$ 195- 2005-E. São Paulo: CETESB, 2005.

COMPANHIA DE TECNOLOGIA DE SANEAMENTO AMBIENTAL - CETESB. Disponível em: <http://www.cetesb.sp.gov.br>. Acesso em: 16 abr. 2012.

CONAMA - Conselho Nacional do Meio Ambiente Resolução n⿳3039, de 7 de abril de 2008. Dispõe sobre a classificação e diretrizes ambientais para o enquadramento das águas subterrâneas e dá outras providências. 
CONDER, J.M.; LANNO, R. P.; BASTA, N. T. Assessment of metal availability in smelter soil using earthworms and chemical extractions. Journal Environmental Quality, v. 30, p. 1231-1237, 2001.

CORNU, S.; NEAL, C.; AMBROSI, J. P.; WHITEHEAD, P.; NEAL, M.; SIGOLO, J.; VACHIER, P. The environmental impact of heavy metals from sewage sludge in ferralsols (São Paulo, Brazil). Science of the Total Environment, v. 271, p. 27-48, 2001.

DEPOI, F. S. Desenvolvimento de métodos analíticos para a caracterização dos carvões brasileiros e suas cinzas. 2007. Dissertação (Mestrado) - Universidade Federal do Rio Grande do Sul, Porto Alegre.

DEPOI, F. S.; POZEBON, D.; KALKREUTH, W. D. Chemical characterization of feed coals and combustion-by-procducts from Brazilian power plants. International Journal of Coal Geology, v. 76, n. 3, p. 227-236, 2008.

DIAS, N. M. P.; ALlEONI, L. R. F.; CASAGRANDE, J. C.; CAMARGO, O. A. Adsorção de cádmio em dois latossolos ácricos e um nitossolo. Revista Brasileira de Ciência do Solo, v. 25, p. 297-304, 2001.

ELETROSUL. Disponível em:< http://www.eletrosul.gov.br/home/index.php>. Acesso em 18 de out. 2012

EMPRESA BRASILEIRA DE PESQUISA AGROPECUÁRIA - EMBRAPA. Manual de métodos de análises de solo. 2.ed. Rio de Janeiro, Centro Nacional de Pesquisas de Solos, 1997.

EMPRESA BRASILEIRA DE PESQUISA AGROPECUÁRIA - EMBRAPA. Sistema Brasileiro de Classificação de Solos. Centro Nacional de Pesquisas de Solos, Brasília, 1999.

ENVIRONMENTAL PROTECTION AGENCY - EPA-3051. Disponível em: http://www.epa.gov/epaoswer/hazwaste/test/pdfs/3051.pdf. Acesso em: 03 de abr. 2012.

FADIGAS, F. S.; AMARAL-SOBRINHO, N. M. B.; MAZUR, N.; ANJOS, L. H. C.; FREIXO, A. A. Concentrações naturais de metais pesados em algumas classes de solos brasileiros. Bragantia, v. 61, n. 2, p. 151-159, 2002.

FADIGAS, F. S.; AMARAL SOBRINHO, N. M. B.; MAZUR, N.; ANJOS, L. H. C.; FREIXO, A. A. Proposição de valores de referência para a concentração natural de metais pesados em solos brasileiros. Revista Brasileira de Engenharia Agrícola e Ambiental, v. 10, n. 3, p. 699-705, 2006. 
FERREIRA, P. C. Estudos sobre a adsorção do corante reativo preto 5 de solução aquosa usando zeólita de cinzas de carvão. 2011. Dissertação (Mestrado) - Instituto de Pesquisas Energéticas e Nucleares, São Paulo.

FERRET, L. S. Zeólitas de cinzas de carvão: síntese e uso. 2004. Tese (Doutorado) Universidade Federal do Rio Grande do Sul, Porto Alegre.

FLUES, M.; HAMA, P.; LEMES, M. J. L.; DANTAS, E. S. K.; FORNARO, A. Evaluation of the rainwater acidity of a rural region due to a coal-fired power plant in Brazil. Atmospheric Environment, v. 36, n. 14, p. 2397-2404, 2002.

FLUES, M.; SATO, I. M.; COTRIM, M. B.; FIGUEIREDO FILHO, P. M.; CAMARGO, I. M. C. Avaliação da influência da operação da termoelétrica a carvão na concentração dos metais e As no solo de Figueira, PR-Brasil. Química Nova, v. 31, n. 1, p. 25-30, 2008.

FLUES, M.; SATO, I. M.; SCAPIN, M. A.; COTRIM, M. E. B.; CAMARGO, I. M. C. Toxic elements mobility in coal and ashes of Figueira coal power plant, Brazil. Fuel, v. 103, p. 430-436, 2013.

GABAS, S. G. Avaliação da adsorção de cádmio e chumbo em solo laterítico compactado por meio de extração sequencial. 2005. Tese (Doutorado) - Universidade de São Paulo, São Paulo.

GAZANO, V. S. O. Contaminação de solo por metais tóxicos provenientes do descarte inadequado de pilhas zinco-carbono de uso doméstico. 2006. Dissertação (Mestrado) - Instituto de Pesquisas Energéticas e Nucleares, São Paulo.

GARCÉS, D. M.; CANO, A. F.; AROCENA, J. M. Dissolved organic carbon and metals release in amended mine soils. Revista de la Sociedad Española de Mineralogia, n. 10, p. 115-117, 2008.

GOLDBERG, S.; GLAUBIG R. A. Anion sorption on a calcareous, montmorillonitic soil - Arsenic. Soil Science Society of America Journal, n. 5, v. 52, p. 1297-1300, 1988.

GOOGLE EARTH. Disponível em: < http://maps.google.com.br/maps?hl=ptBR\&tab=wl $>$. Acesso em: 15 ago. 2012.

HARTLEY, W.; EDWARDS, R.; LEPP, N. W. Arsenic and heavy metal mobility in iron oxide-amended contaminated soils as evaluated by shortand long-term leaching tests. Environmental Pollution, v. 131, n. 3, p. 495-504, 2004.

HELLWEG, S.; FISCHER, U.; HOFSTETTER, T. B.; HUNGERBÜHLER, K. Sitedependent fate assessment in LCA: transport of heavy metals in soil. Journal of Cleaner Production, v. 13, p. 341-361, 2005. 
HYPOLITO, R.; ANDRADE, S.; EZAKI, S. Geoquímica da Interação Água Rocha Solo-Estudos preliminares. 1.ed. São Paulo: All Print Editora, 2011.

INSTITUTO DE ASTRONOMIA, GEOFÍSICA E CIÊNCIAS ATMOSFÉRICAS IAG. Disponível em: <http://www.iag.usp.br>. Acesso em: 21 set. 2009.

INSTITUTO BRASILEIRO DE GEOGRAFIA E ESTATÍSTICA - IBGE. Disponível em: < http://www.ibge.gov.br/>. Acesso em: 04 out. 2012.

INSTITUTO BRASILEIRO DE GEOGRAFIA E ESTATÍSTICA - IBGE. Manual Técnico de Pedologia. 2ed. Rio de Janeiro, 2007.

IZIDORO, J. C. Estudos sobre a remoção de íons metálicos em água usando zeólitas sintetizadas a partir de cinzas de carvão. 2008. Dissertação (Mestrado) - Instituto de Pesquisas Energéticas e Nucleares, São Paulo.

KABALA, C.; SINGH, B. R. Fractionation and mobility of copper, lead, and zinc in soil profiles in the vicinity of a copper smelter. Journal of Environmental Quality, v. 30, n. 2, p. 485-492, 2001.

KER, J. C. Latossolos do Brasil: uma revisão. Geonomos, v. 5, n. 1, p. 17-40, 1997.

LADEIRA, A. C. Q.; CIMINELLI, V. S.; NEPOMUCENO, A. L. Seleção de solos para a imobilização de arsênio. Revista Escola de Minas, v. 55, n. 3, p. 215-221, 2002.

LANGE, C. N. Contaminação do solo e mobilidade de As, Cd, Mo, Pb e Zn em colunas de solo franco arenoso com cinza de carvão. 2012. Dissertação (Mestrado) Instituto de Pesquisas Energéticas e Nucleares, São Paulo.

LEPSCH, I. F. Formação e conservação dos solos. 2.ed. São Paulo: Oficina de Textos, 2002.

LEVANDOWSKI, J.; KALKREUTH, W. D. Chemical and petrographical characterization of feed coal, fly ash and bottom ash from the Figueira Power Plant, Paraná, Brazil. International Journal of Coal Geology, v.77, p. 269-281, 2009.

LEWIS, J.; SJÖSTROM, J. Optimizing the experimental design of soil columns in satured and unsaturated transport experiments. Journal of Contaminant Hydrology, v. 115, p. 1-13, 2010.

LINHARES, L. A.; EGREJA FILHO, F. B.; OLIVEIRA, C. V.; BELliS, V. M. Adsorção de cádmio e chumbo em solos tropicais altamente intemperizados. Pesquisa Agropecuária Brasileira, v. 44, n. 3, p. 291-299, 2009. 
LUCHESE, E. B.; FAVERO L. O. B.; LENZI, E. Fundamentos da química do solo Teoria e Prática. 2.ed. Rio de Janeiro: Freitas Bastos Editora, 2002.

MA, L. Q.; DONG, Y. Effects of incubation on solubility and mobility of trace metals in two contaminated soils. Environmental Pollution, v. 130, n. 3, p. 301-307, 2004.

MAGDALENA, C. P. Adsorção de corante reativo remazol vermelho $R B$ de solução aquosa usando zeólita de cinzas de carvão e avaliação da toxicidade aguda com daphnia similis. 2010. Dissertação (Mestrado) - Instituto de Pesquisas Energéticas e Nucleares, São Paulo.

MARTÍNEZ, C. E.; MOTTO, H. L. Solubility of lead, zinc and copper added to mineral soils. Environmental Pollution, n. 107, p. 153-158, 2000.

MATOS, A. T.; FONTES, M. P. F.; COSTA, L. M.; MARTINEZ, M. A. Mobility of heavy metals as related to soil chemical and mineralogical characteristics of Brazilian soils. Environmental Pollution, v. 111, n. 3, p. 429-435, 2001.

McBRIDE, M. B. Environmental Chemistry of Soils. 1.ed. New York: Oxford University Press, 1994.

MELFI, A. J.; MONTES, C. R.; CARVALHO, A.; FORTI, M. C. Use of pedological maps in the identification of sensitivity of soils to acidic deposition: application to Brazilian soils. Anais da Academia Brasileira de Ciências, v. 76, n. 1, p. 139-145, 2004.

MESSIAS, A. S.; SILVA, H. A.; LIMA, V. N.; SOUZA, J. E. G. Avaliação da mobilidade de micronutrientes em solo tratado com lodo de esgoto. Revista Brasileira de Gestão e Desenvolvimento Regional, v. 3, n. 3, p. 193-211, 2007.

MONIZ, A. C (coord). Elementos de Pedologia. São Paulo: Polígono, 1972.

MONTEIRO, K. V. (Coord.). Carvão: o combustível de ontem. Porto Alegre: Núcleo Amigos da Terra Brasil, 2004.

NAVARRO-PEDREÑO, J.; ALMENDRO-CANDEL, M. B.; JORDÁNVIDAL, M. M.; MATAIX-SOLERA, J.; GARCÍA-SÁNCHEZ, E. Mobility of cadmium, chromium, and nickel through the profile of a calcisol treated with sewage sludge in the southeast of Spain. Environmental Geology, v. 44, n. 5, p. 545-553, 2003.

NORRSTRÖM, A. C. Metal mobility by de-icing salt from an infiltration trench for highway runoff. Applied Geochemistry, v. 20, n. 10, p. 1907-1919, 2005.

OLIVEIRA, J.B.; CAMARGO, M.N.; ROSSI, M. \& CALDERANO FILHO, B. Mapa pedológico do Estado de São Paulo: legenda expandida. Campinas, Instituto Agronômico/EMBRAPA-Solos. Campinas. 1999. 
OLIVEIRA, L. F. C.; LEMKE-DE-CASTRO, M. L.; RODRIGUES, C.; BORGES, J. D. Adsorção e deslocamento do íon cádmio em solos do cerrado. Revista Brasileira de Engenharia Agrícola e Ambiental, v. 14, n. 8, p. 848-855, 2010.

OSEI, B. A.; SINGH, B. Effect of selective removal of organic matter and iron oxides on the specific surface áreas of some tropical soil clays. Ghana Journal of Agricultural Science, v. 33, p. 55-61, 2000.

PERK, M. V. D. Soil and water contamination from molecular to catchment scale. London: Taylor \& Francis, 2006.

PIERANGELI, M. A. P.; GUILHERME, L. R. G.; CURI, N.; SILVA, M. L. N.; LIMA, J. M.; COSTA, E. T. S. Efeito do pH na adsorção e dessorção de cádmio em latossolos brasileiros. Revista Brasileira de Ciência do Solo, v. 29, p. 523-532, 2005.

PLANO DECENAL DE EXPANSÃO DE ENERGIA 2021 - PDE. Ministério de Minas e Energia. Empresa de Pesquisa Energética. Brasília: MME/EPE, 2012.

RESENDE, M.; CURI, N.; RESENDE, S. B.; CORREAA, G. F. Pedologia - Base para distinção de ambientes. NEPUT, Viçosa, 2002.

ROCHA, F. R.; SILVA, J. A. F.; LAGO, C. L.; FORNARO, A.; GUTZ, I. G. R. Wet deposition and related atmospheric chemistry in the São Paulo Metropolis, Brazil: Part 1. Major inorganic ions in rainwater as evaluated by capillary electrophoresis with contactless conductivity detection. Atmospheric Environment, v. 37, n. 1, p. 105-115, 2003.

ROHDE, G. M.; ZWONOK, O.; CHIES, F.; SILVA, N. I. W. Cinzas de carvão fóssil no Brasil-Aspectos técnicos e ambientais. Porto Alegre: CIENTEC, 2006.

ROSSI, M.; OLIVEIRA, J. B. Informações técnicas - O mapa pedológico do Estado de São Paulo. O Agronômico, n. 52, v. 1, p. 21-23, 2000.

SCOKART, P. O.; MEEUS-VERDINNE, K.; BORGER, R. Mobility of heavy metals in polluted soils near zinc smelters. Water, air and soil pollution, v. 20, n. 4, p. 451-463, 1983.

SERRANO, S.; GARRIDO, F.; CAMPBELL, C. G.; GARCIA-GONZÁLEZ, M. T. Competitive sorption of cadmium and lead in acid soils of Central Spain. Geoderma, v. 124, p. 91-104, 2005.

SIEGEL, F. R. Environmental geochemistry of potentially toxic metals. Germany: Springer, 2002. 
SOARES, M. R. Coeficiente de distribuição (Kd) de metais pesados em solos do Estado de São Paulo. 2004. Tese (Doutorado) - Escola Superior de Agricultura "Luiz Queiroz", Universidade de São Paulo, Piracicaba, São Paulo.

SOUZA, R. S.; CHAVES, L. H. G.; FERNANDES, J. D. Adsorção de Zn e sua relação com características de solos do estado da Paraíba. Revista Brasileira de Ciências Agrárias, v. 1, p. 1-6, 2006.

SPARKS, D. L. Environmental soil chemistry. California: Academic Press, 1995.

SPOSITO, G. The chemistry of soils. New York: Oxford University Press, 1989.

STUERMER, M. M. Contribuição ao estudo de um solo saprolítico como revestimento impermeabilizante de fundo de aterros de resíduos. 2005. Tese (Doutorado) - Escola Politécnica da Universidade de São Paulo, São Paulo.

SUN, B.; ZHAO, F. J.; LOMBI, E.; McGRATH, S. P. Leaching of heavy metals from contaminated soils using EDTA. Environmental Pollution, v. 113, n. 2, p. 111-120, 2001.

TAN, K.H. Principles of soil chemistry. New York: Marcel Dekker, 1993.

URE, A. M. Single extraction schemes for soil analysis and related applications. Science of the Total Environment, v. 178, p. 3-10, 1996.

USDA-United State Department of Agriculture Soil Staff; Soil Taxonomy, Washington, 1974.

WORLD COAL. Disponível em: <http://www.worldcoal.org/>. Acesso em: 12 set. 2012.

YONG, R. N.; MULLIGAN, C. N. Natural attenuation of contaminants in soil. Florida: CRC Press LLC, 2004.

ZHANG, M. K.; HE, Z. L.; CALVERT, D. V.; STOFFELLA, P. J. Extractability and Mobility of Copper and Zinc Accumulated in Sandy Soils. Pedosphere, v. 16, n. 1, p. 43-49, 2006. 